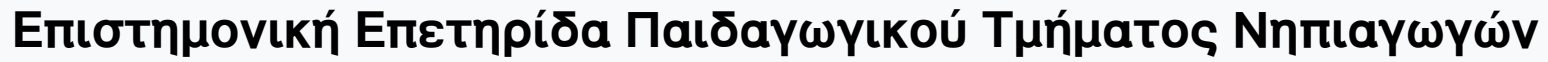 חavertotnuíou Iwavvívwv
}

Tóp. 7 (2014)

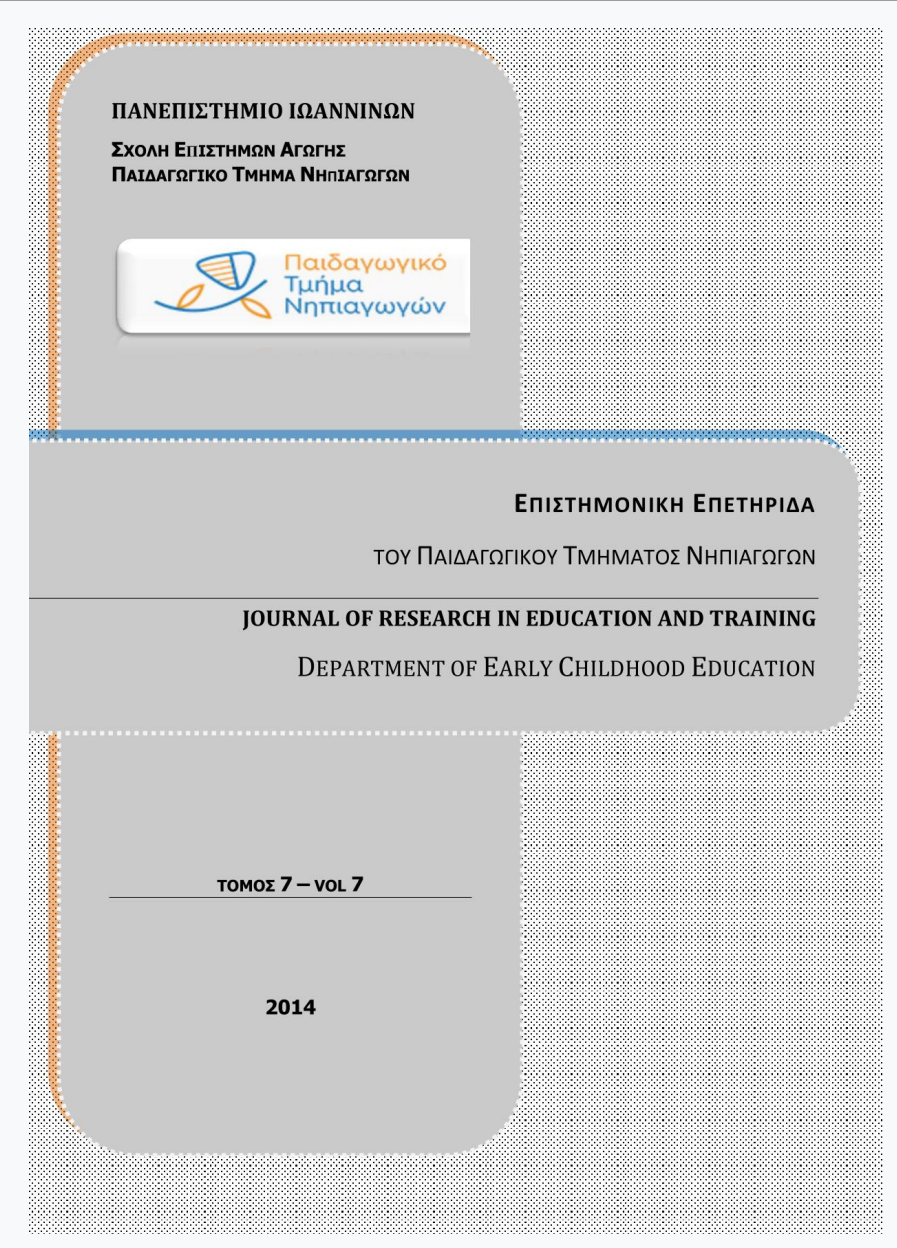

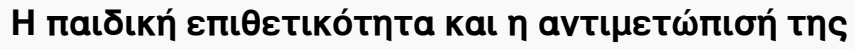

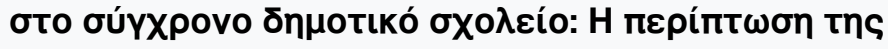

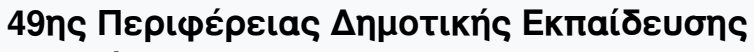 Aтtки́́s}

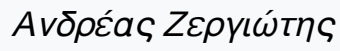

doi: $10.12681 /$ jret.852

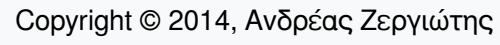

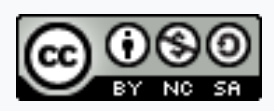

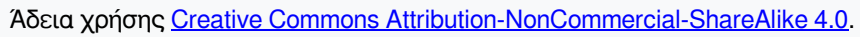

\section{Bıß入ıорачıкń avaчopá:}

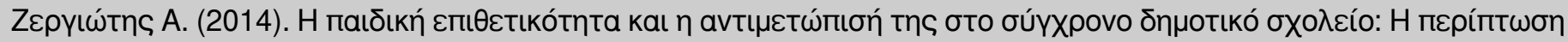

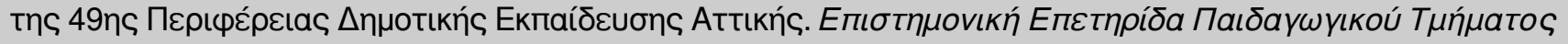

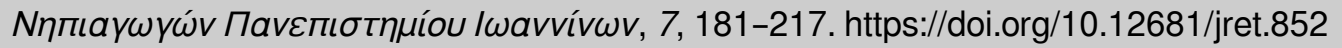




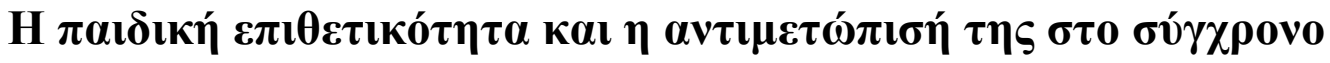

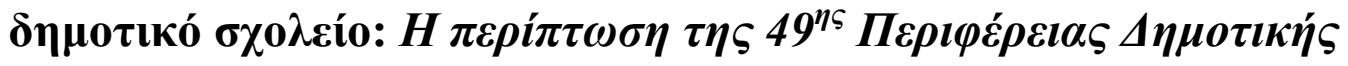

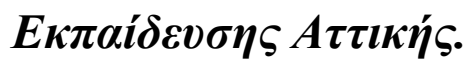

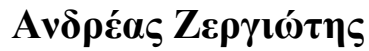

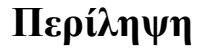

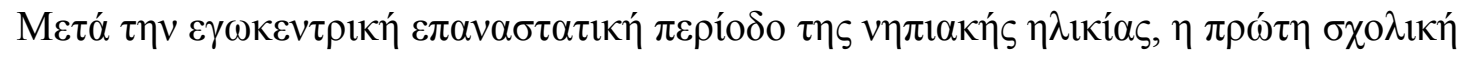

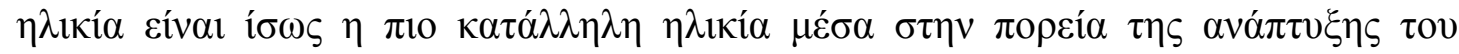

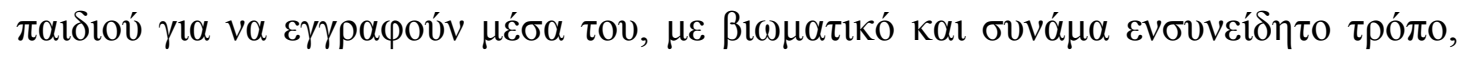

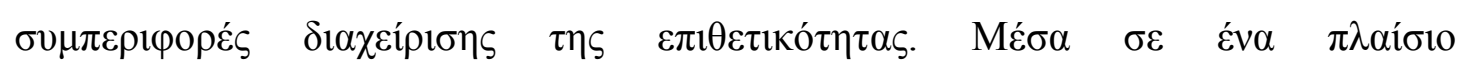

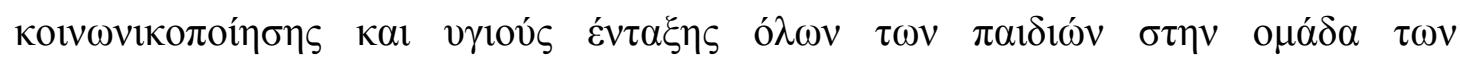

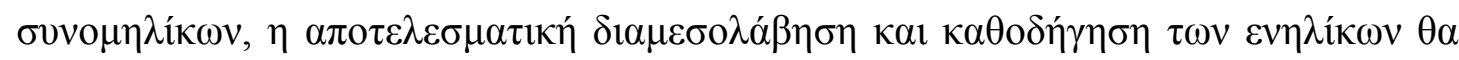

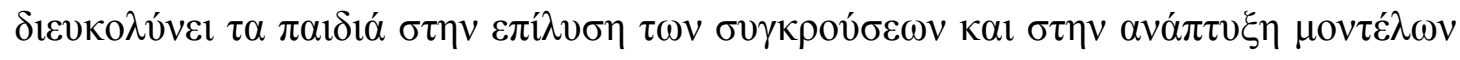

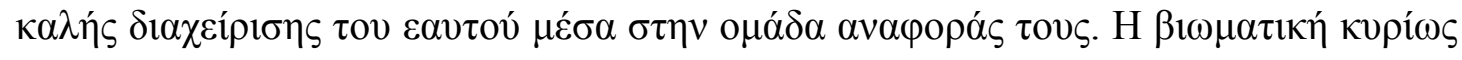

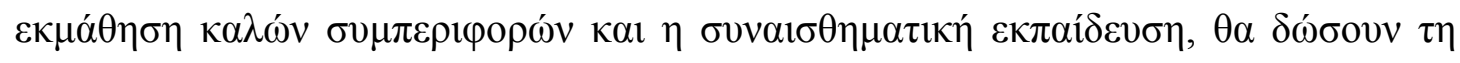

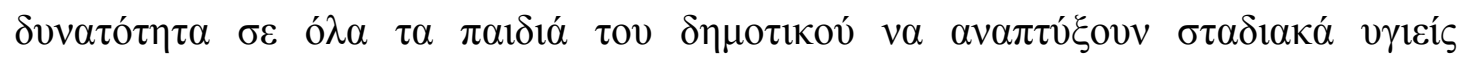

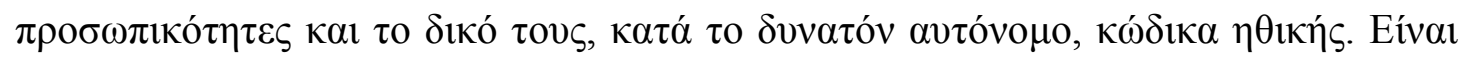

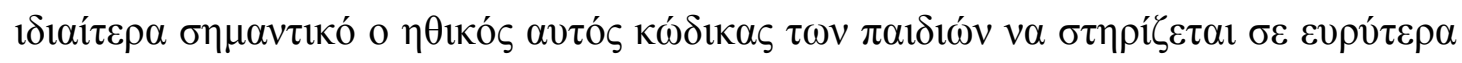

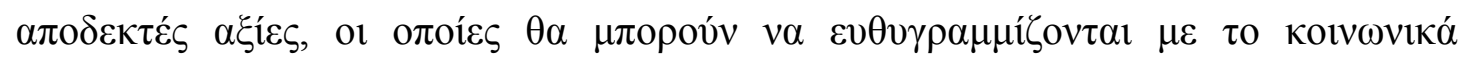

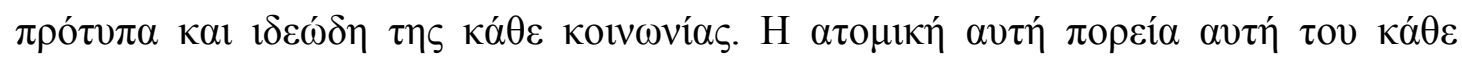

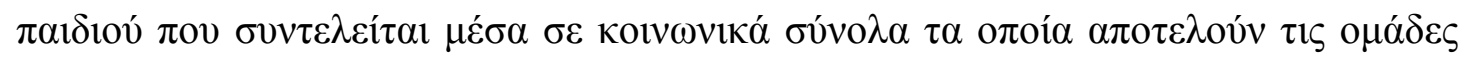

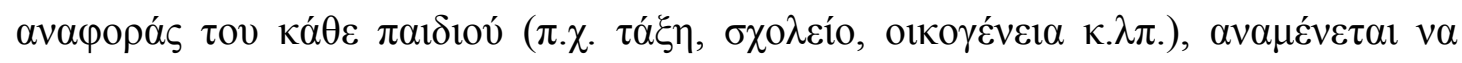

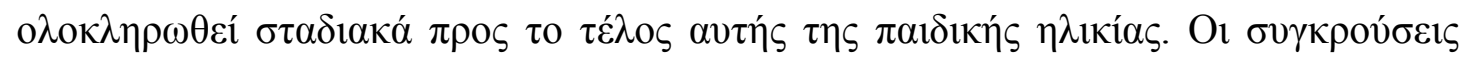




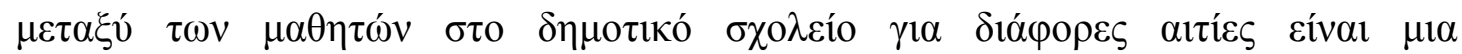

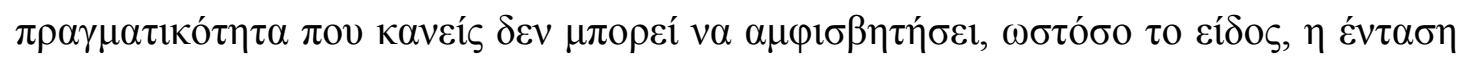

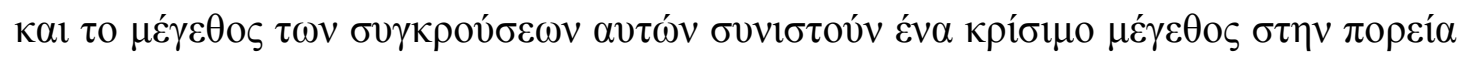

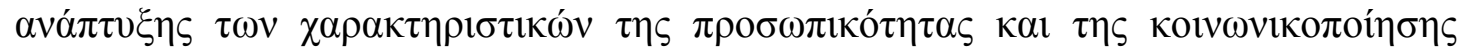

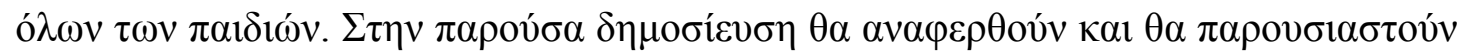

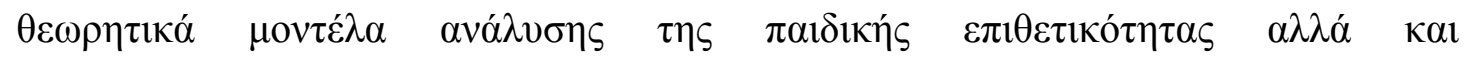

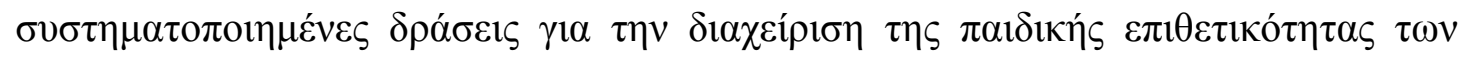

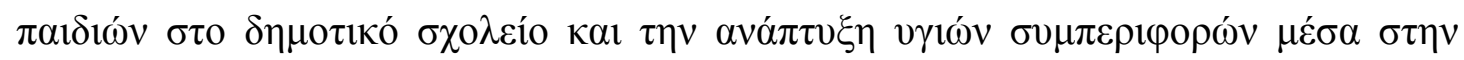

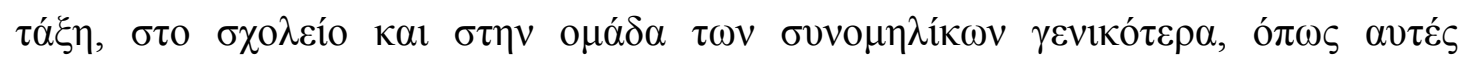

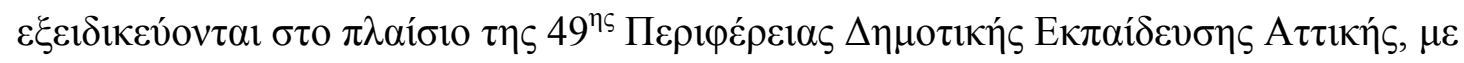

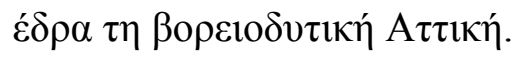

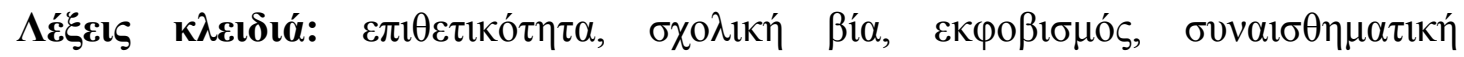

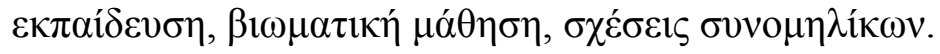




\title{
How to Deal with childrens' aggression in the primary school in our Days: The example of the 49th District of Primary Education in
}

\section{Attika}

\section{Andreas Zergiotis}

\begin{abstract}
After the egocentrism period of life of the pre-school age, the first school age in children's life is the most appropriate age to teaching children how to manage themselves with aggression and feelings of anger. In the context of the primary school, all the pupils are capable for socializing their behavior. In this period of life children are able to internalize rules for better interpersonal relationships and maintain friendly contact into their peer group. In every primary school the experiential learning of good behavior and the emotional educational training, can give in every first school age pupil the possibility to develop a healthy personality with a stable moral system against violence. Every pupil in his classroom is able to learn in an experiential way the rules for living in piece with his peers. The present paper will focus on the theoretical approaches of aggression during childhood and the implementation of a systematic action against violence in the frame of 49th educational district of primary schools of Attica.
\end{abstract}

Key words: violence, school violence, bullying, emotional education, experiential learning, peer relationships. 


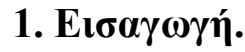

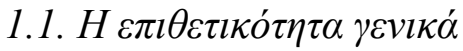

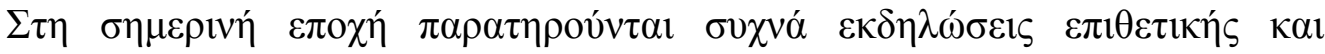

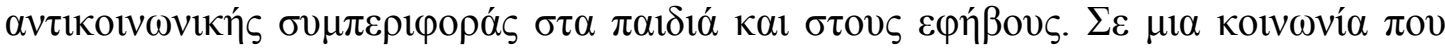

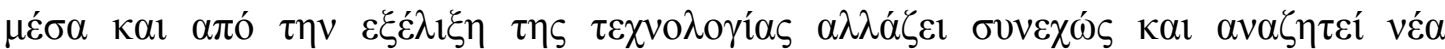

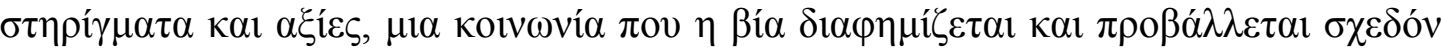

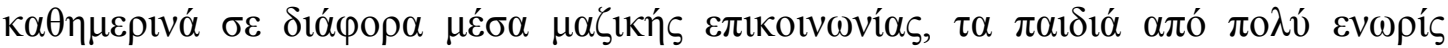

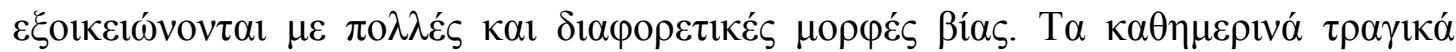

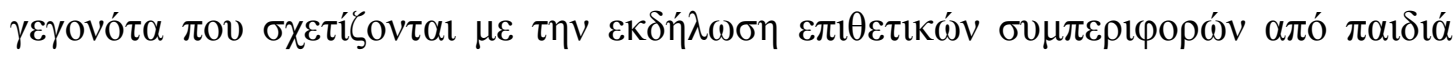

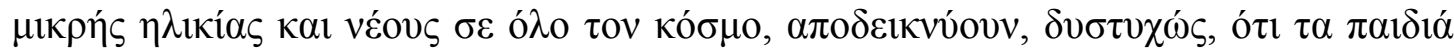

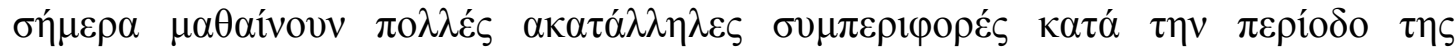

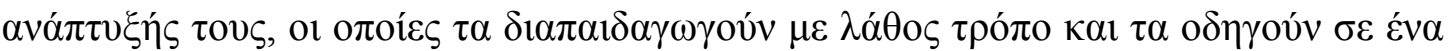

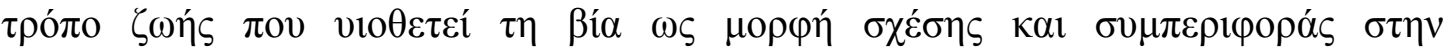

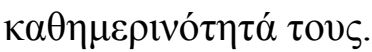

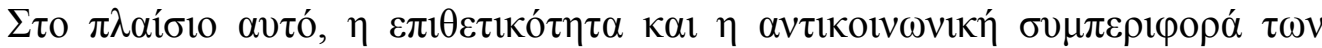

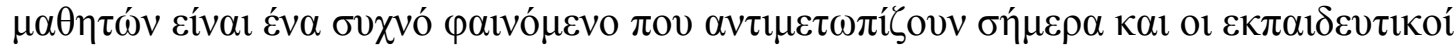

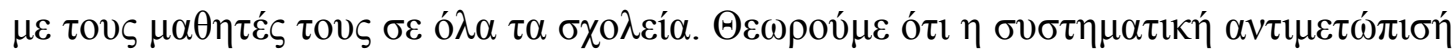

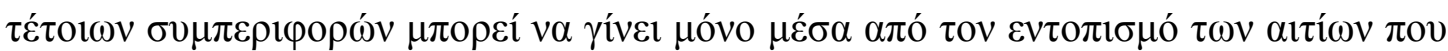

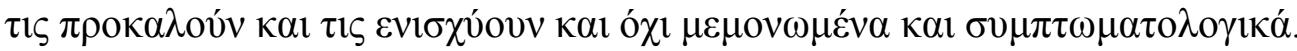

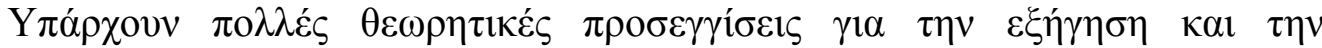

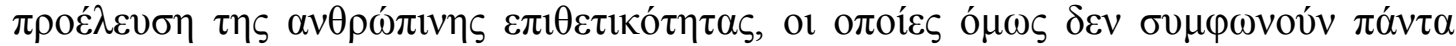

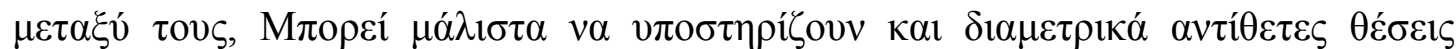

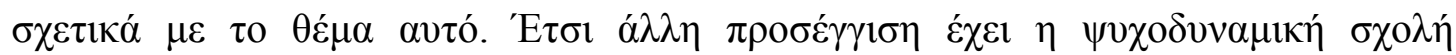

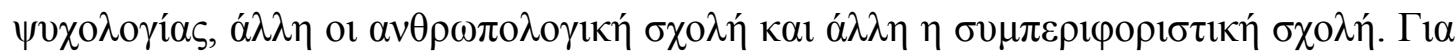




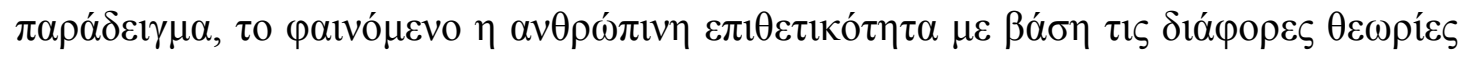

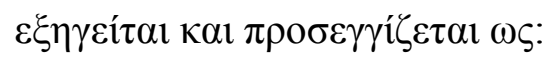

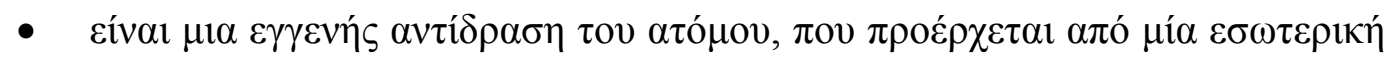

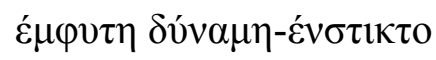

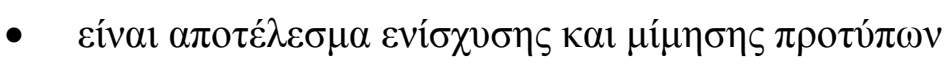

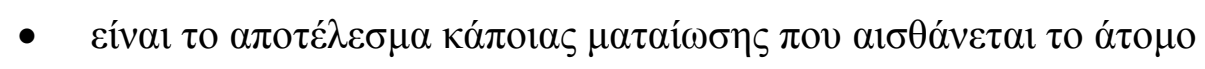

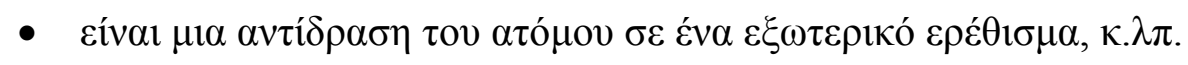

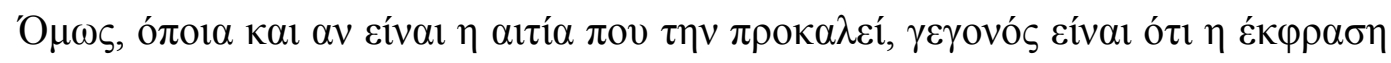

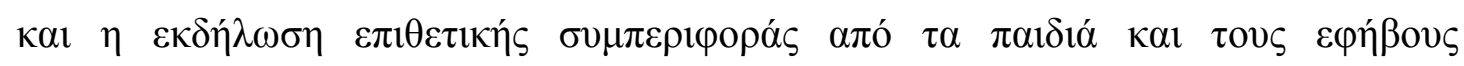

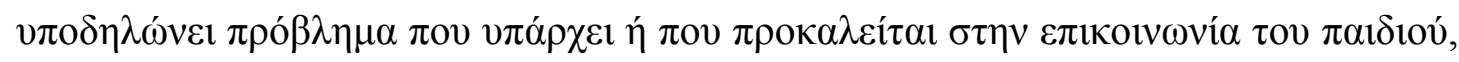

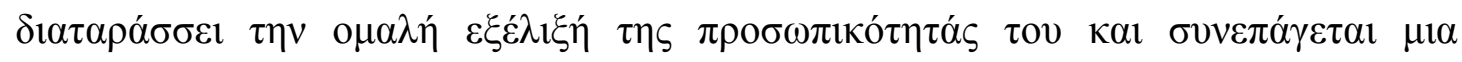

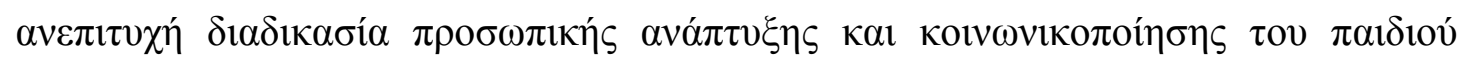

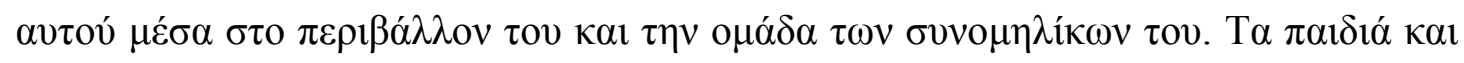

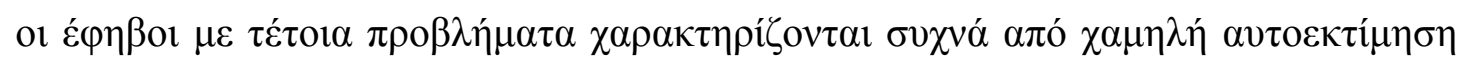

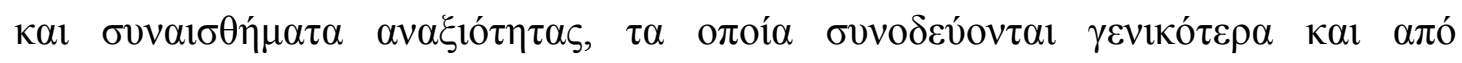

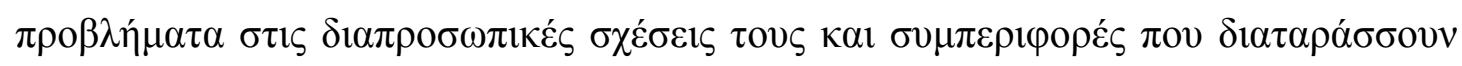

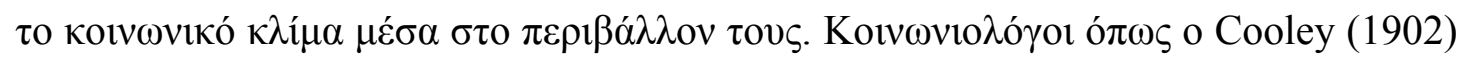

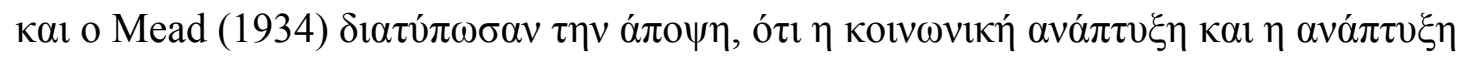

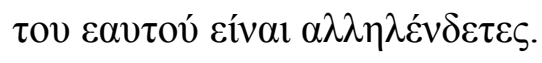

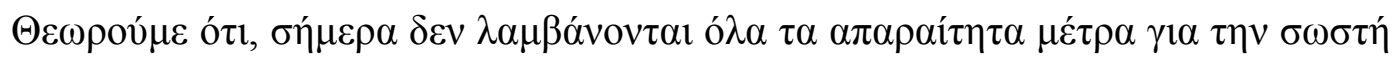

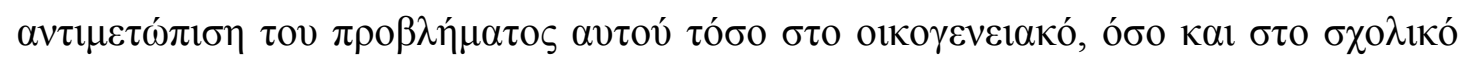

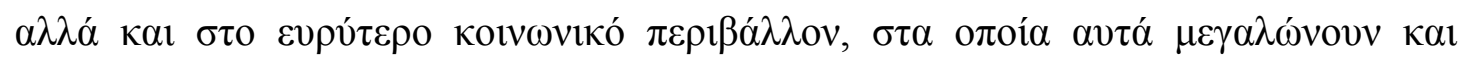

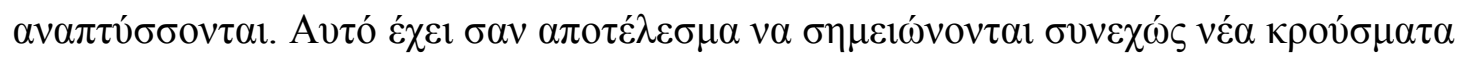




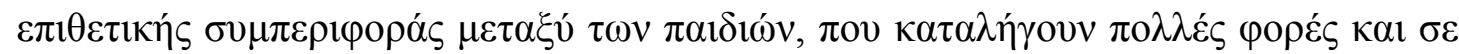

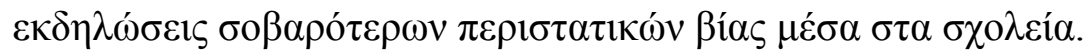

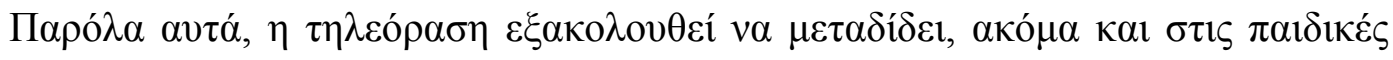

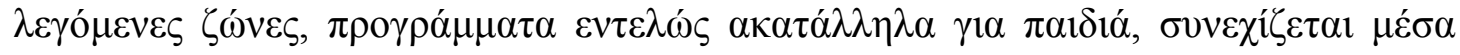

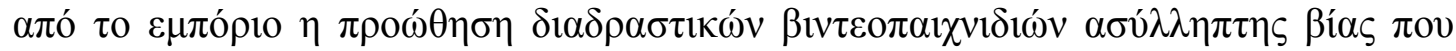

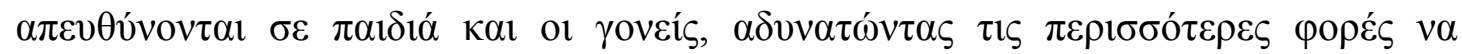

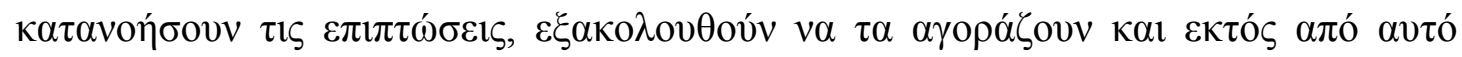

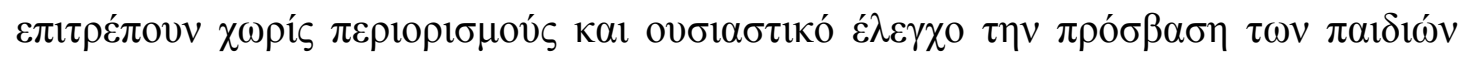

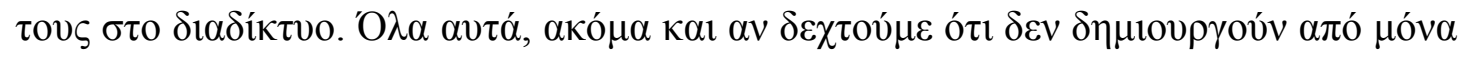

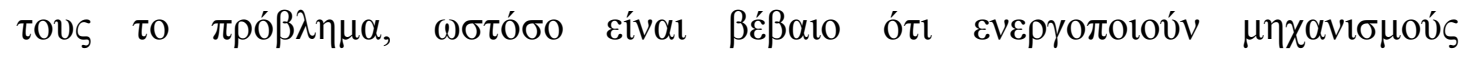

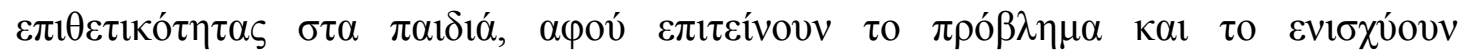

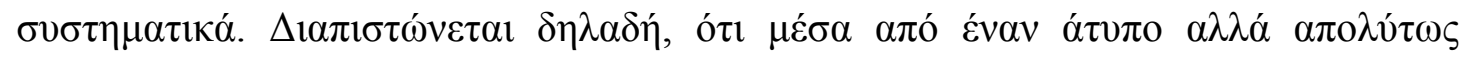

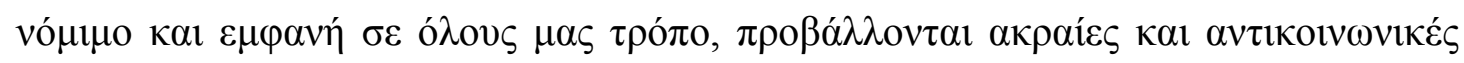

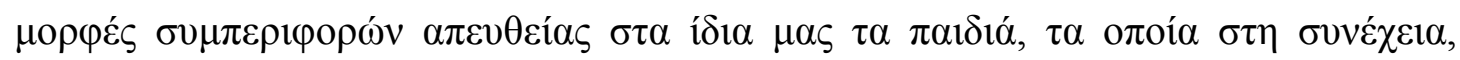

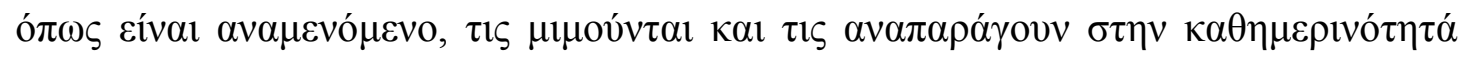

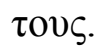

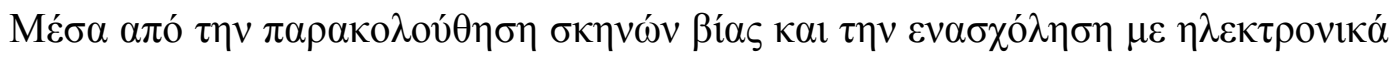

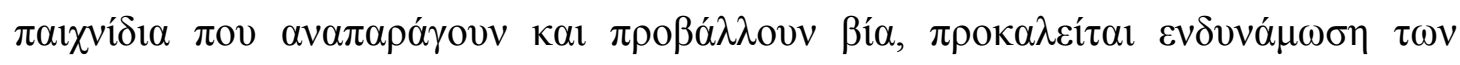

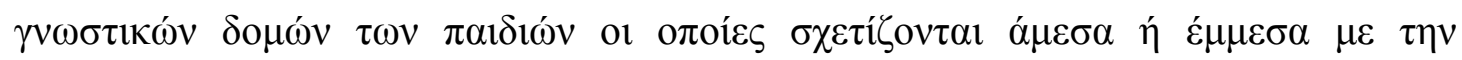

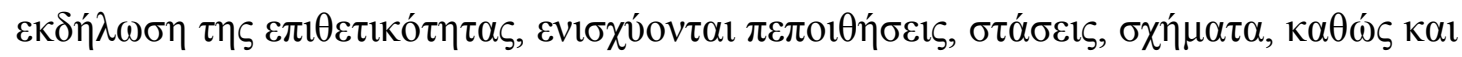

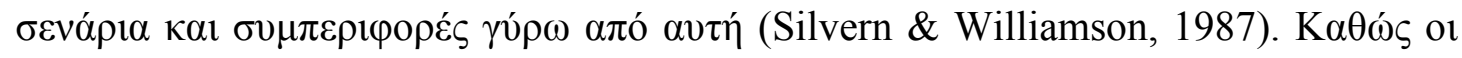

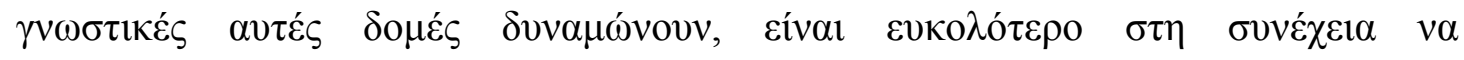

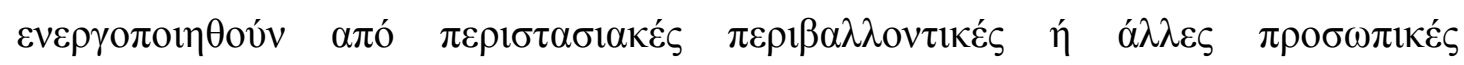

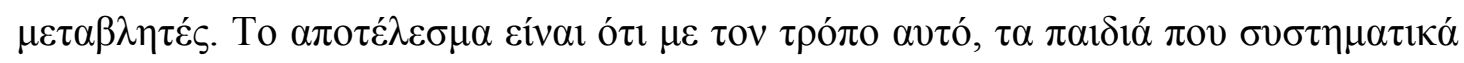

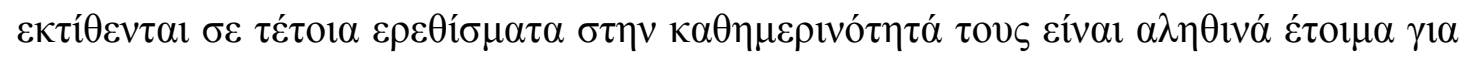




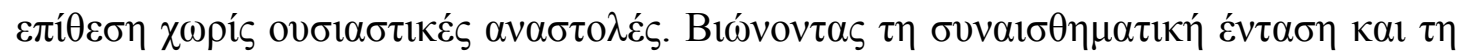

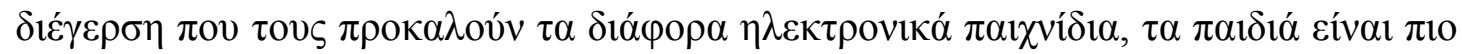

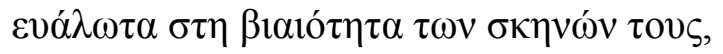

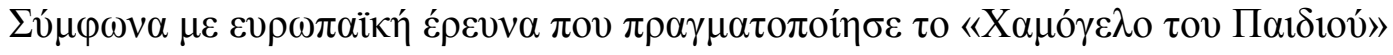

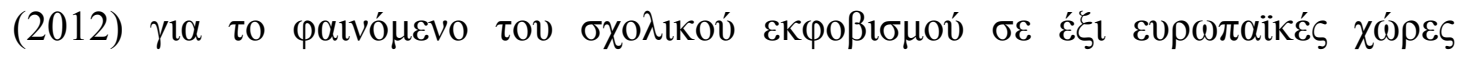

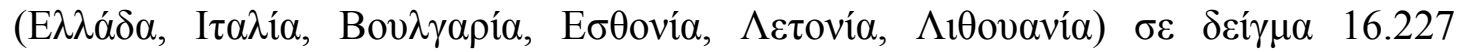

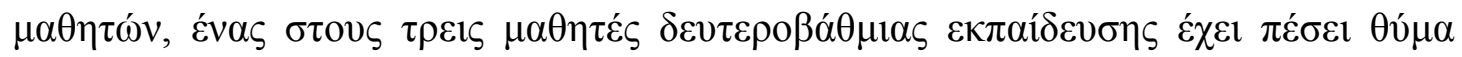

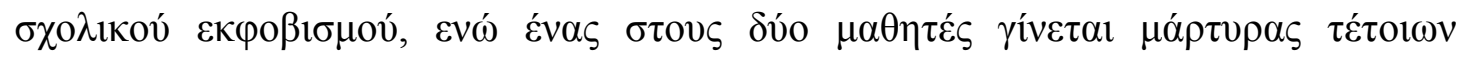

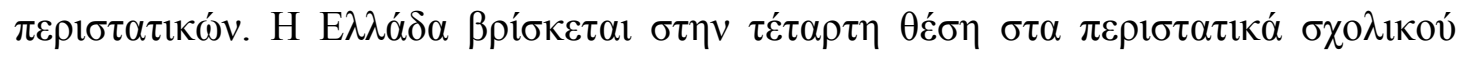

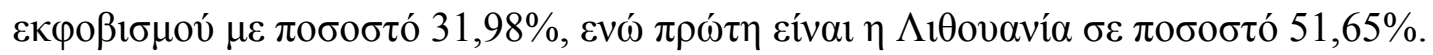

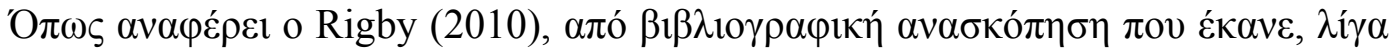

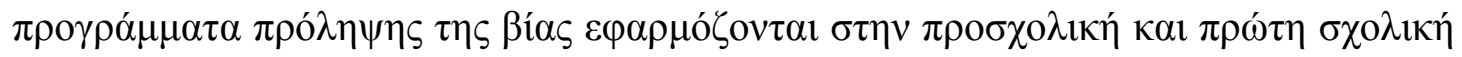

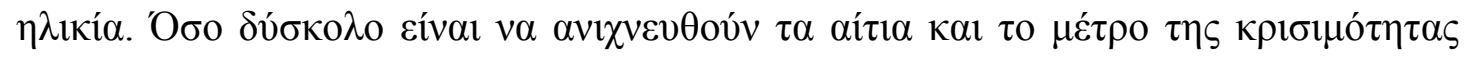

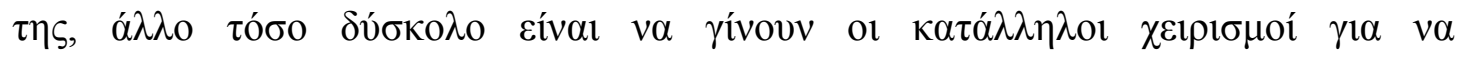

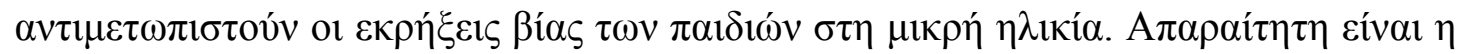

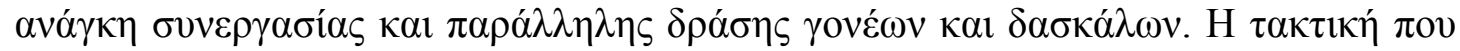

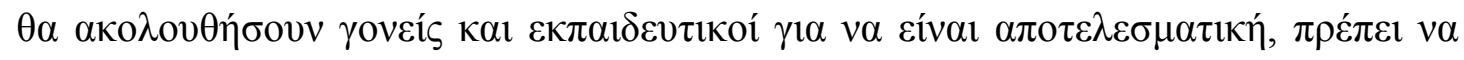

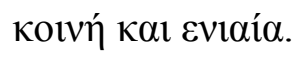

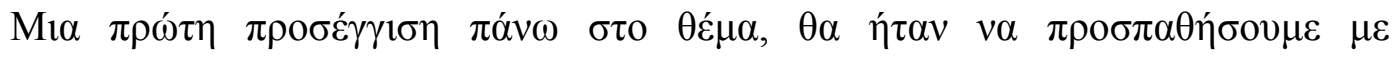

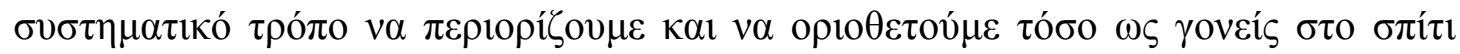

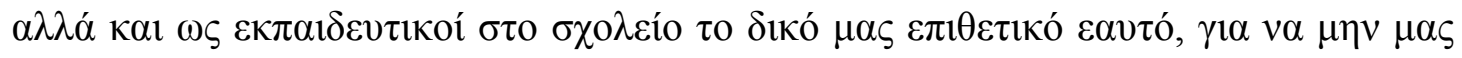

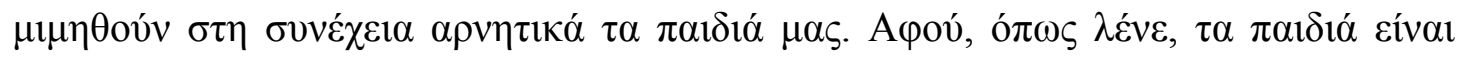

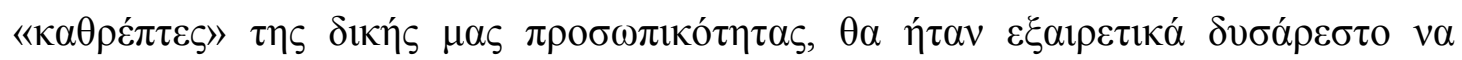

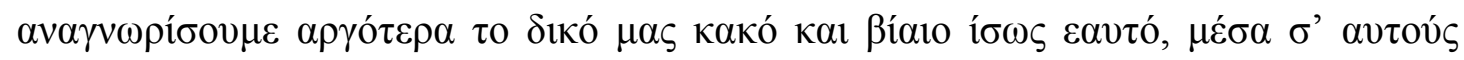
$\tau o v \varsigma \ll \kappa \alpha \theta \rho \varepsilon ́ \pi \tau \varepsilon \varsigma »$. 


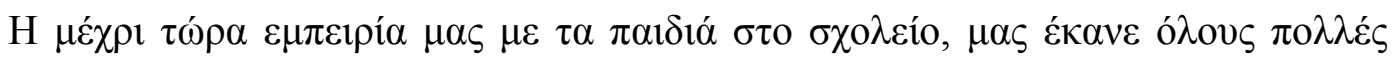

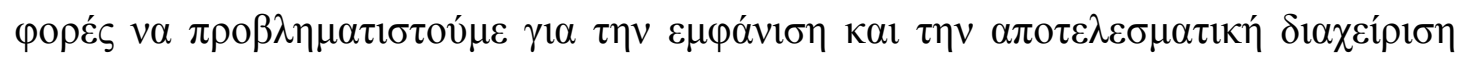

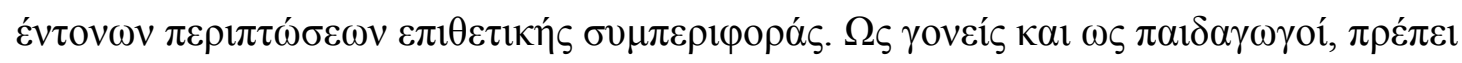

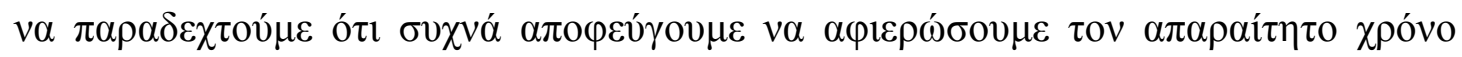

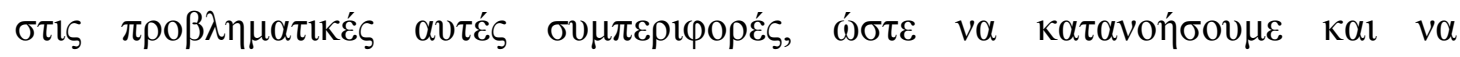

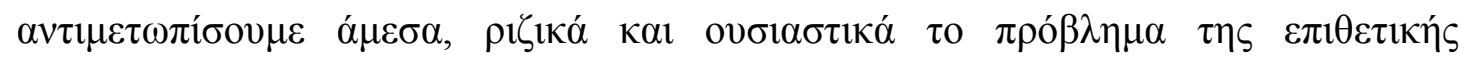

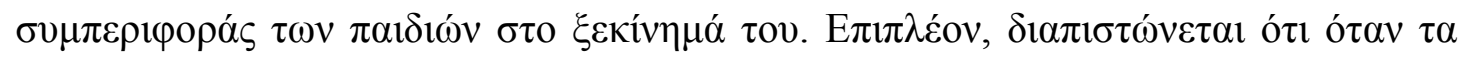

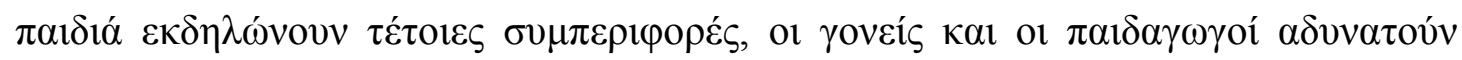

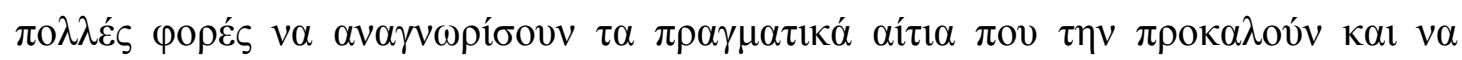

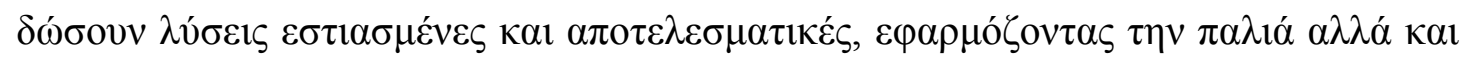

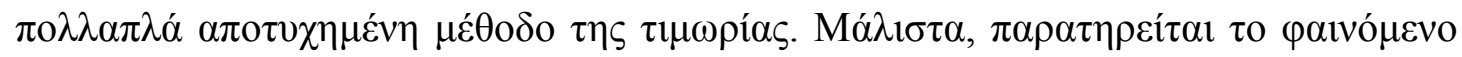

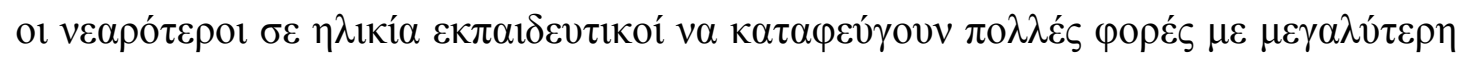

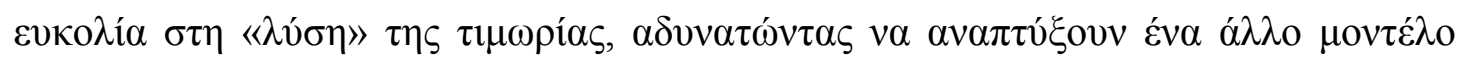

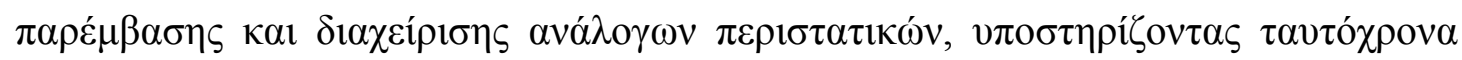

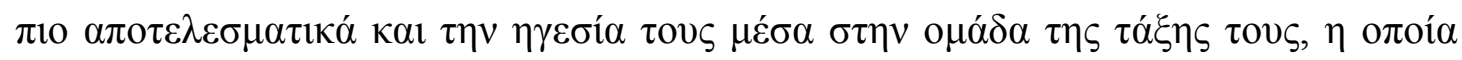

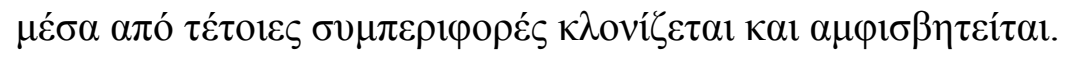

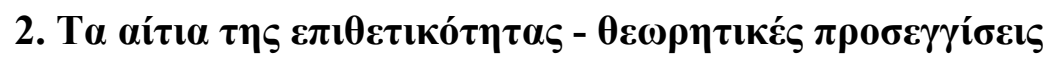

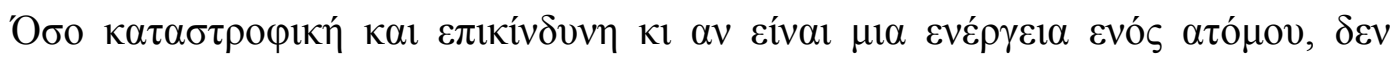

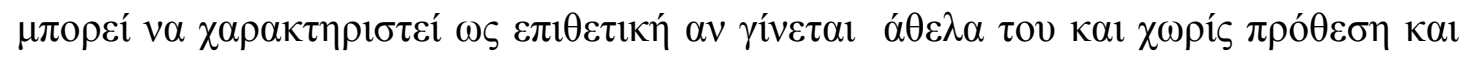

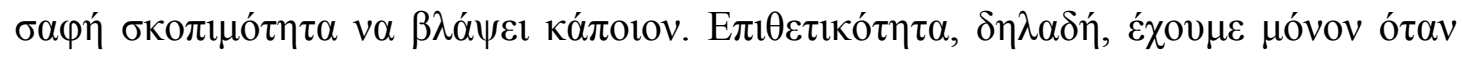

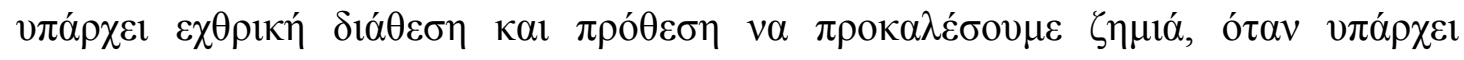

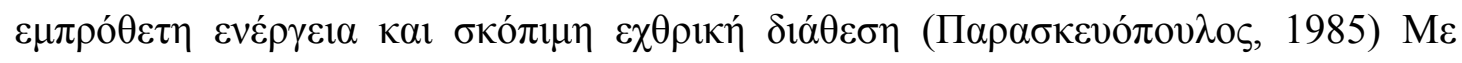

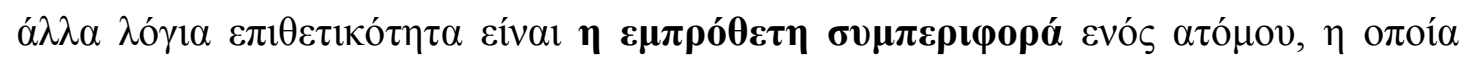

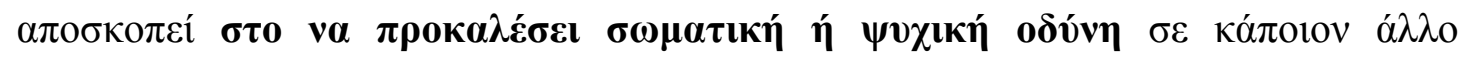




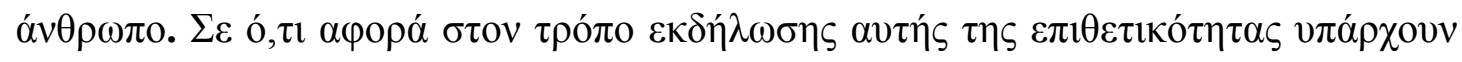

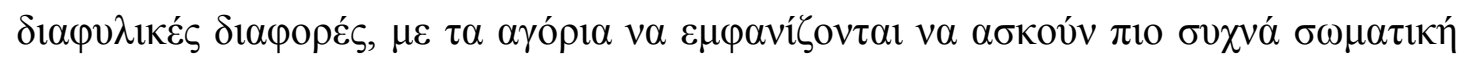

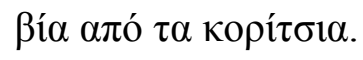

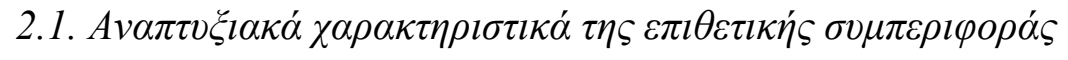

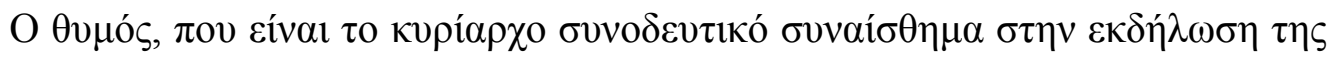

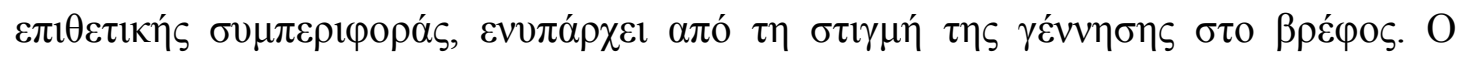

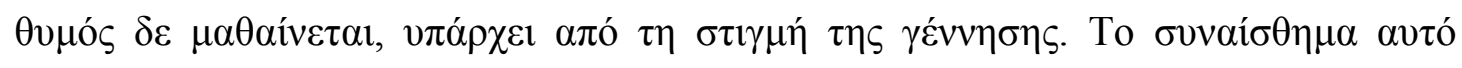

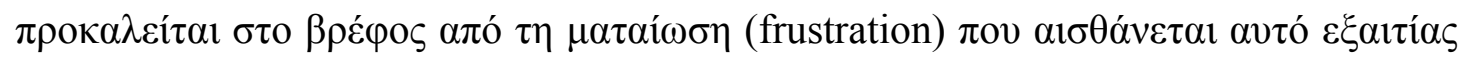

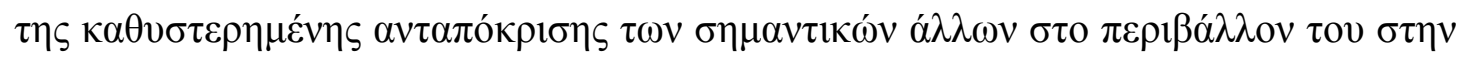

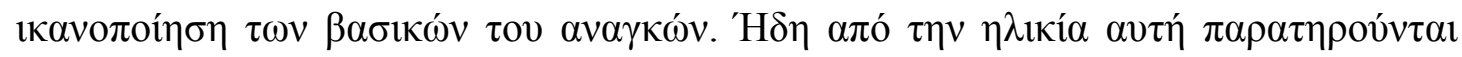

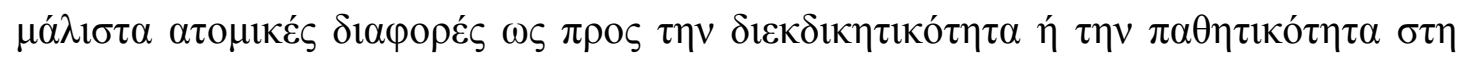

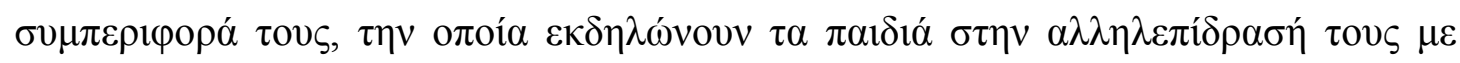

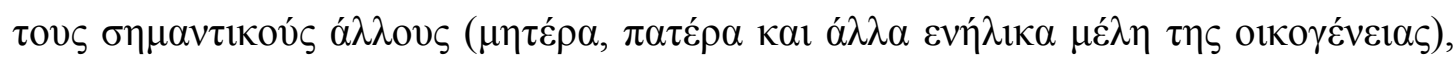

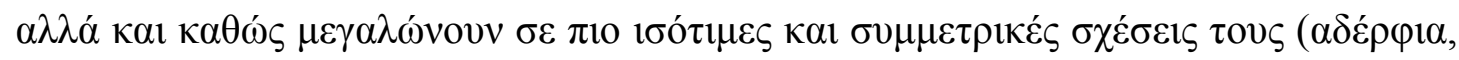

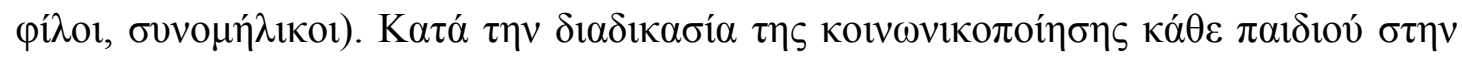

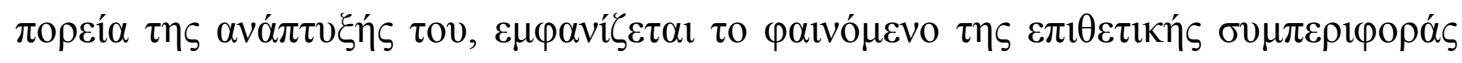

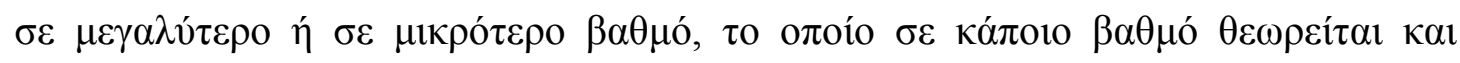

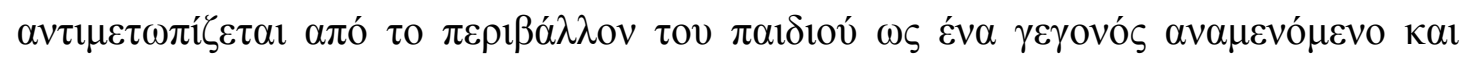

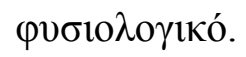

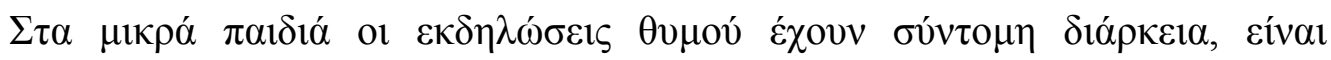

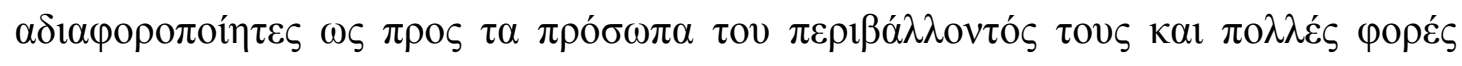

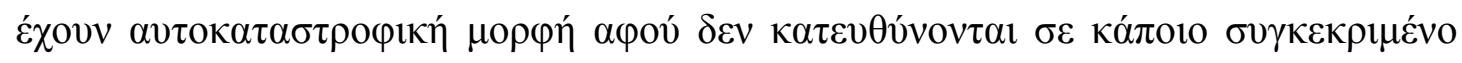

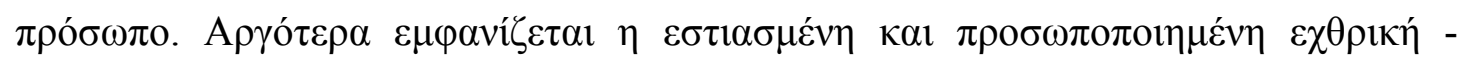

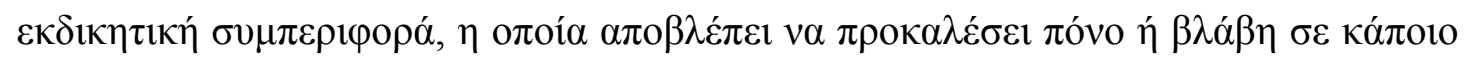




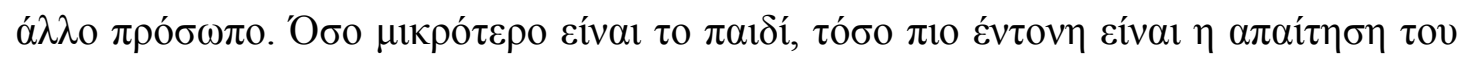

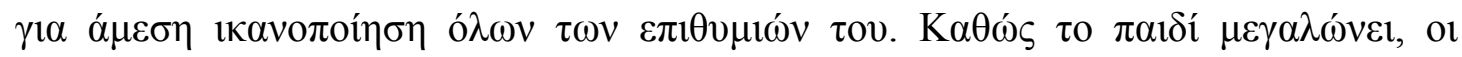

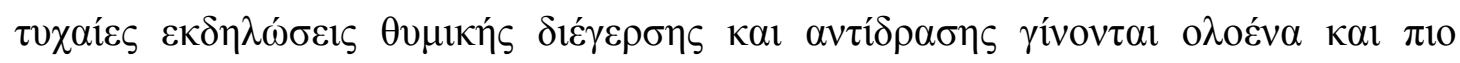

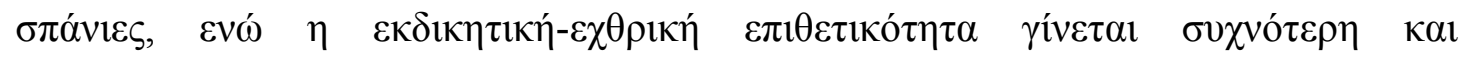

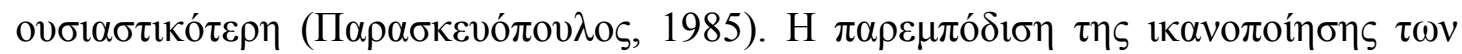

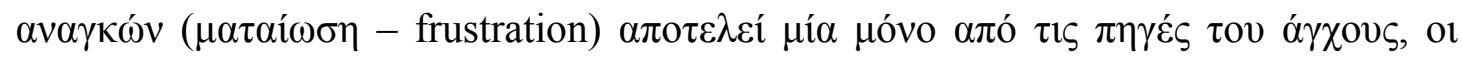

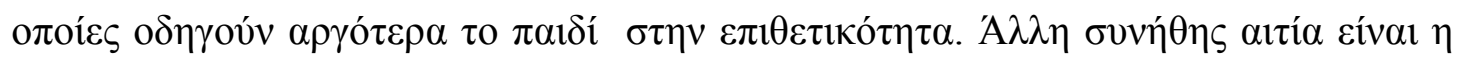

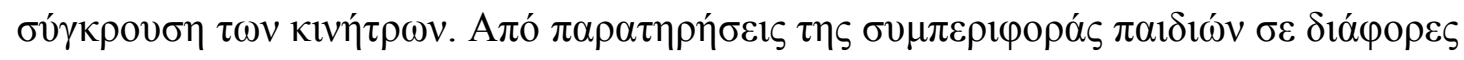

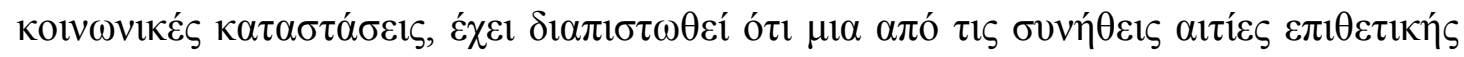

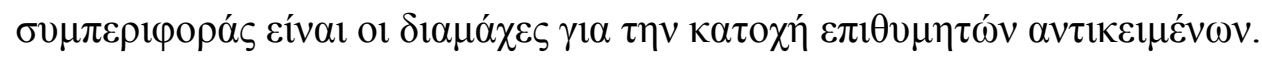

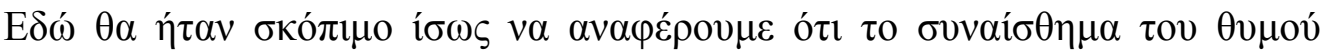

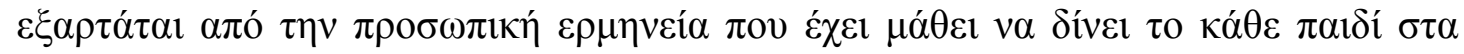

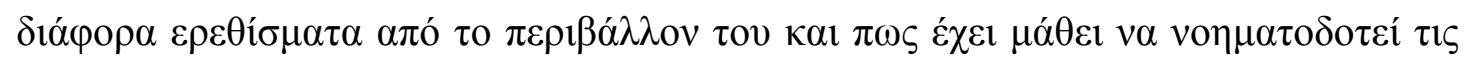

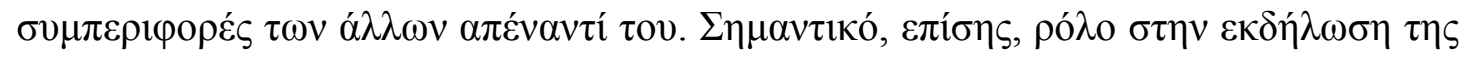

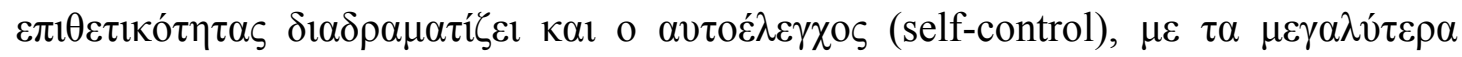

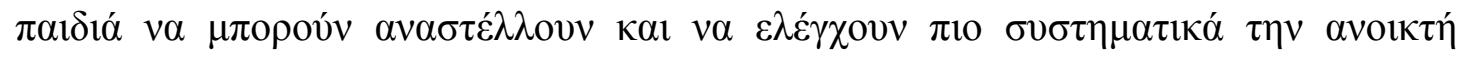

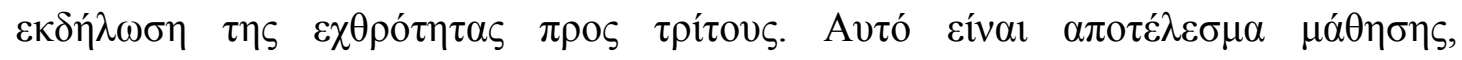

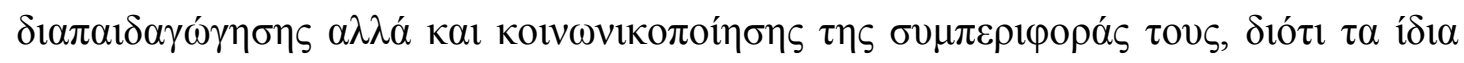

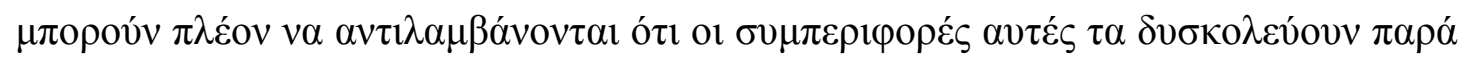

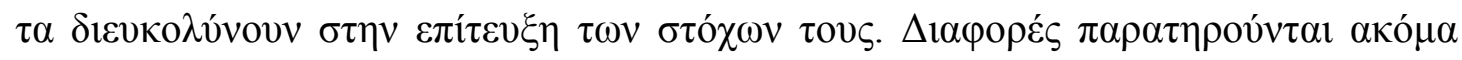

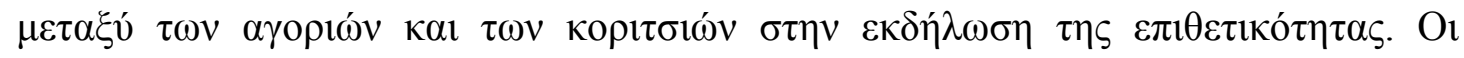

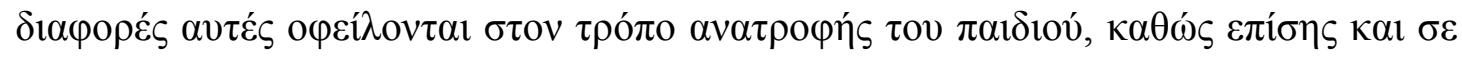

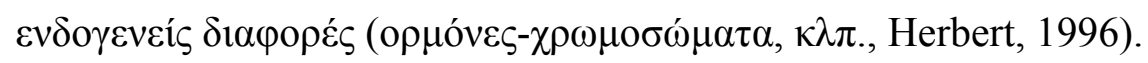

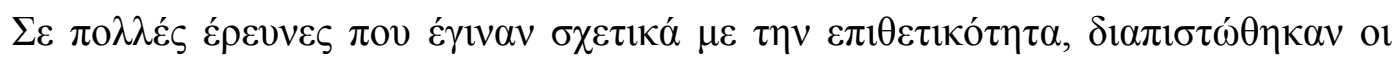

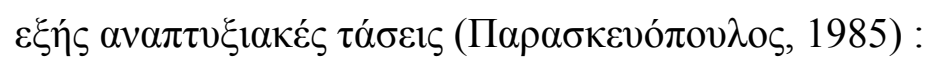




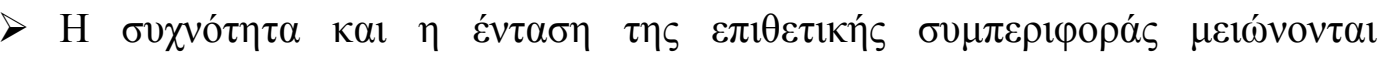

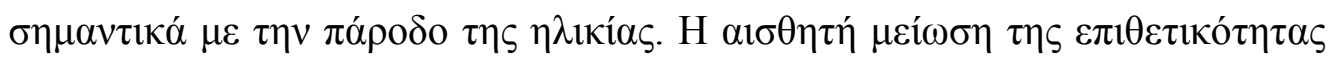

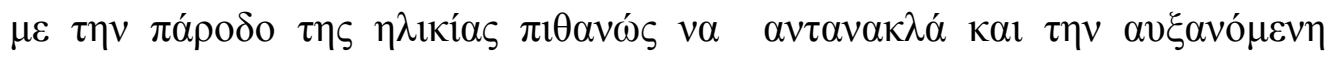

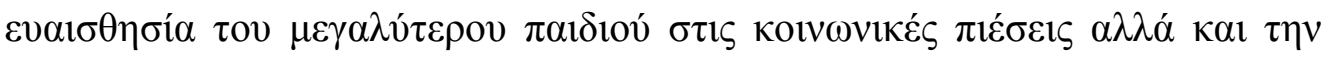

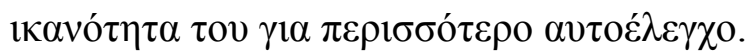

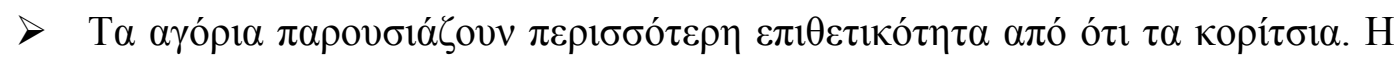

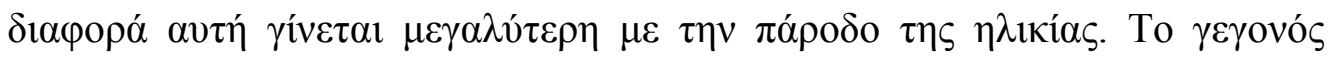

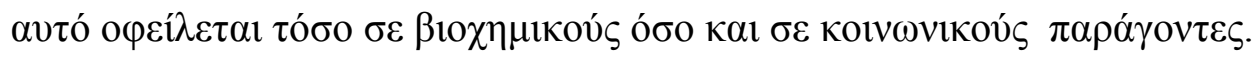

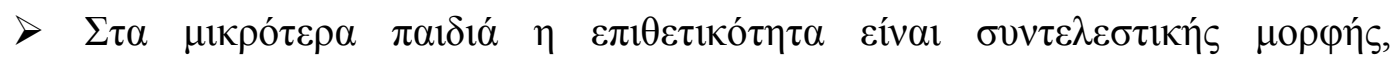
$\alpha \pi$

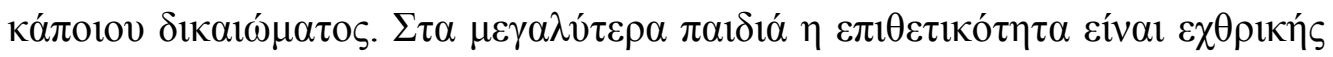

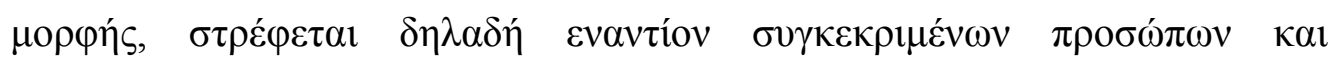

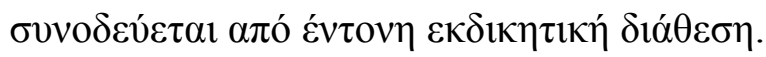

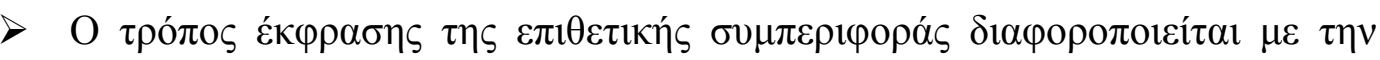

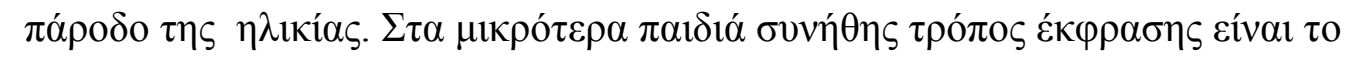

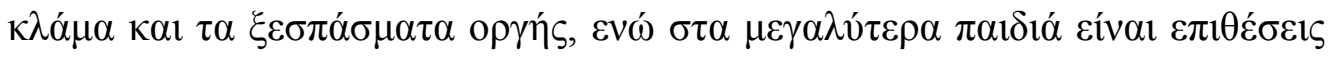

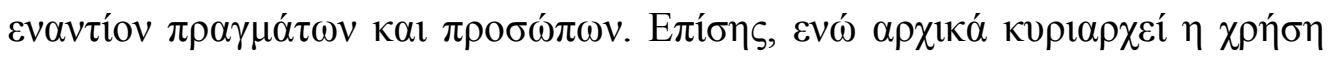

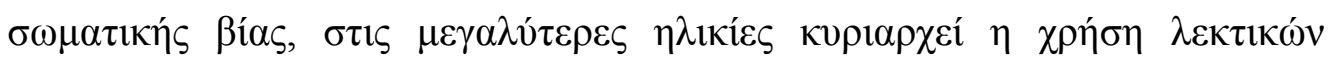

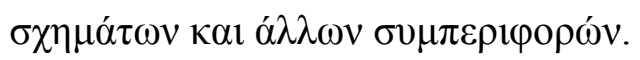

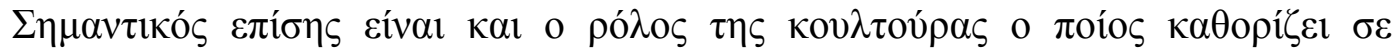

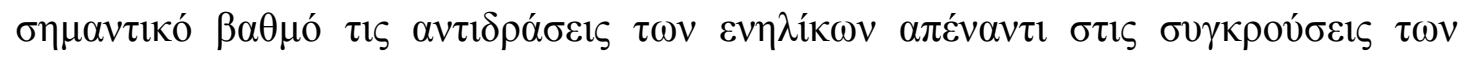

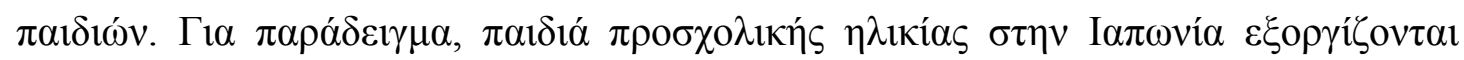

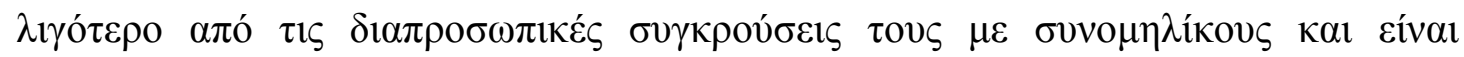




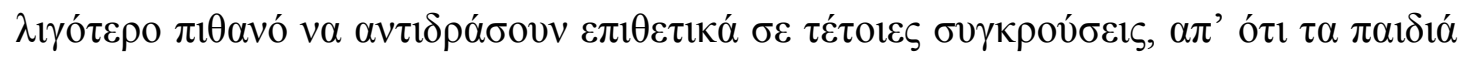

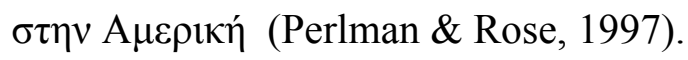

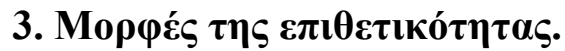

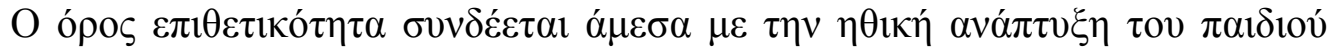

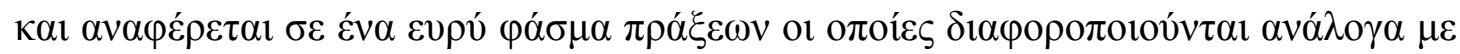

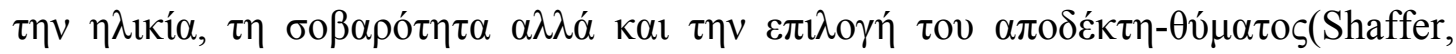

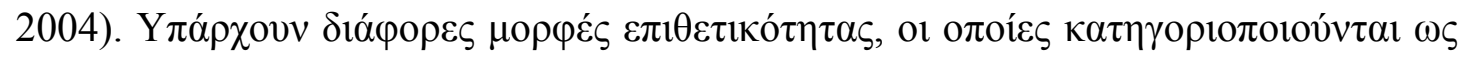
$\varepsilon \xi \dot{n} s:$

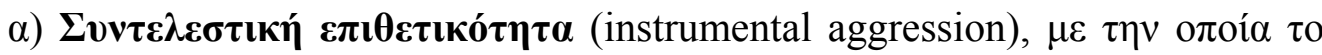

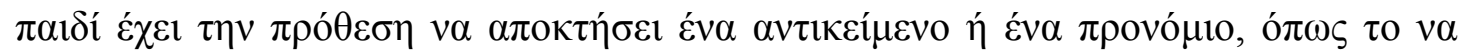

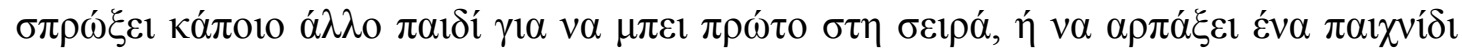

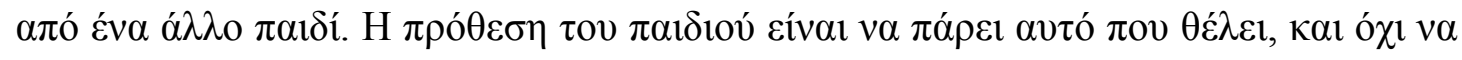

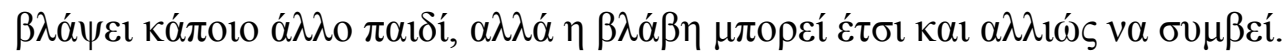

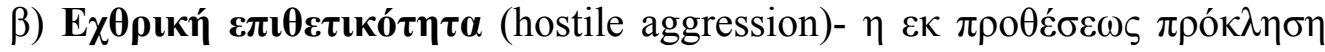

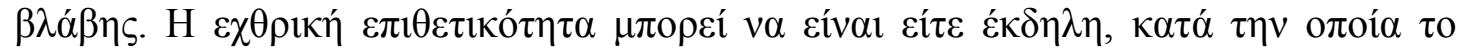

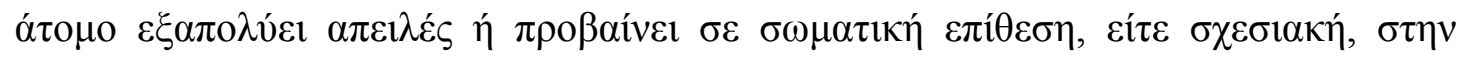

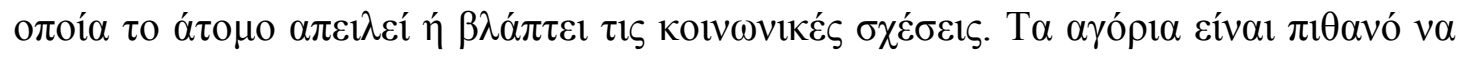

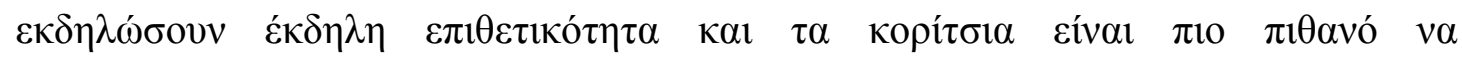

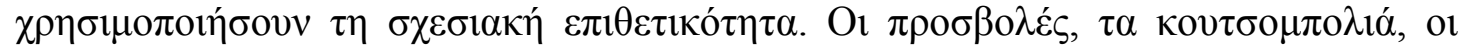

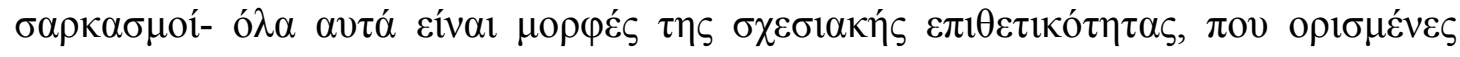

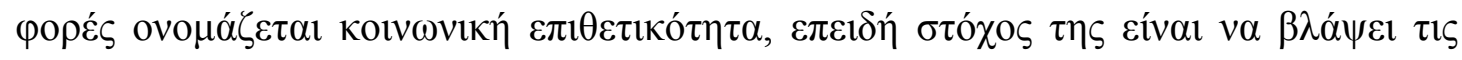

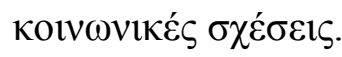

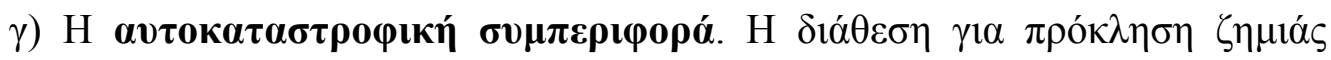

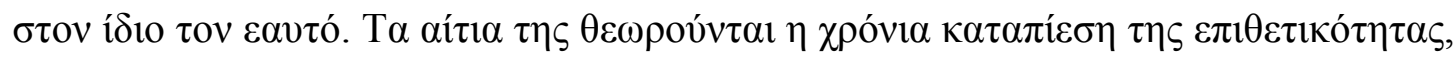




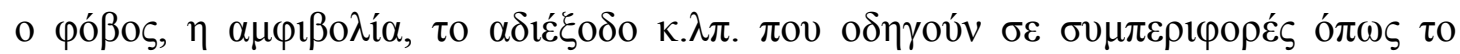

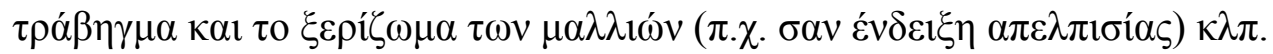

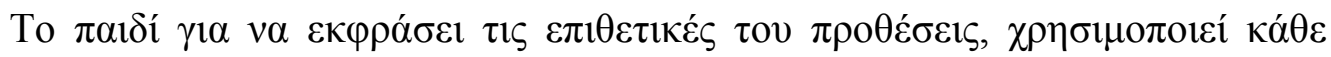

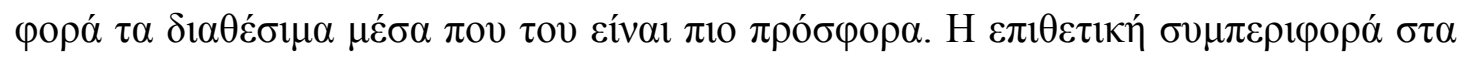

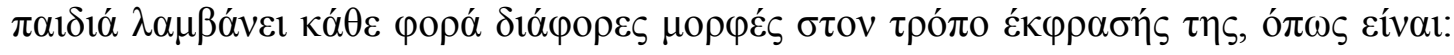

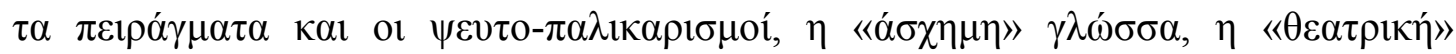

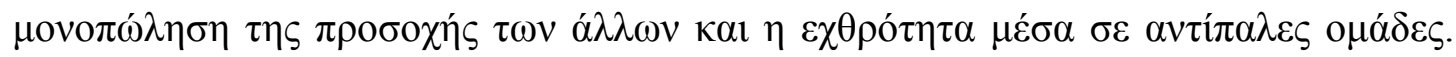

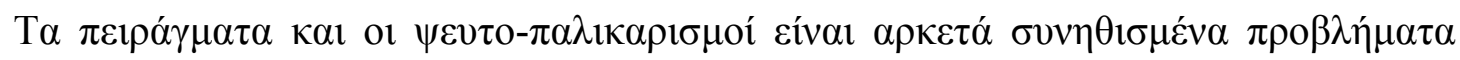

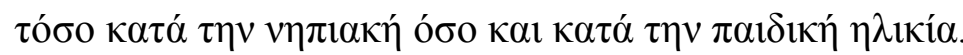

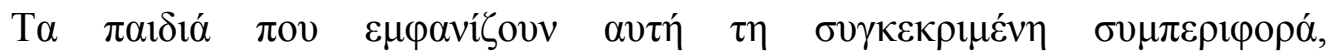

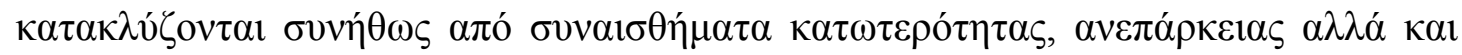

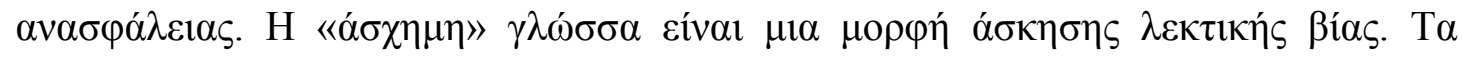

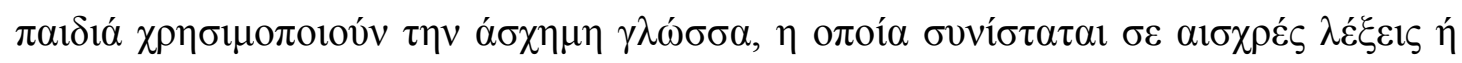

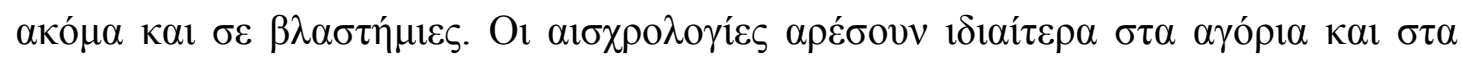

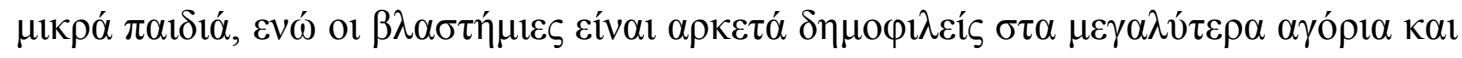

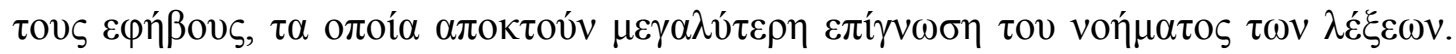

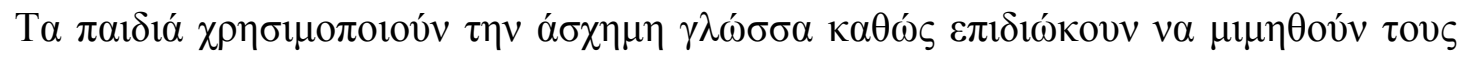

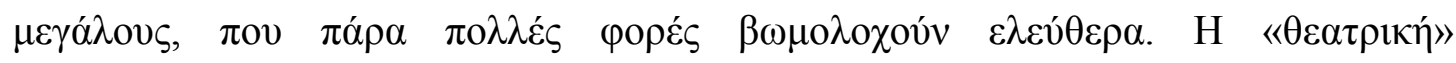

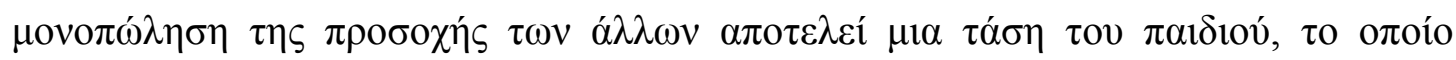

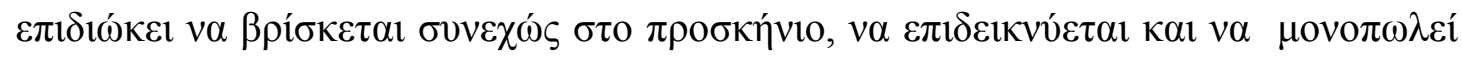

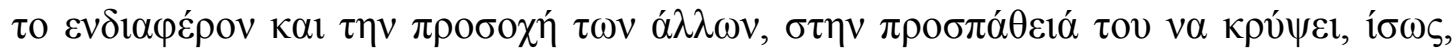

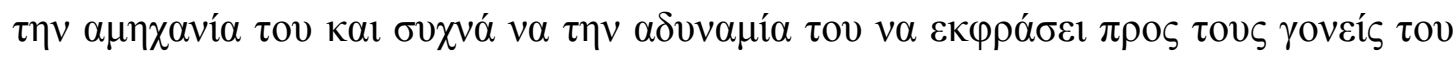

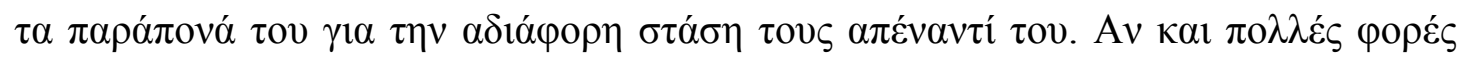

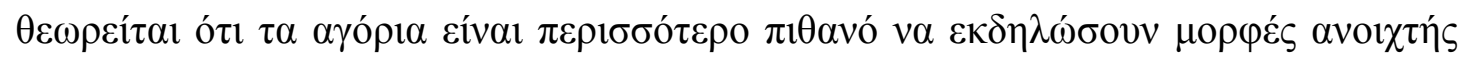

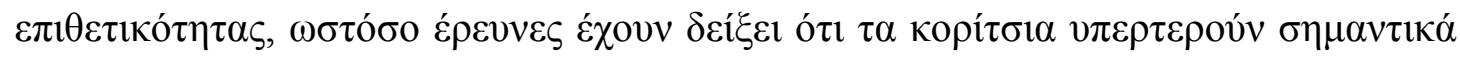




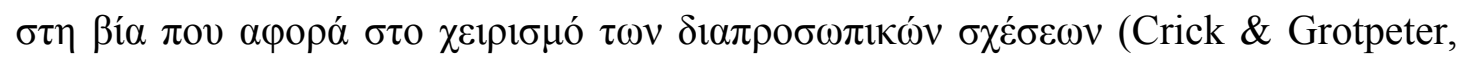
1995).

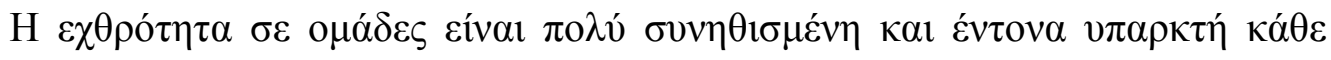

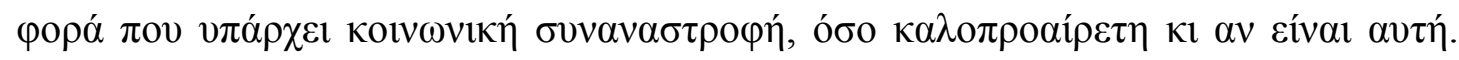

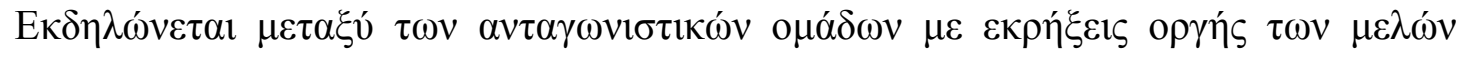

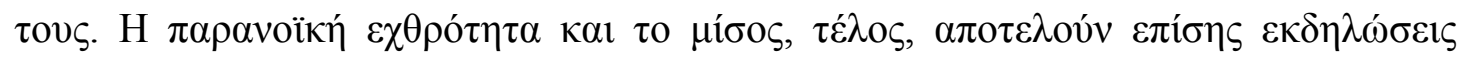

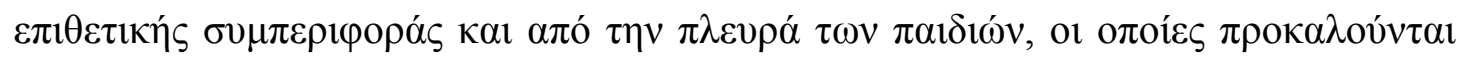

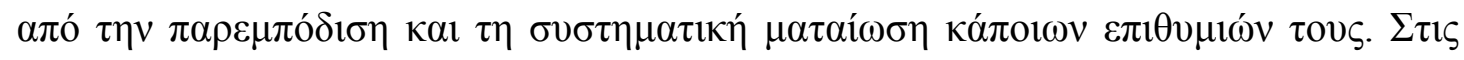

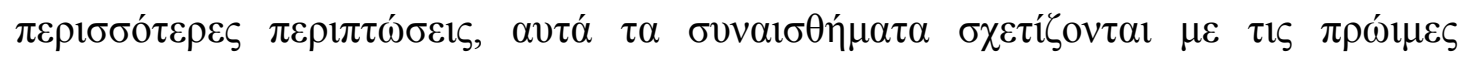

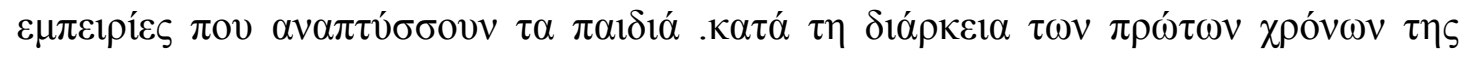

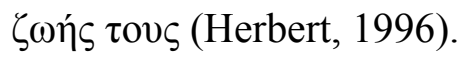

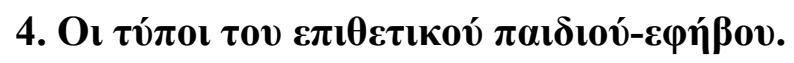

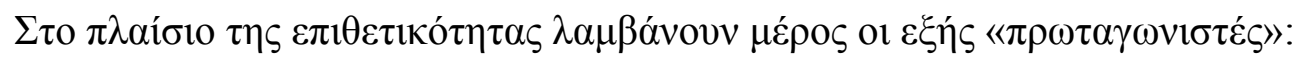

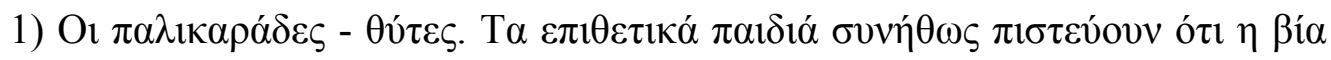

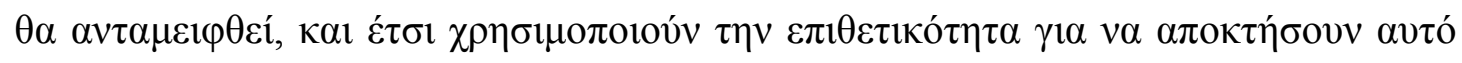

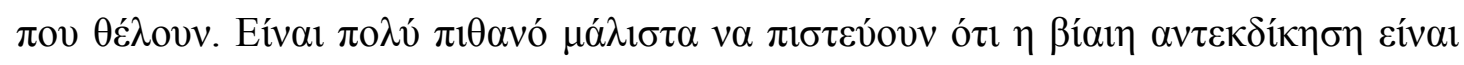

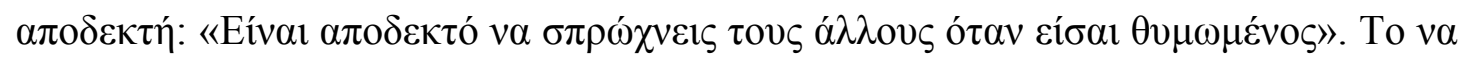

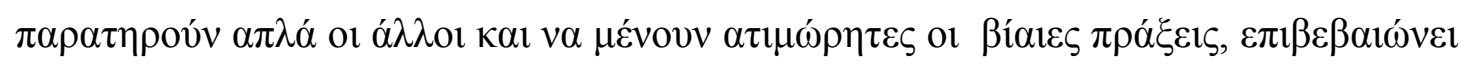

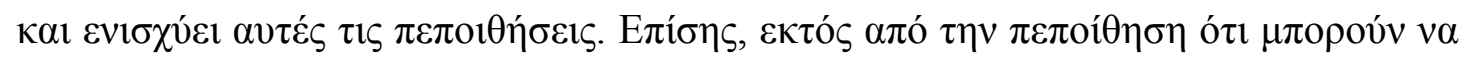

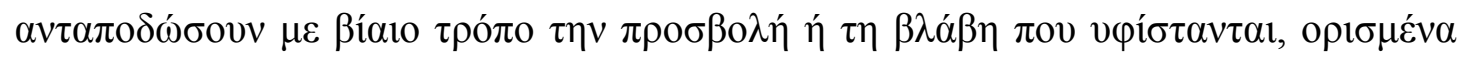

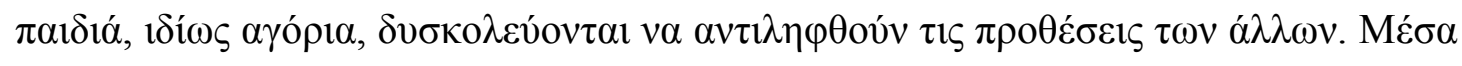

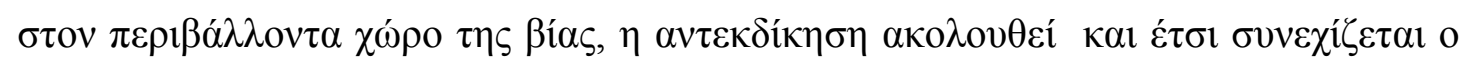

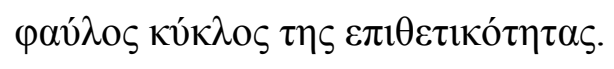




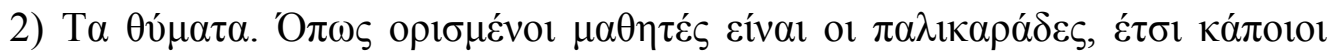

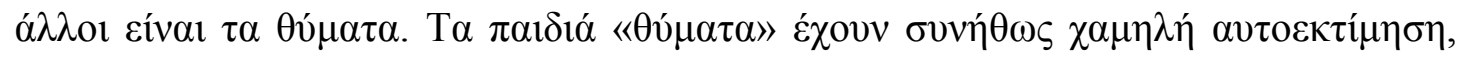

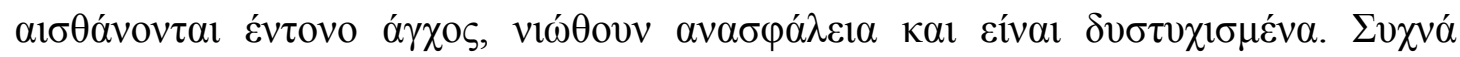

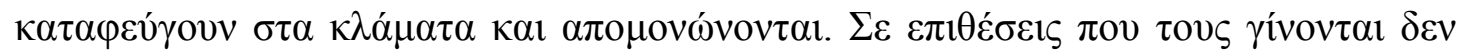

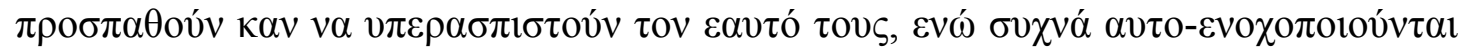

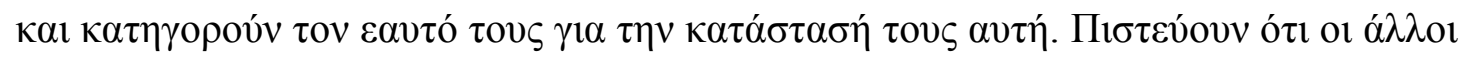

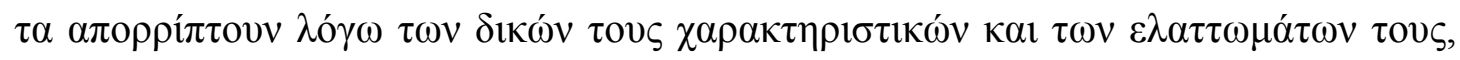

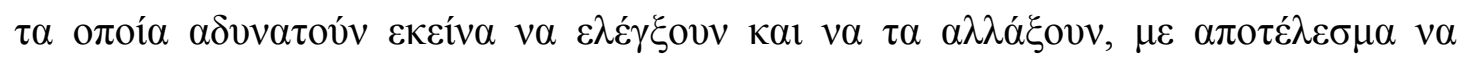

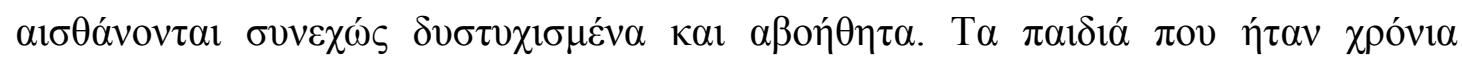

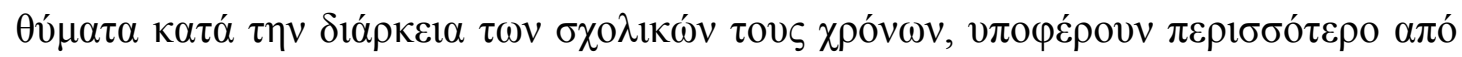

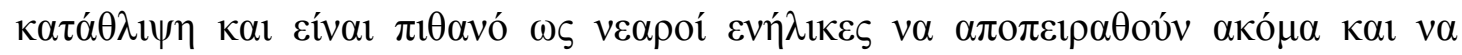

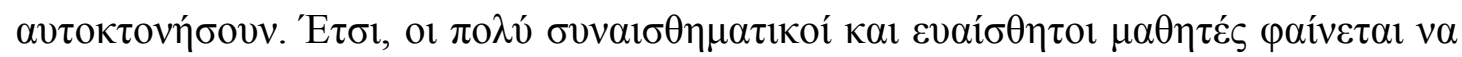

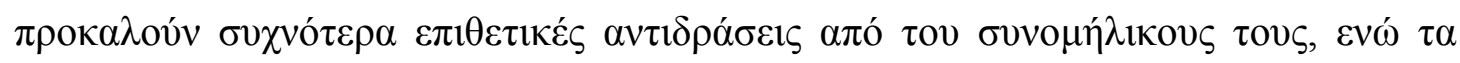

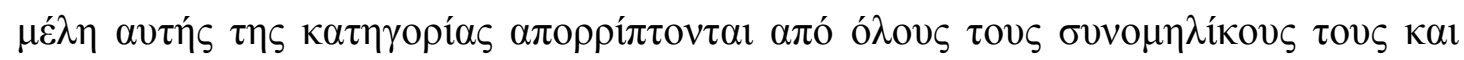

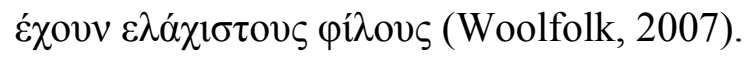

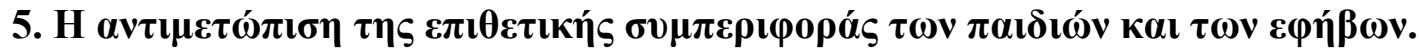

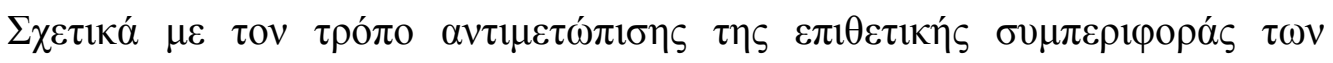

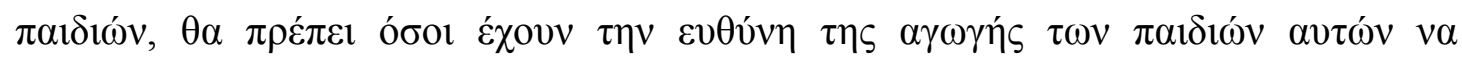

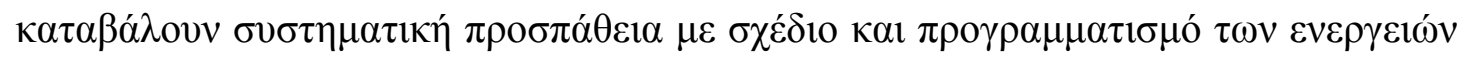

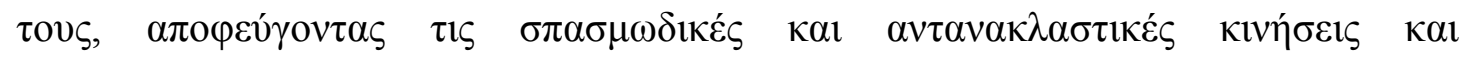

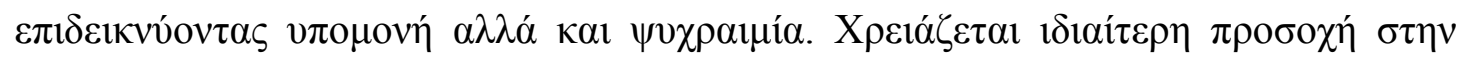

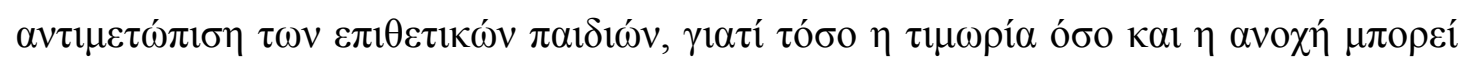

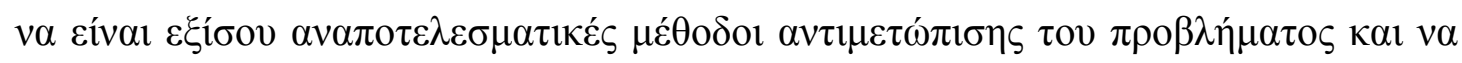

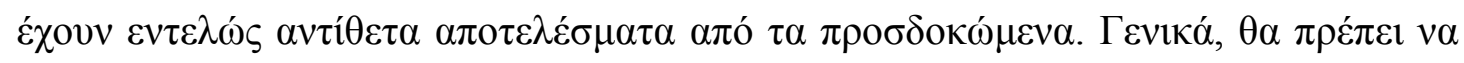




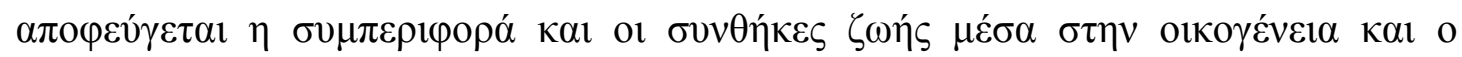

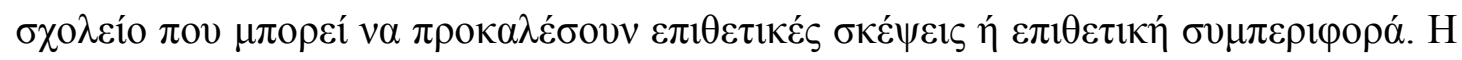

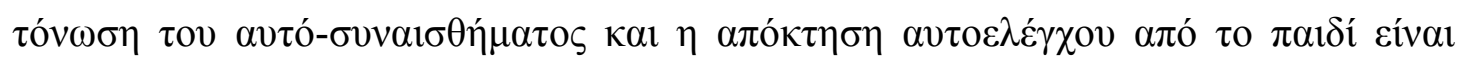

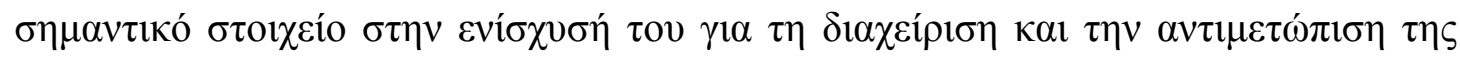

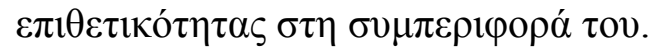

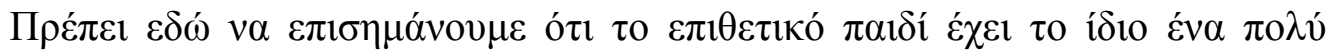

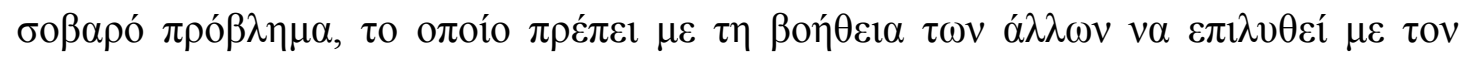

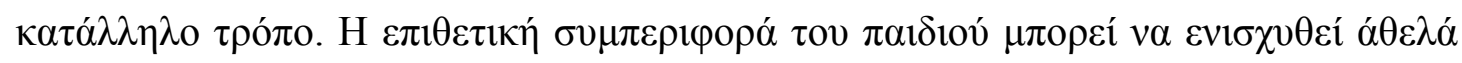

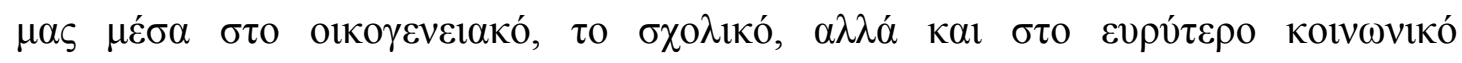

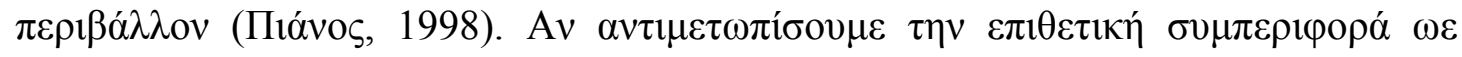

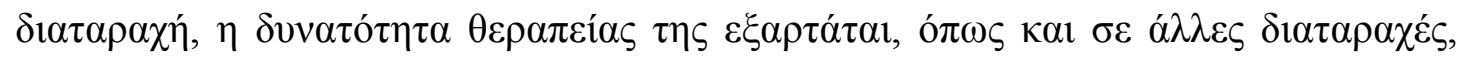

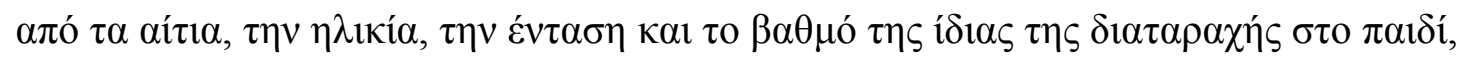

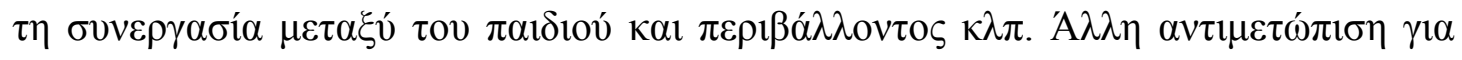

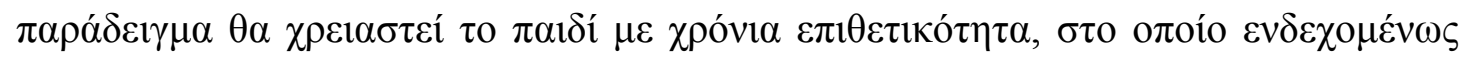

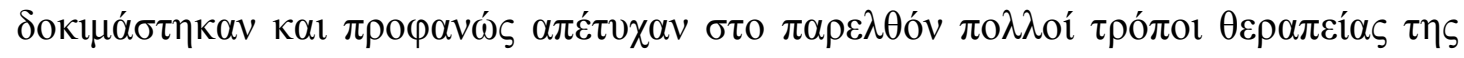

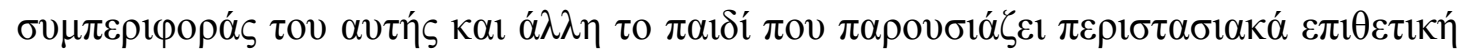

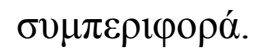

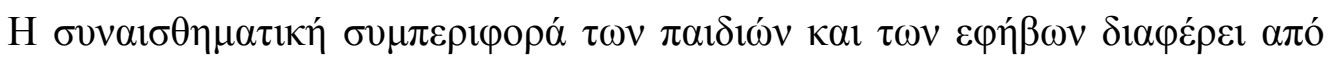

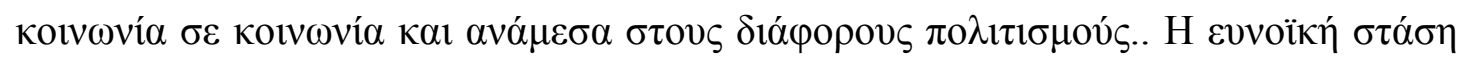

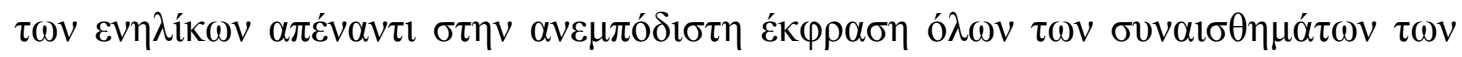

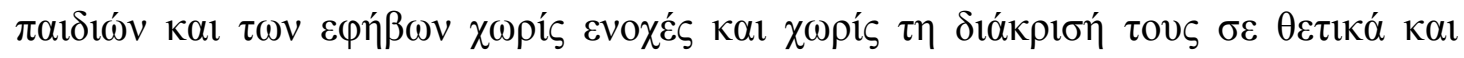

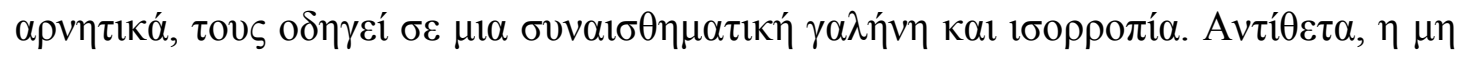

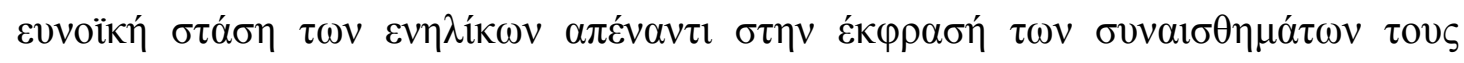

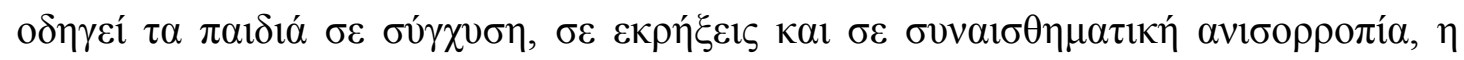

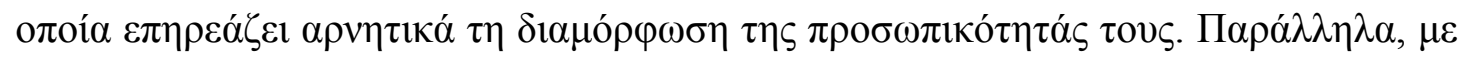




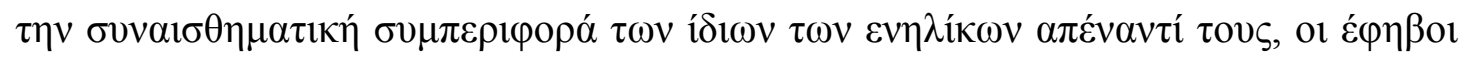

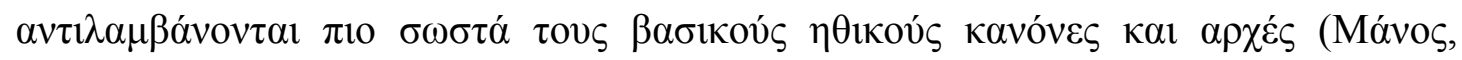
2005).

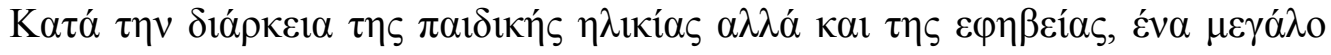

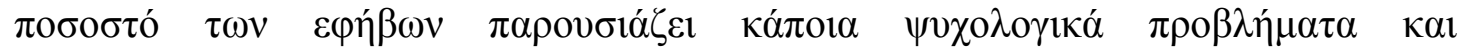

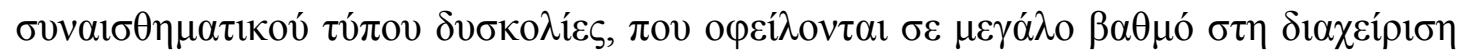

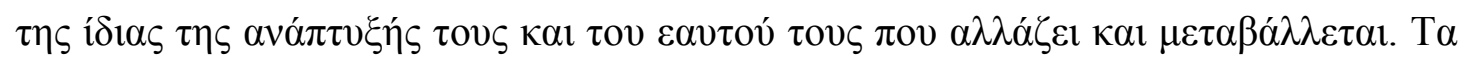

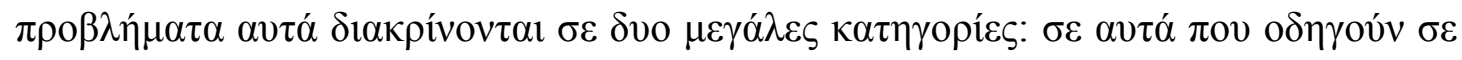

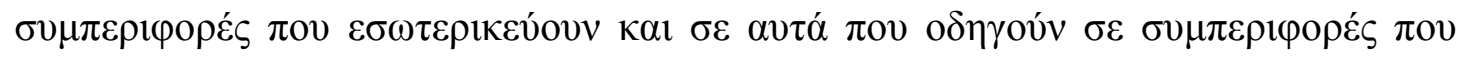

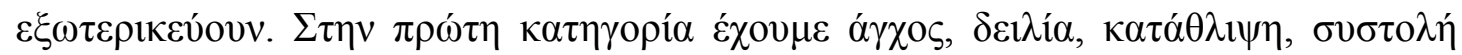

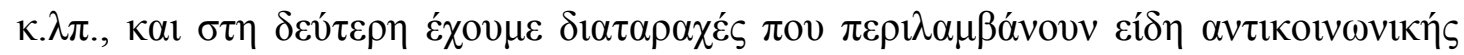

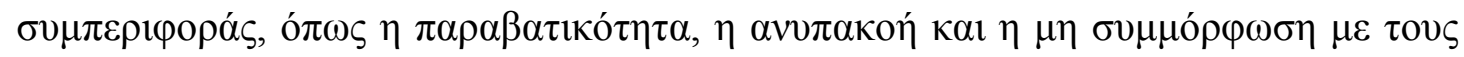

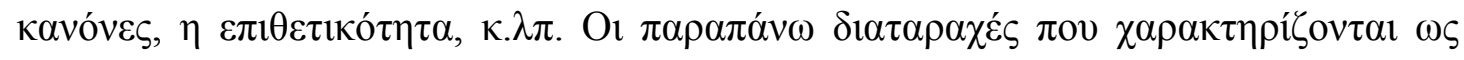

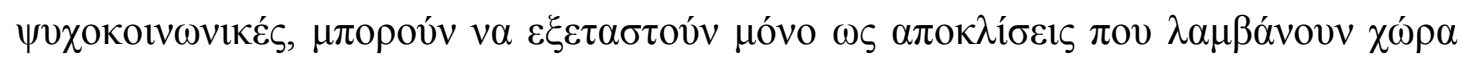

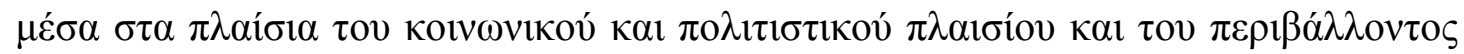

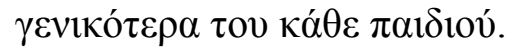

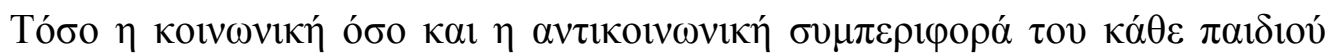

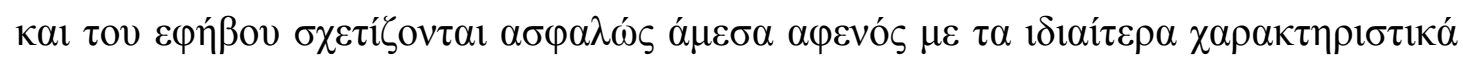

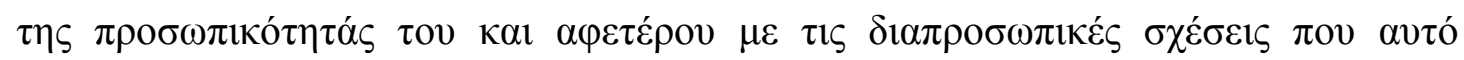

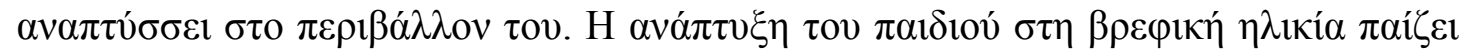

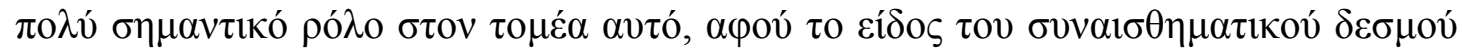

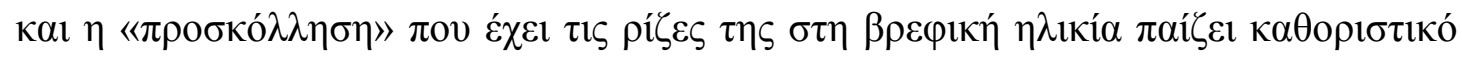

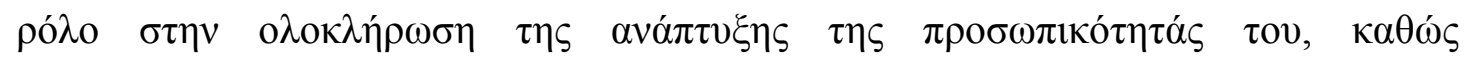

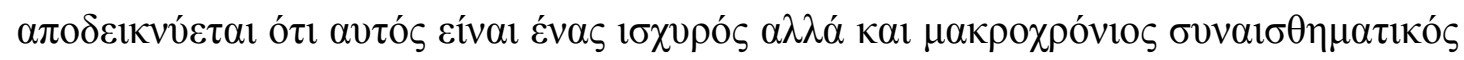

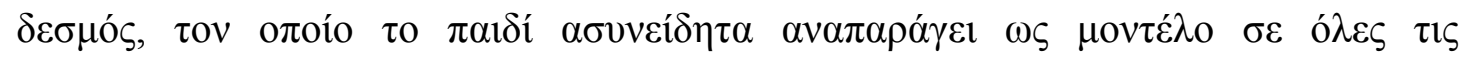




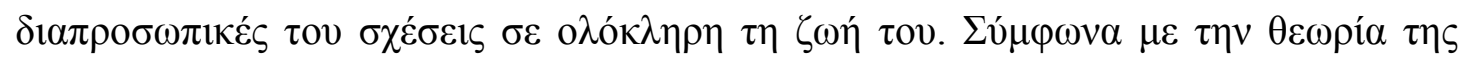

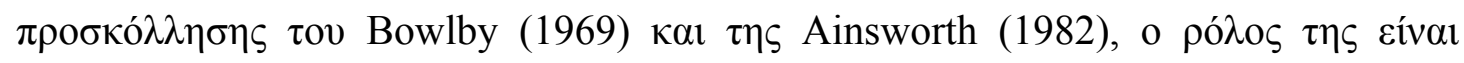

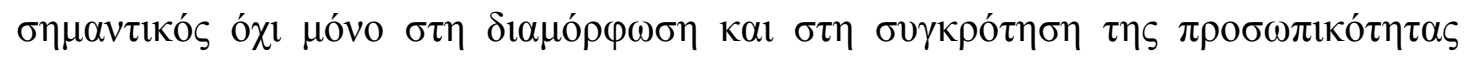

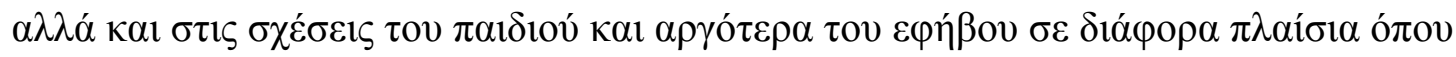

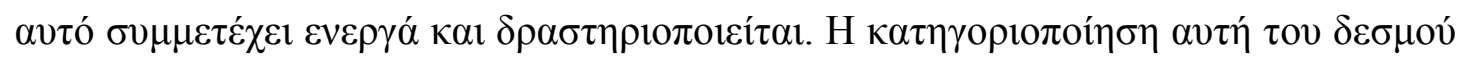

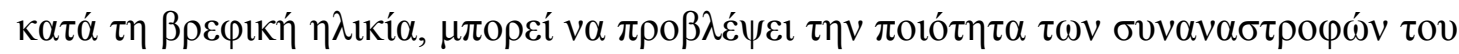

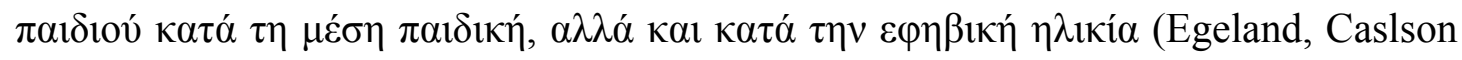
\& Sroufe, 1993. Sroufe, Carlson \& Shulman, 1993).

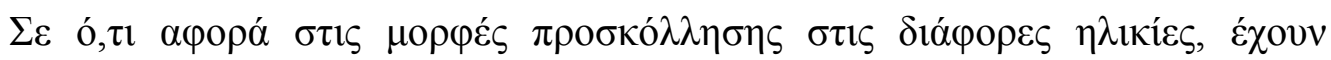

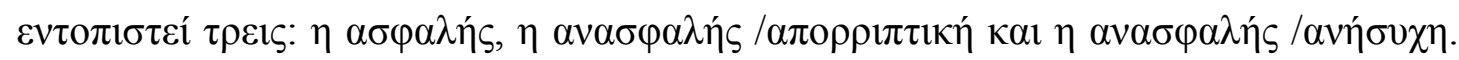

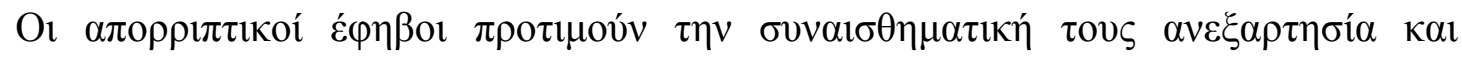

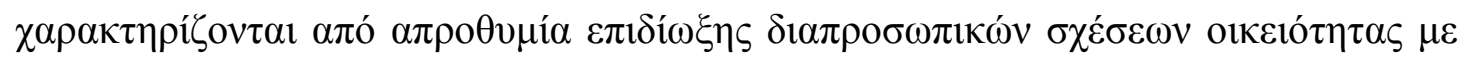

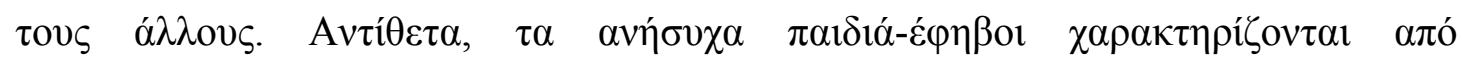

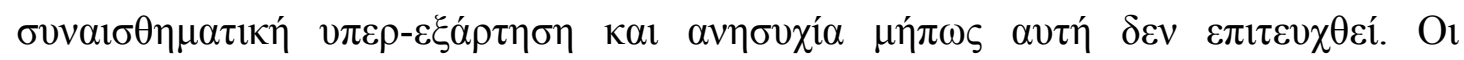

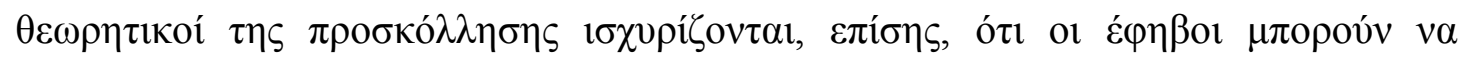

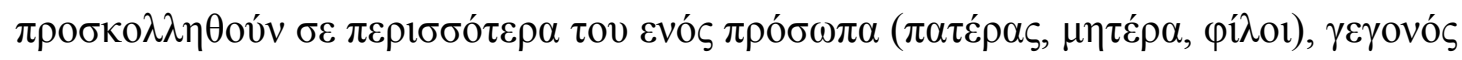

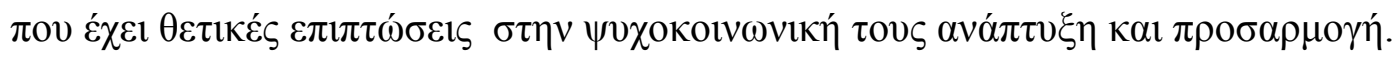

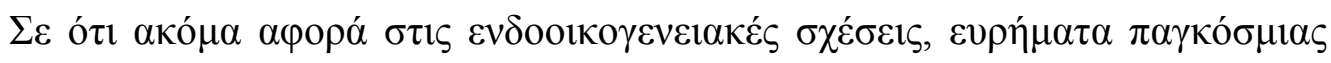

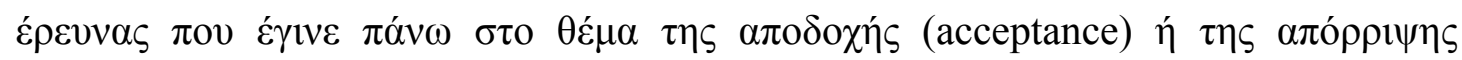

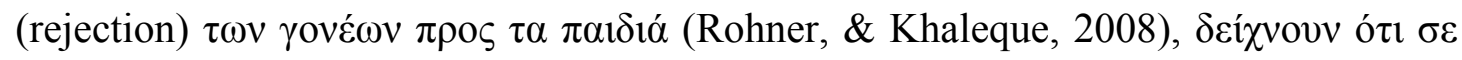

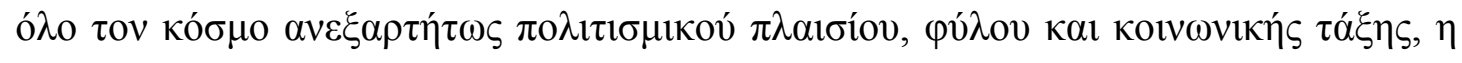

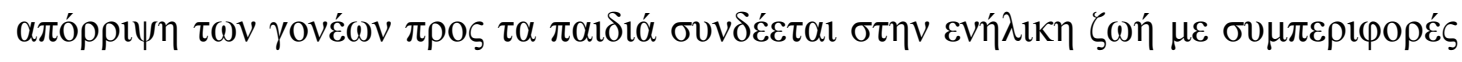

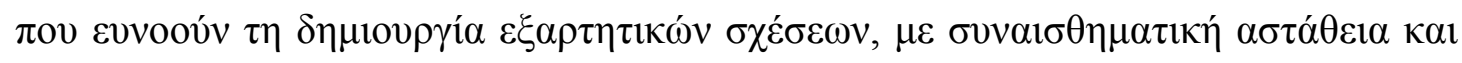

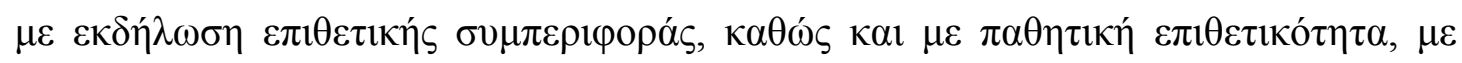

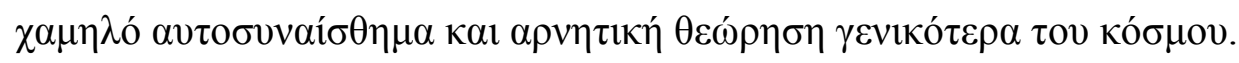




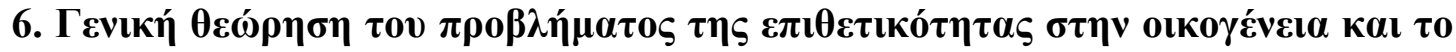 $\sigma \chi 0 \lambda \varepsilon i ́ o$.}

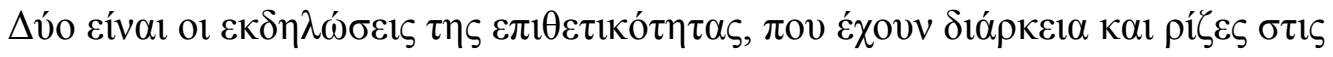

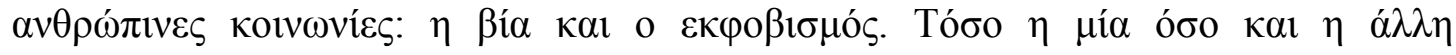

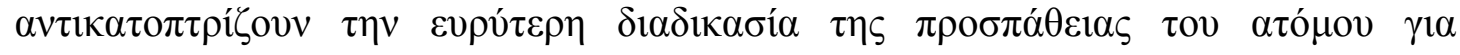

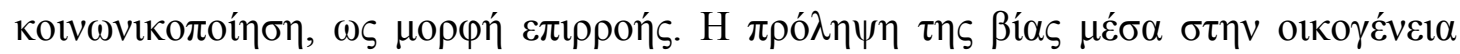

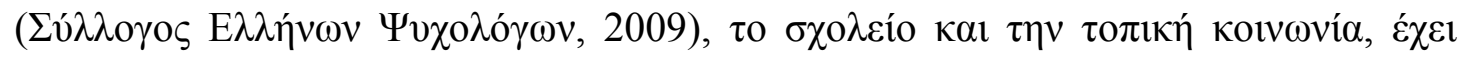

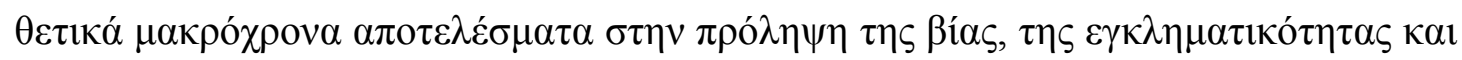

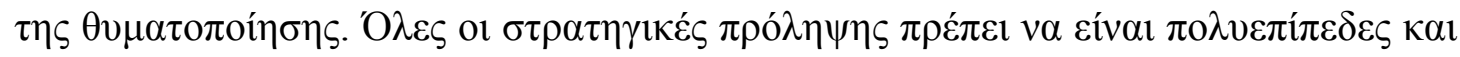

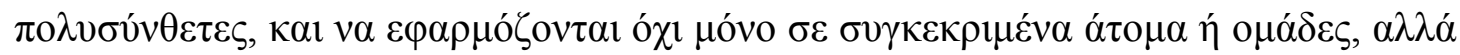

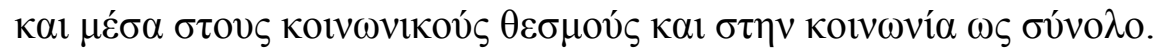

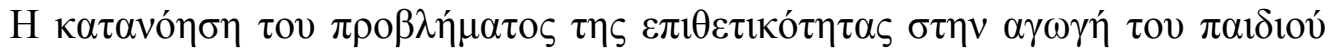

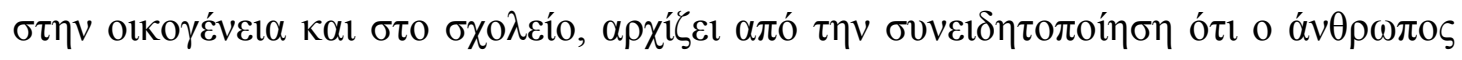

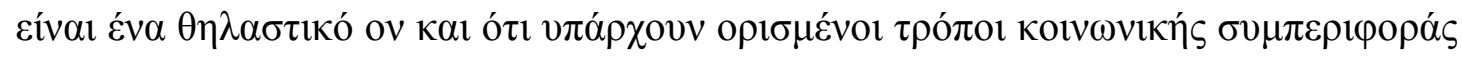

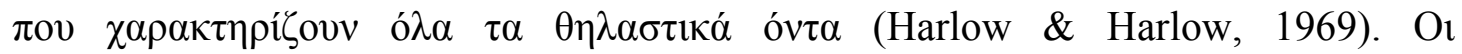

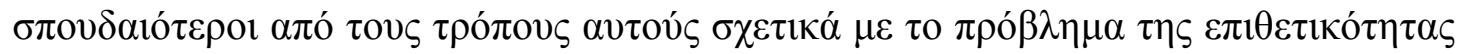

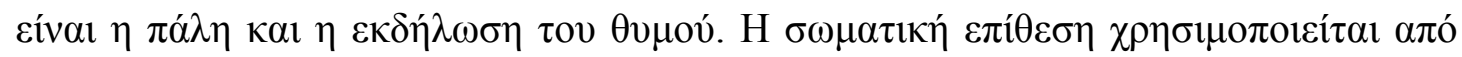

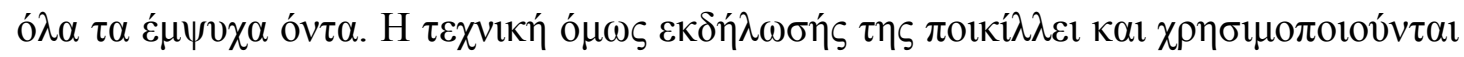

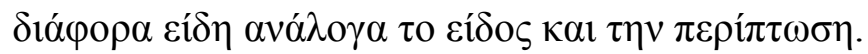

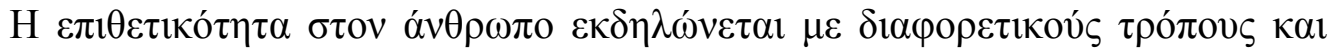

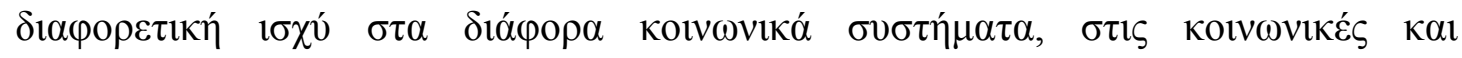

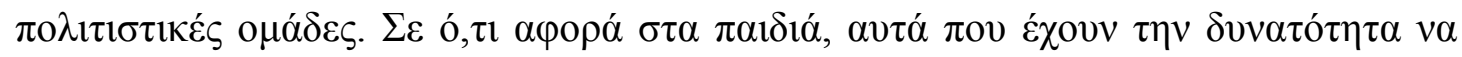

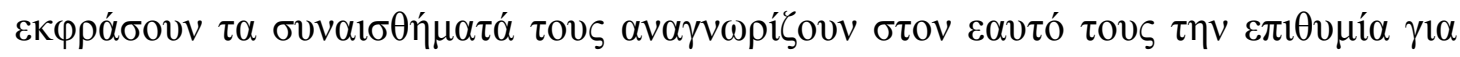

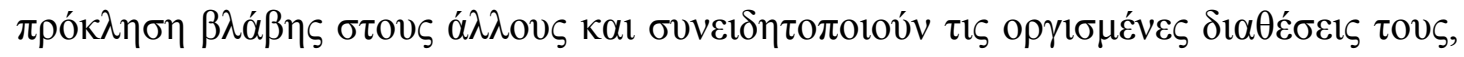

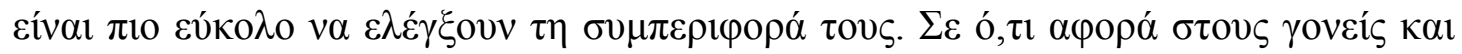




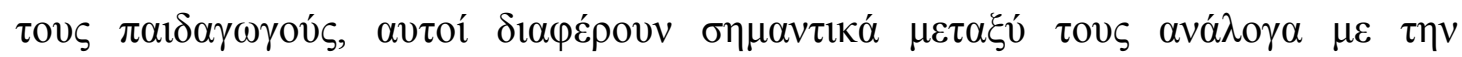

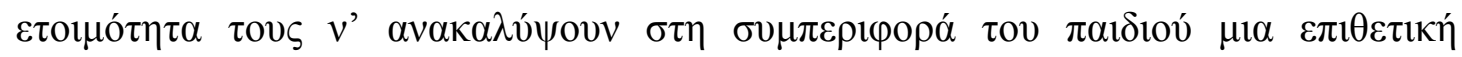

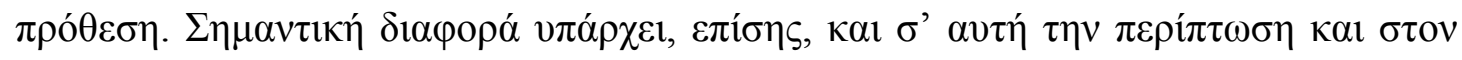

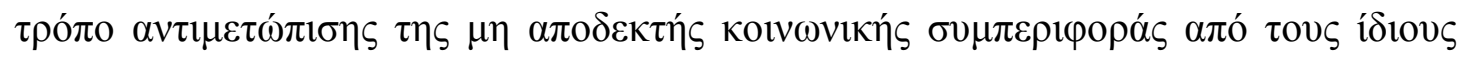

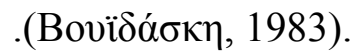

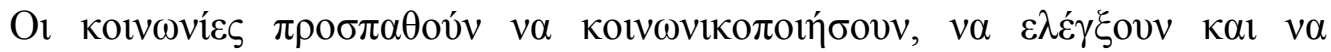

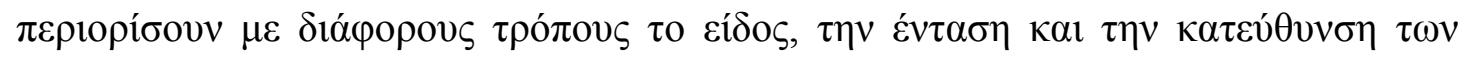

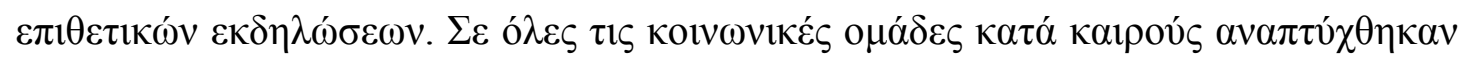

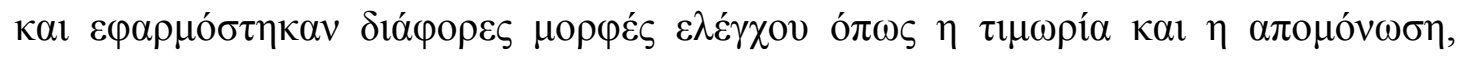

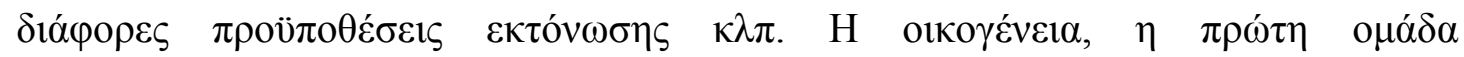

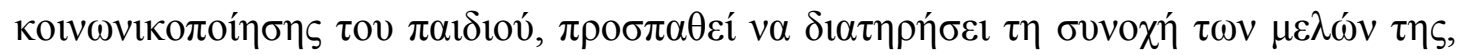

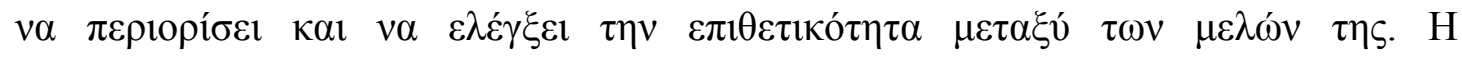

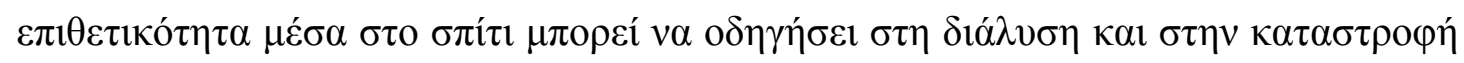

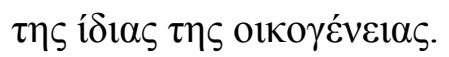

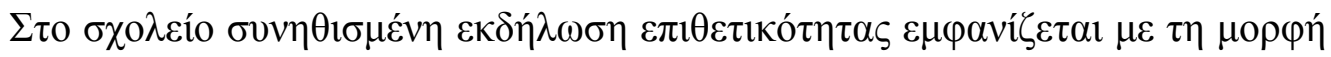

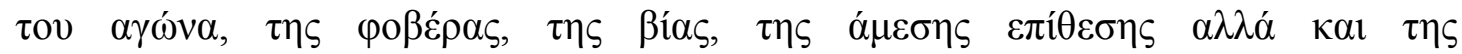

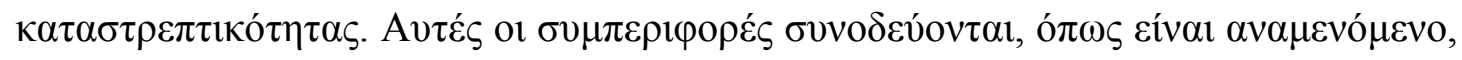

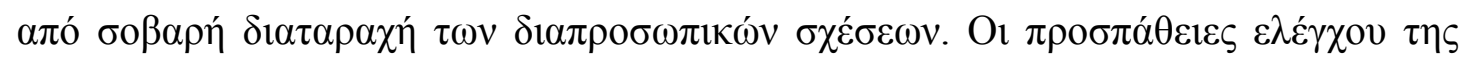

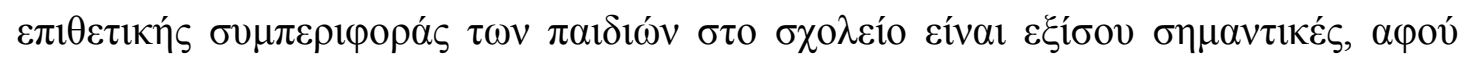

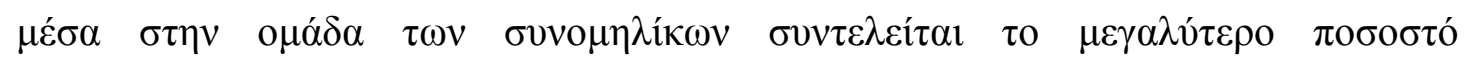

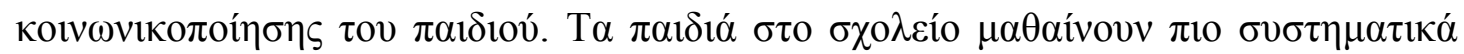

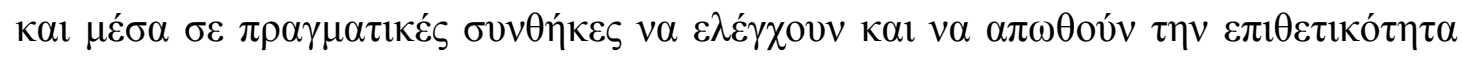

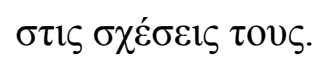

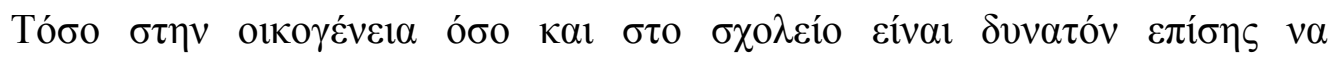

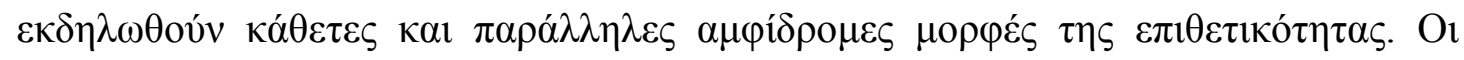




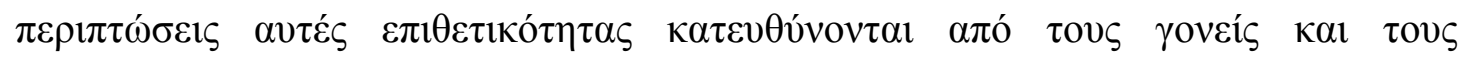

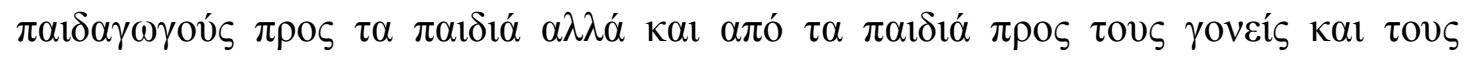

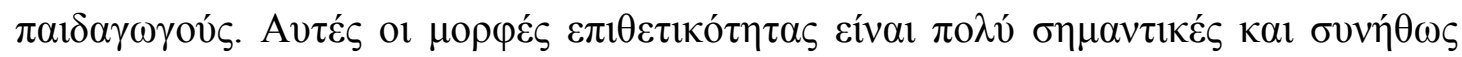

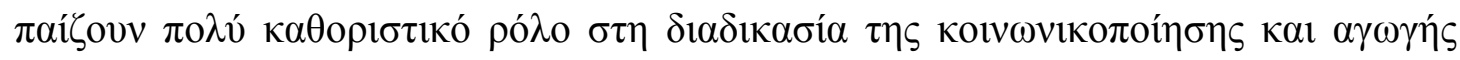

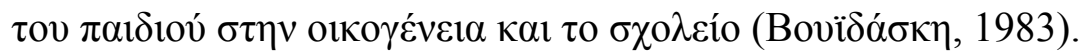

To

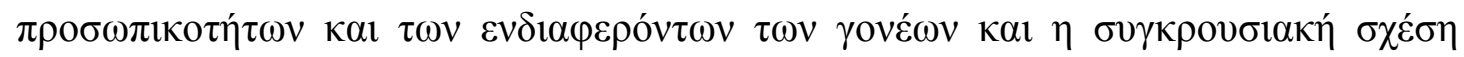

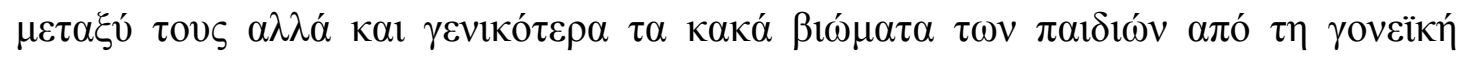

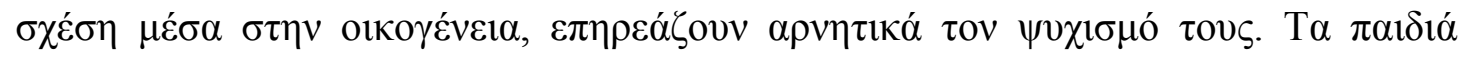

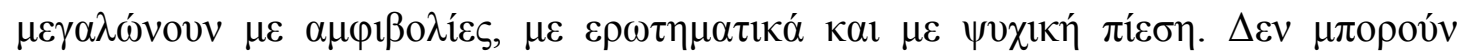

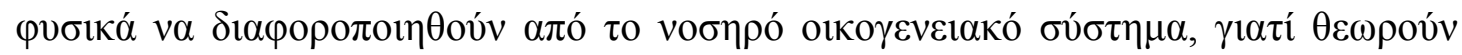

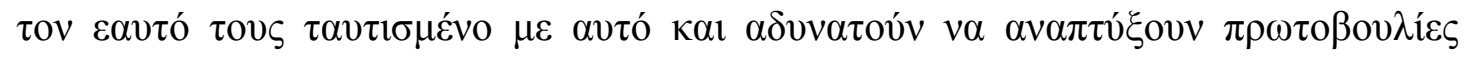

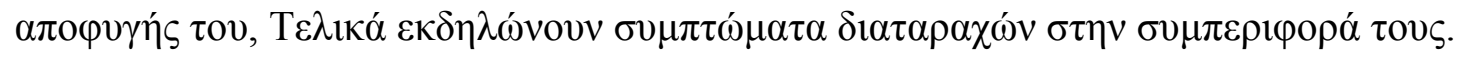

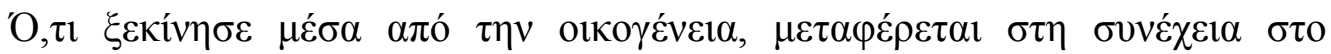

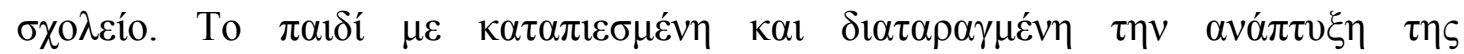

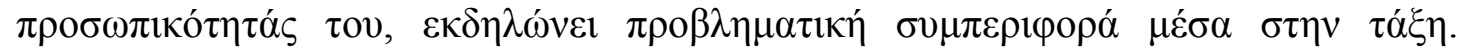

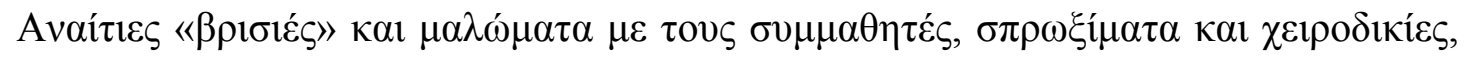

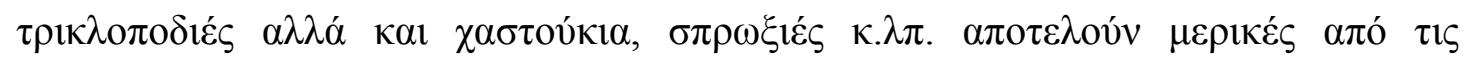

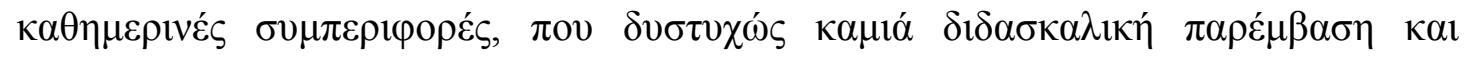

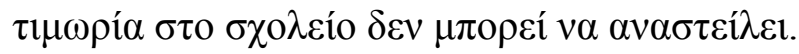

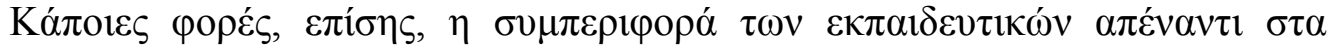

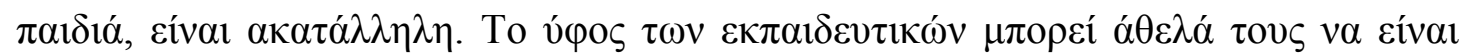

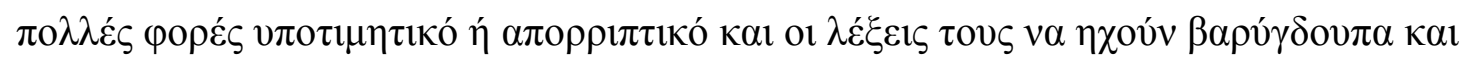

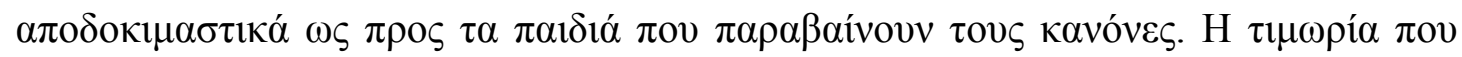

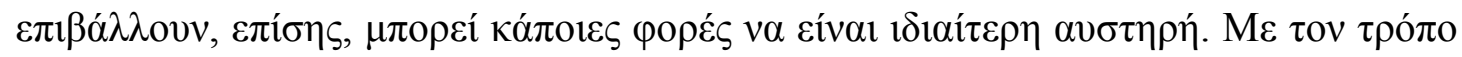




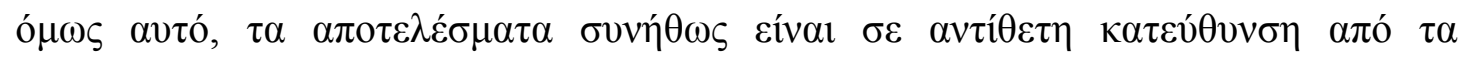

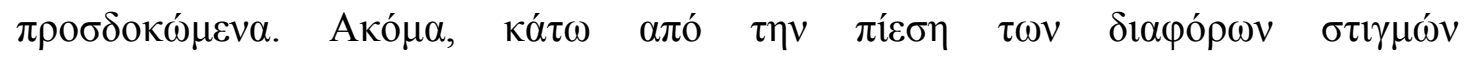

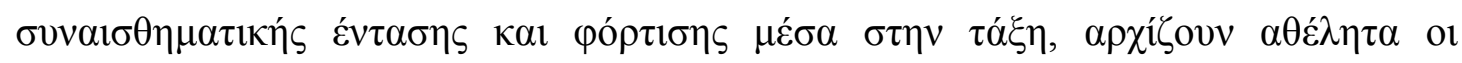

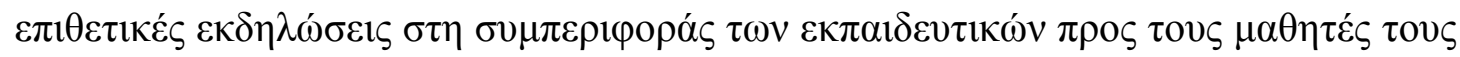

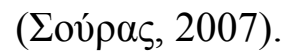

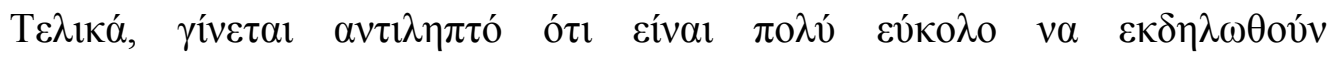

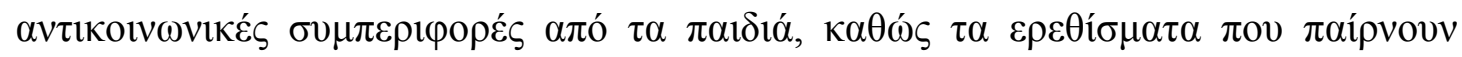

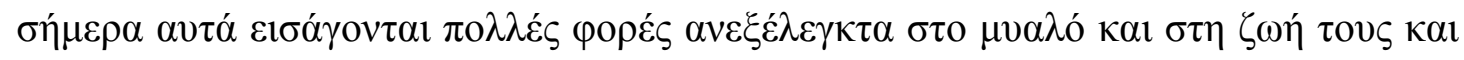

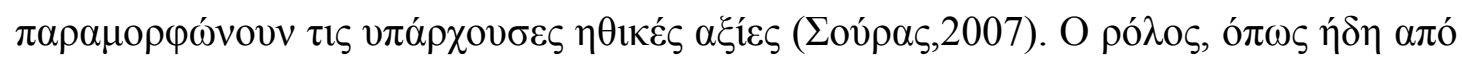

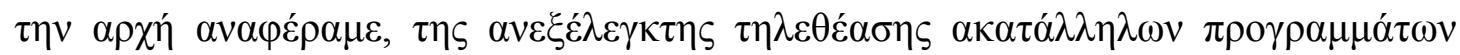

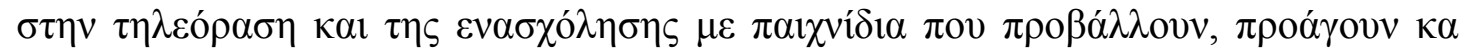

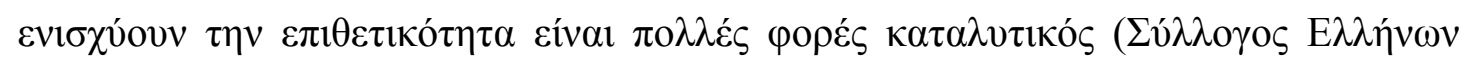

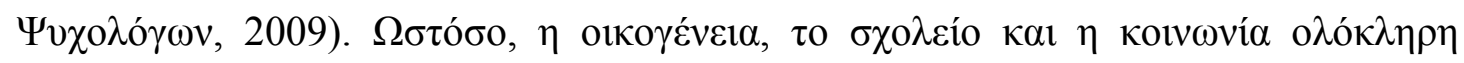

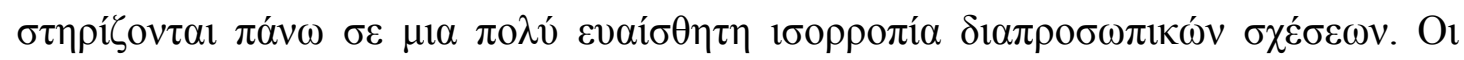

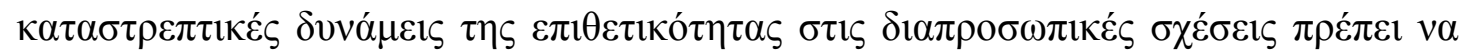

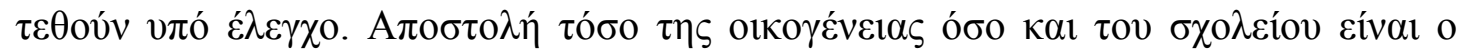

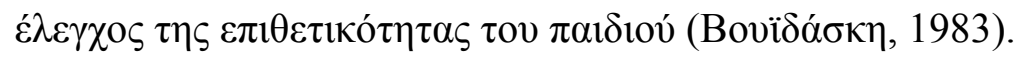

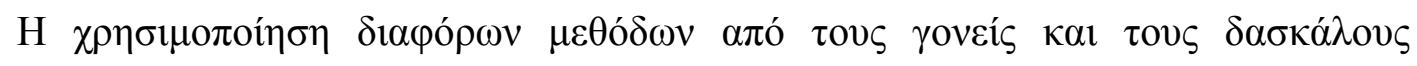

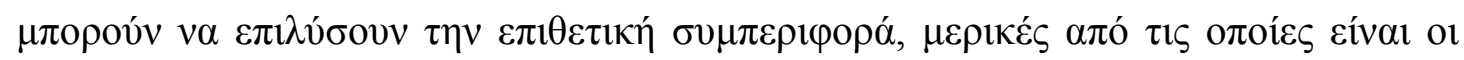
$\varepsilon \xi \dot{n} \zeta:$

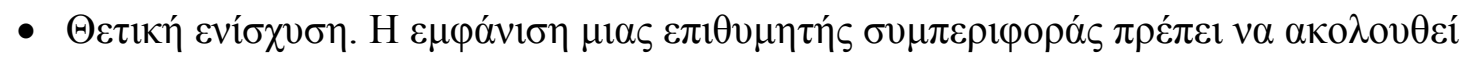

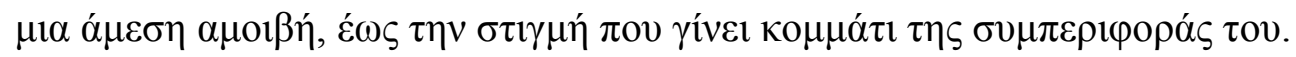

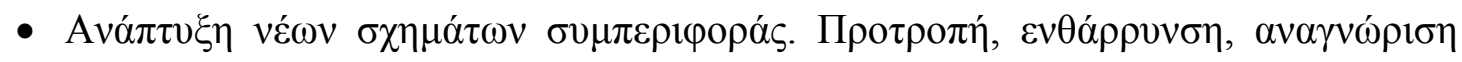

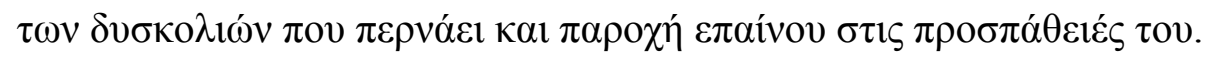




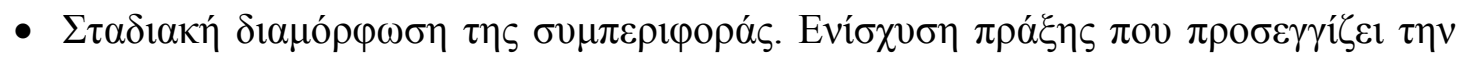

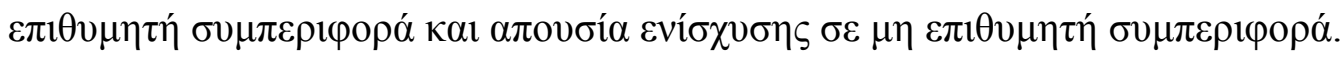

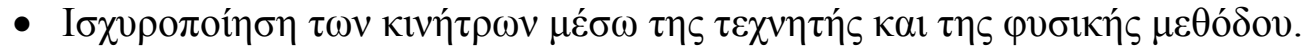

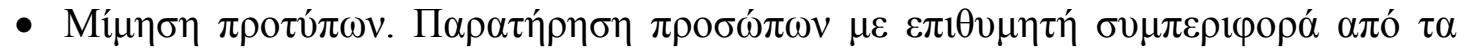
$\pi \alpha 1 \delta 1 \alpha$.

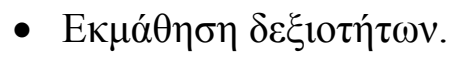

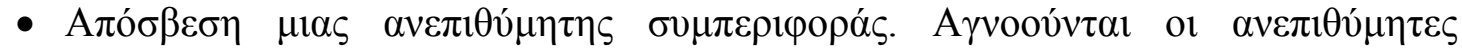

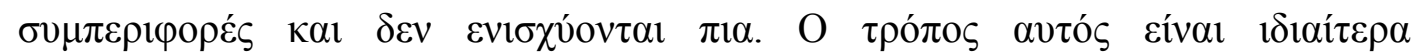
$\alpha \pi \mathrm{0} \varepsilon \lambda \varepsilon \sigma \mu \alpha \tau \iota \kappa o ́ s$.

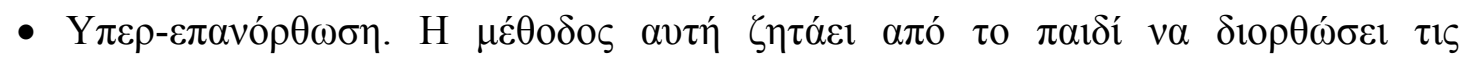

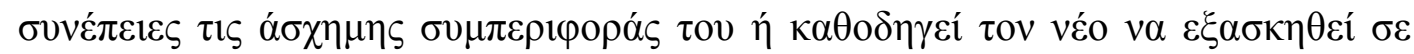

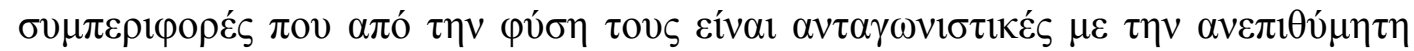

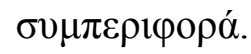

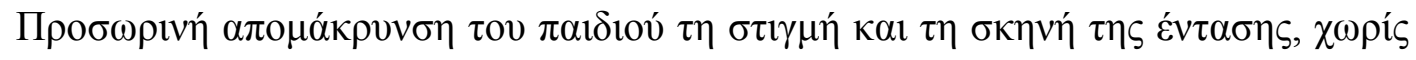

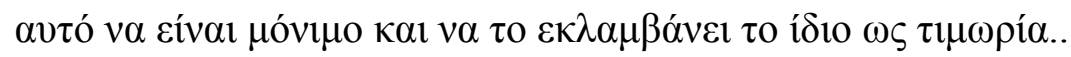

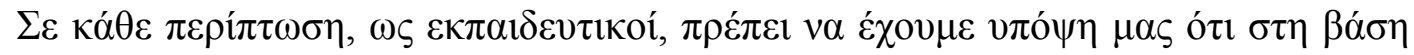

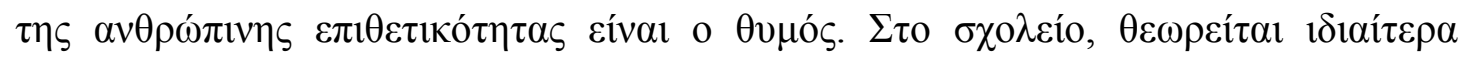

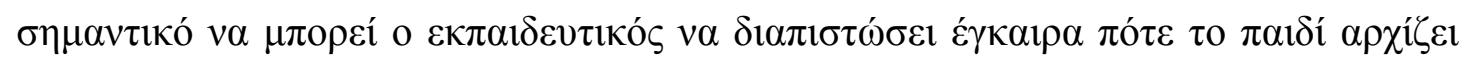

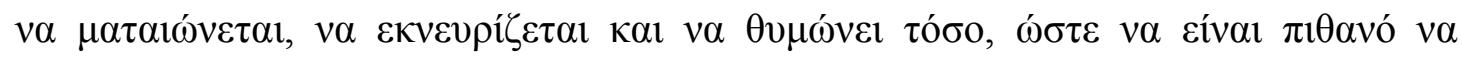

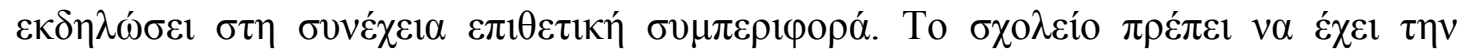

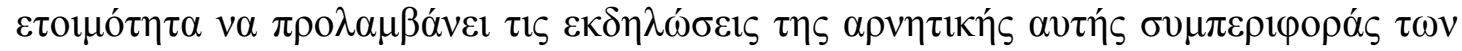

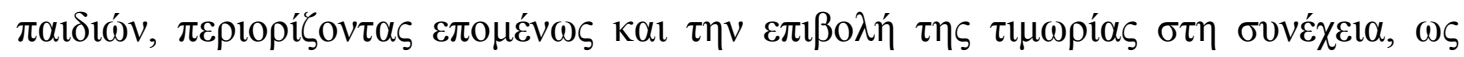

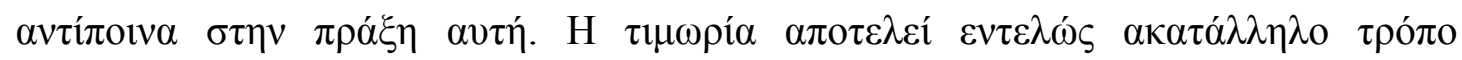

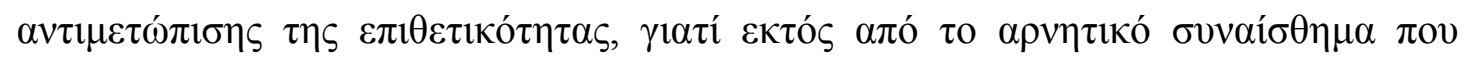




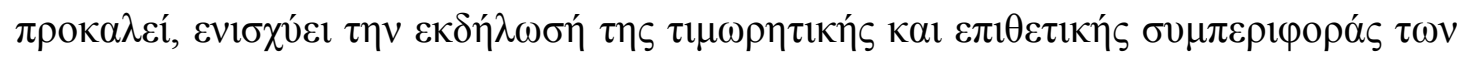

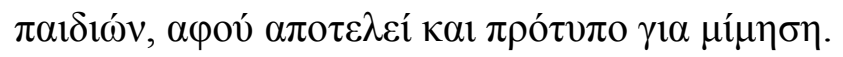

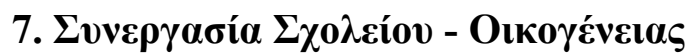

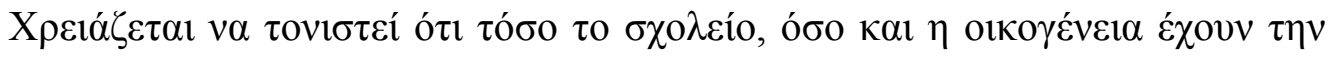

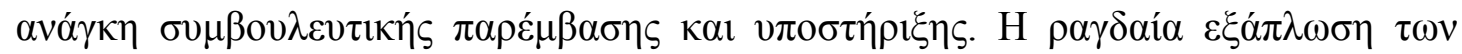

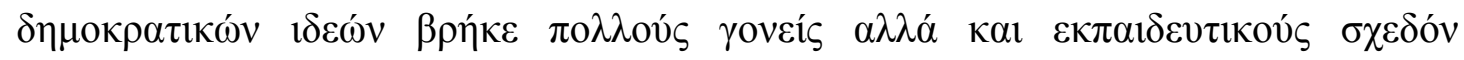

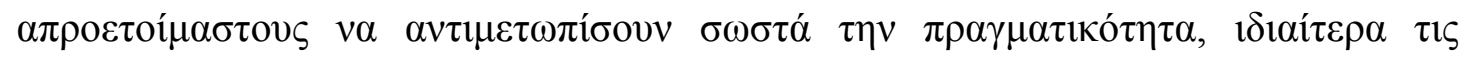

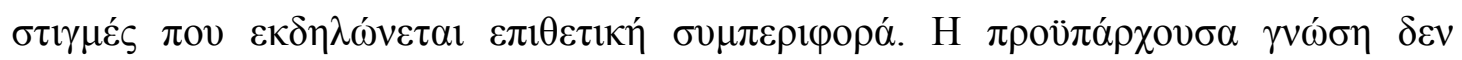

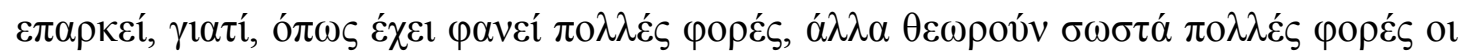

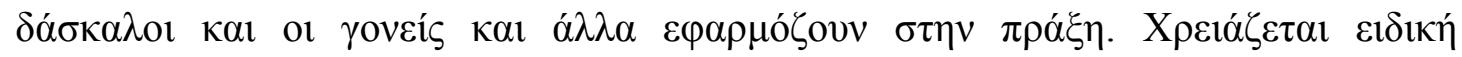

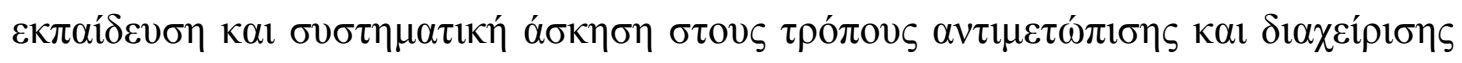

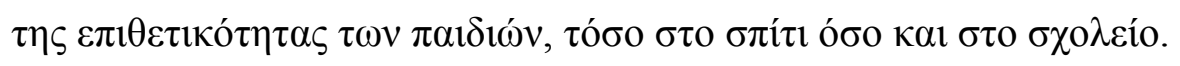

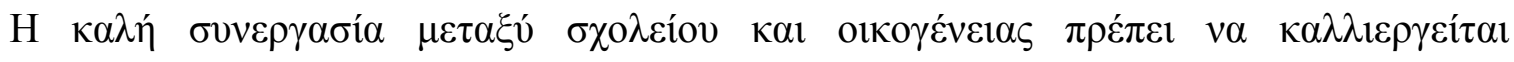

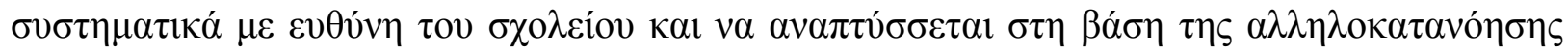

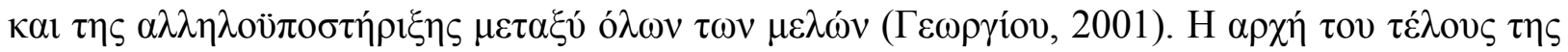

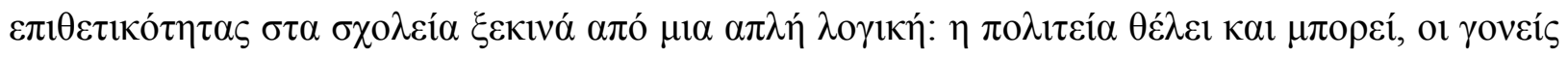

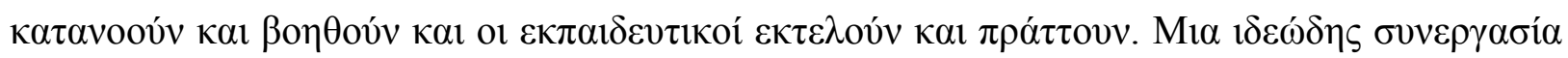

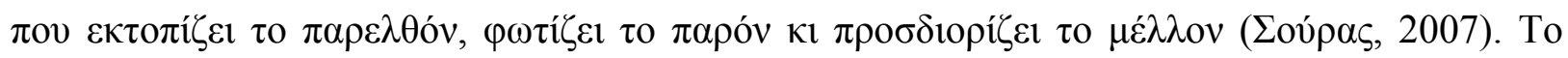

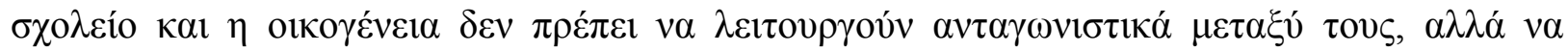

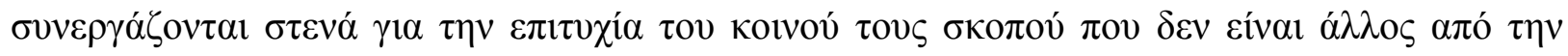

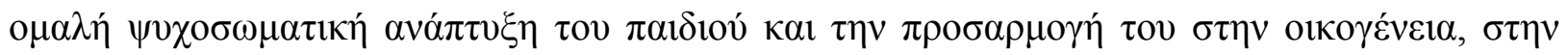

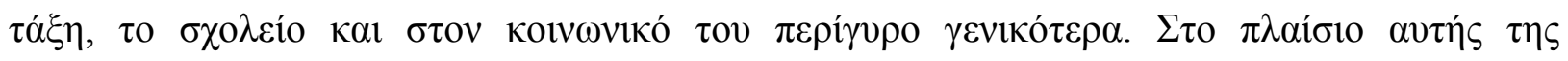

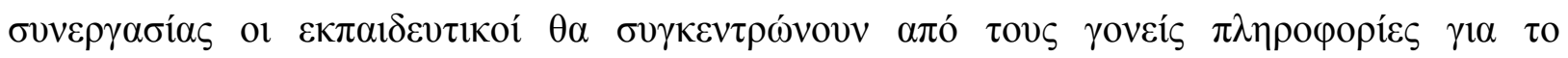




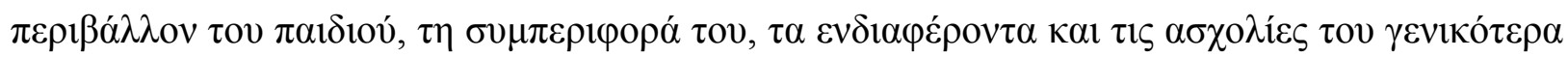

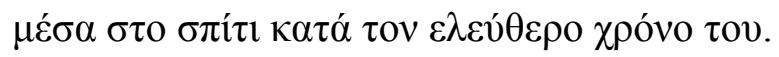

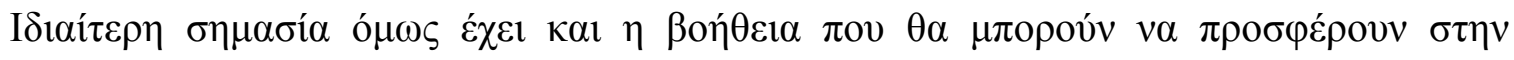

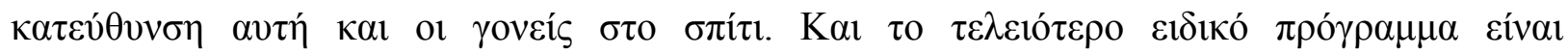

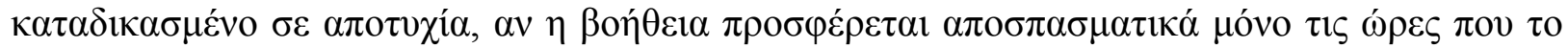

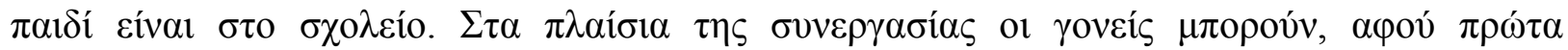

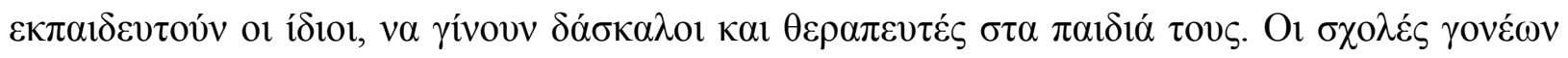

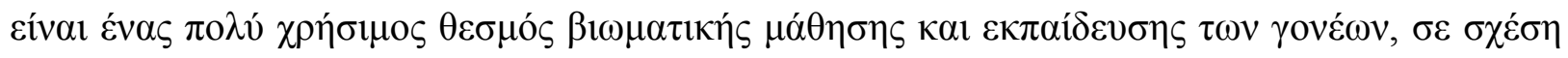

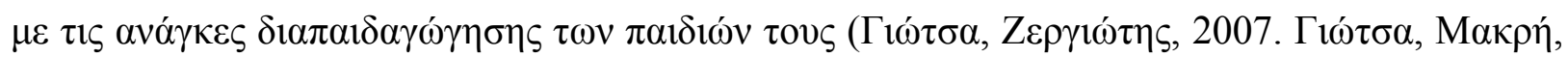

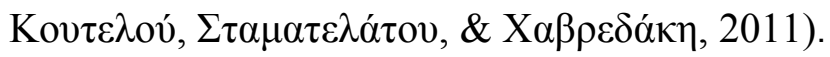

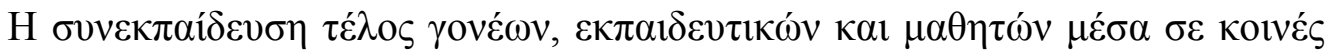

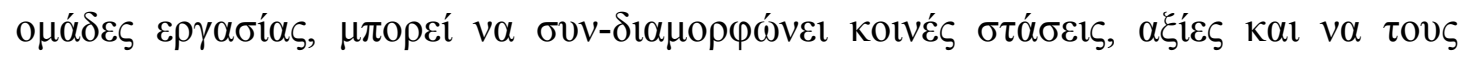

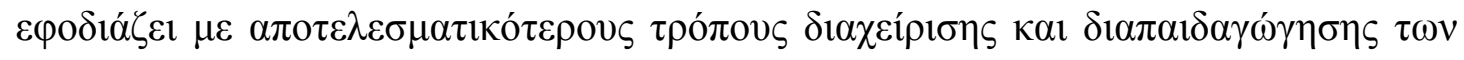
$\pi \alpha 1 \delta i \omega ́ v(M v \lambda \omega v \alpha ́ \kappa o v, 2009)$.

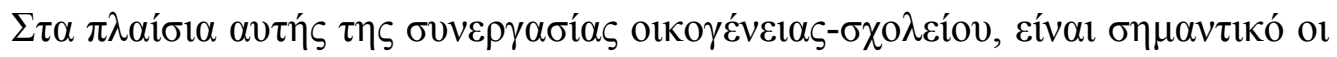

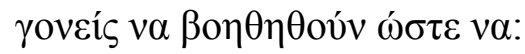

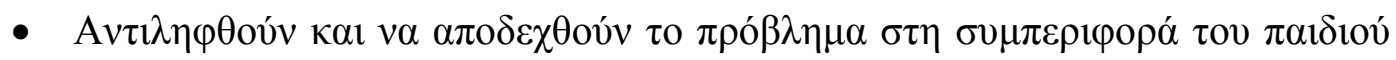
tovs.

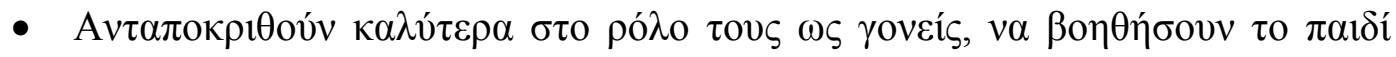

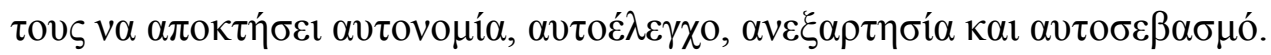

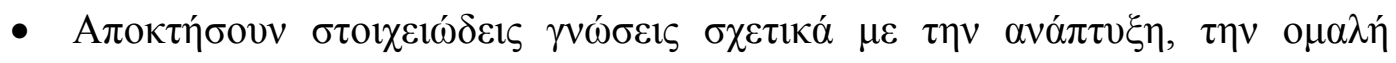

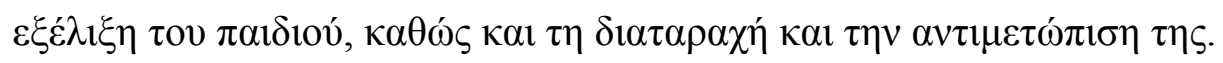

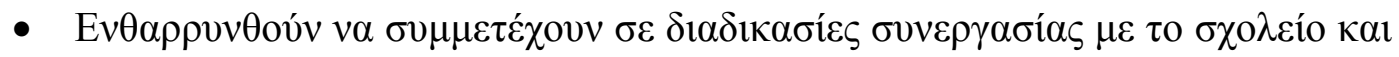

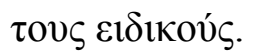




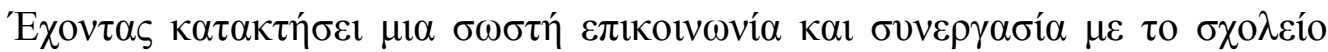

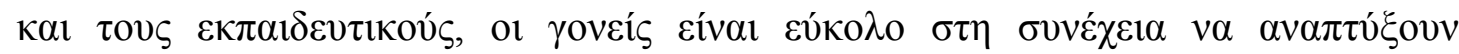

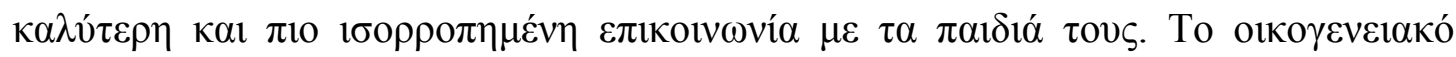

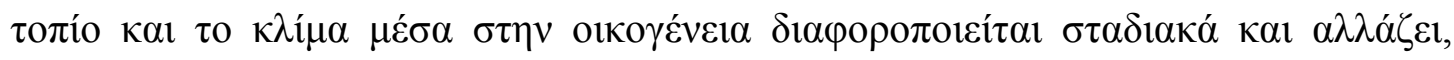

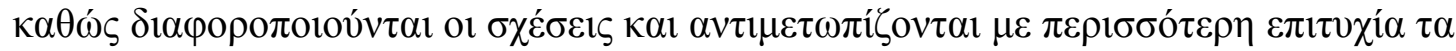

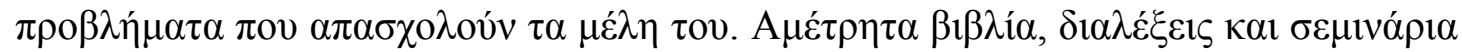

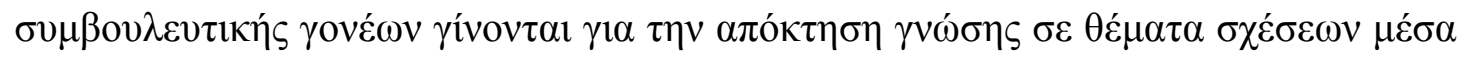

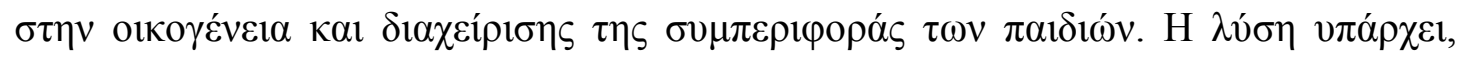

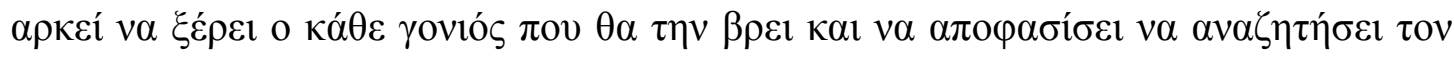

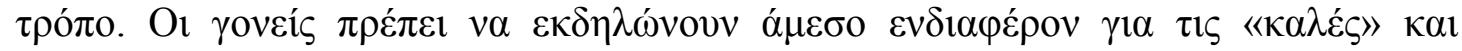

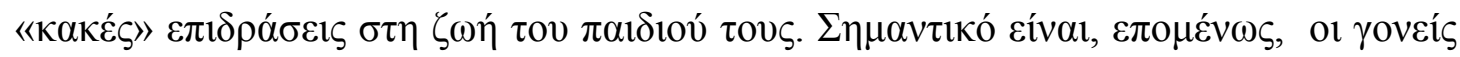

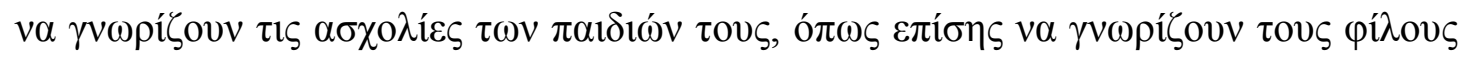

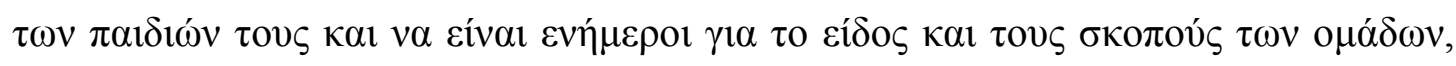

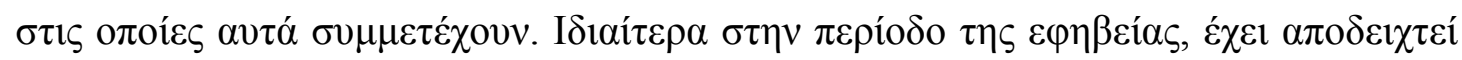

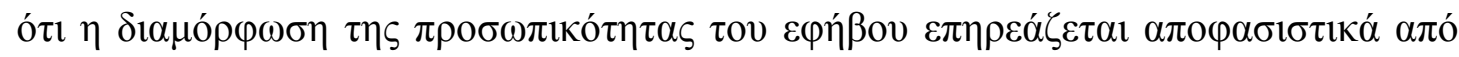

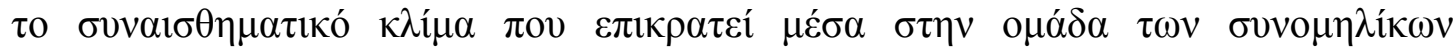

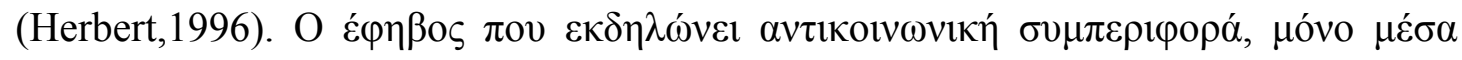

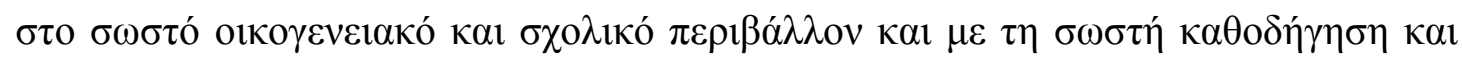

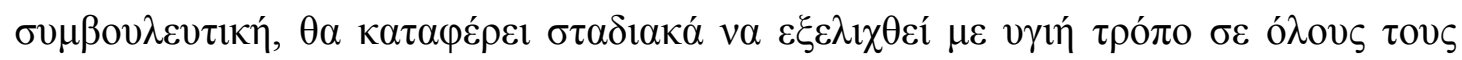

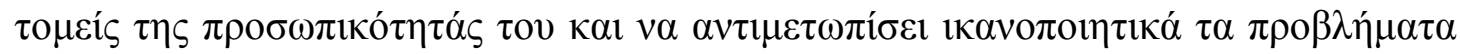

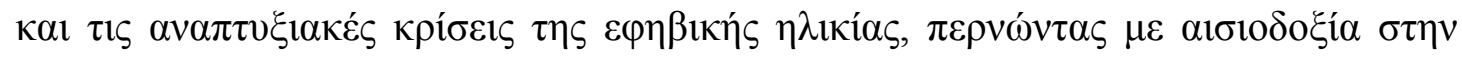

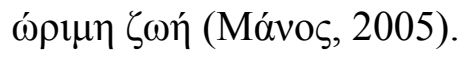




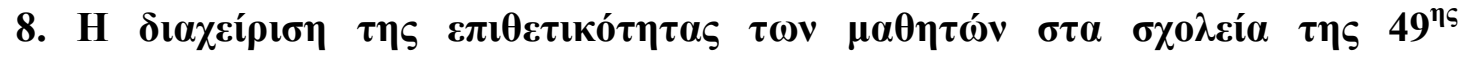

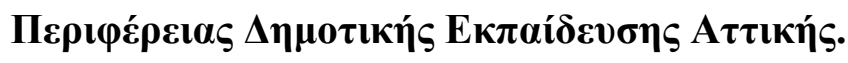

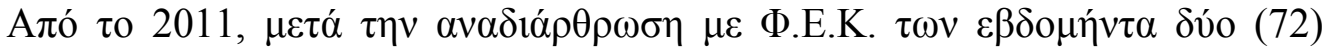

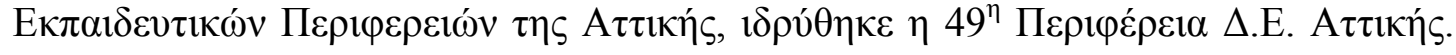

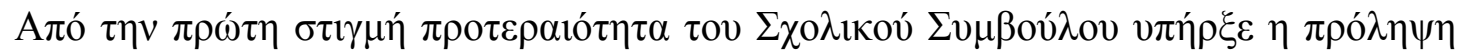

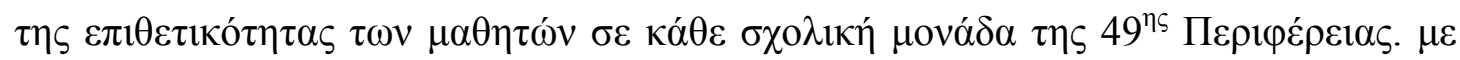

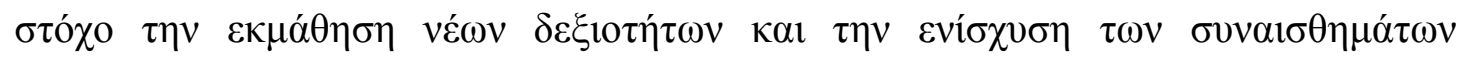

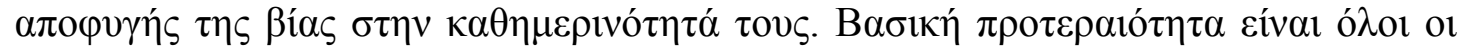

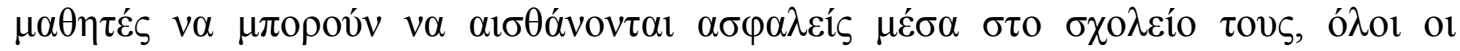

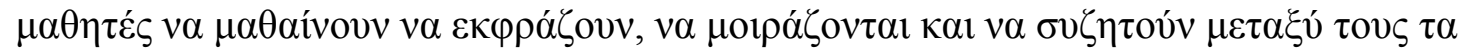

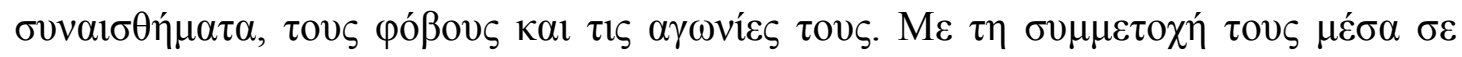

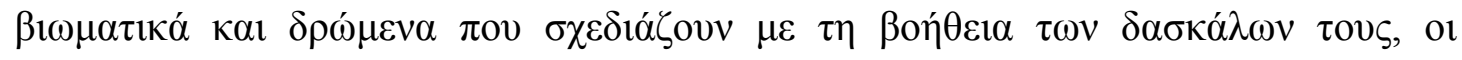

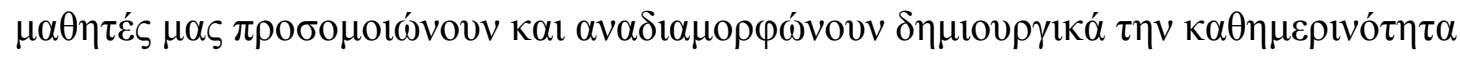

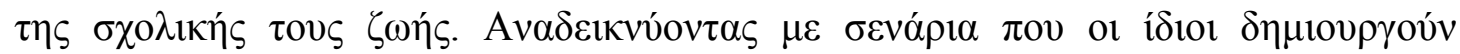

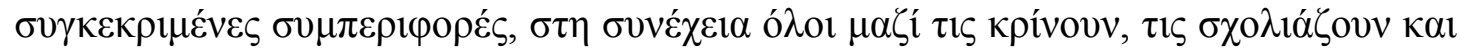

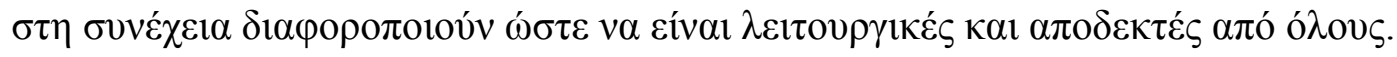

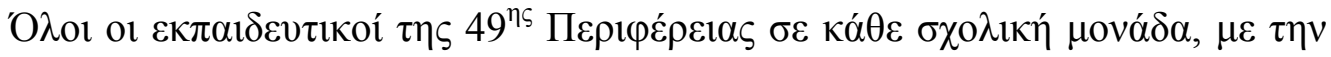

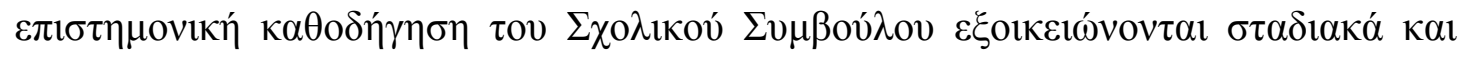

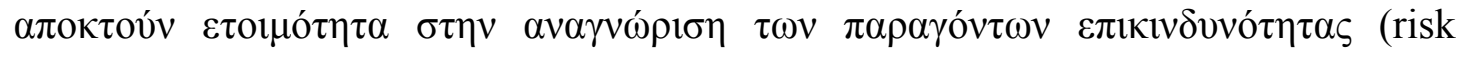

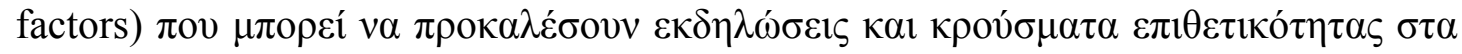

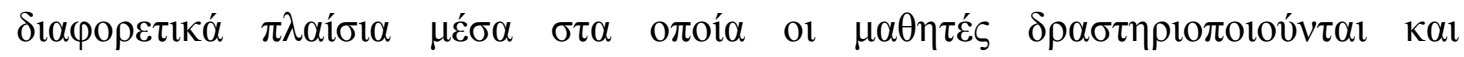

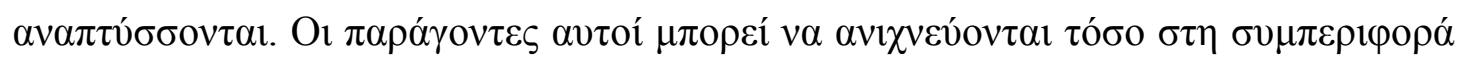

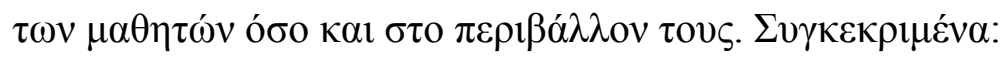




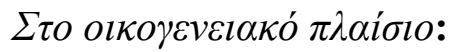

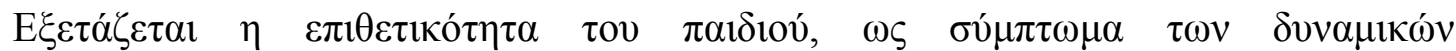

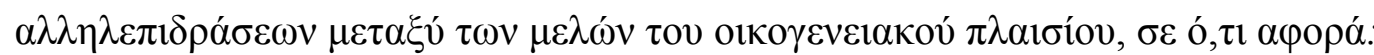

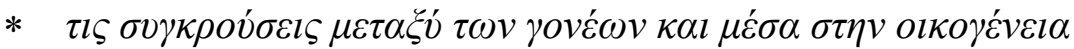

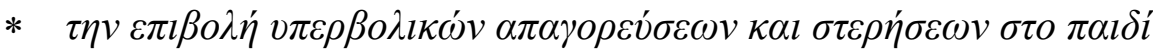

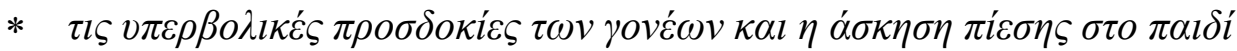

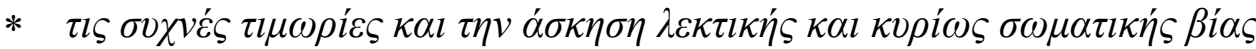
$\sigma \tau o \pi \alpha l \delta i$

* $\quad \tau \eta v \pi \alpha \rho \alpha \mu \dot{\lambda} \lambda \eta \sigma \eta \dot{\eta} \tau \eta v \alpha \pi o ́ \rho \rho \imath \psi \eta \tau o v \pi \alpha ı \delta \imath o v ́$

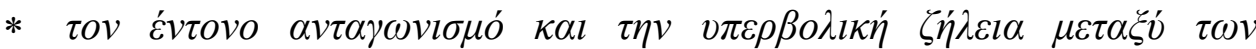
$\alpha \delta \varepsilon \rho \varphi \omega ́ v$

* $\quad \tau \eta \sigma \nu \mu \pi \lambda \eta \rho \omega \mu \alpha \tau \imath \kappa o ́ \tau \eta \tau \alpha \tau \omega v \rho o ́ \lambda \omega v \mu \varepsilon \tau \alpha \xi \dot{v} \tau \omega v \alpha \delta \varepsilon \rho \varphi \omega ́ v$

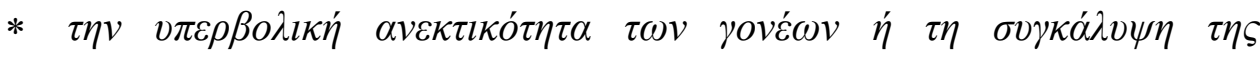

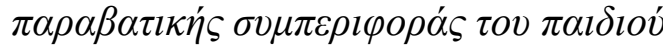

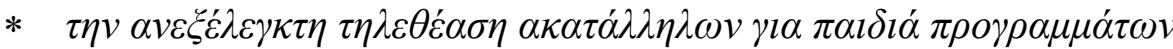

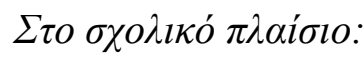

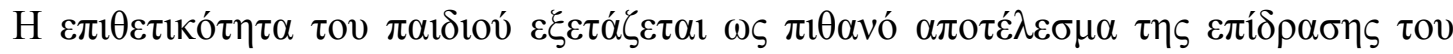

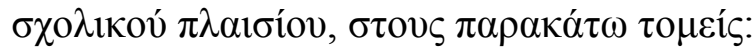

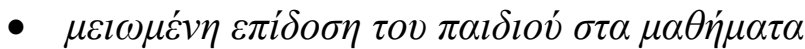

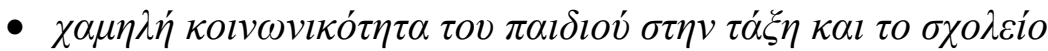

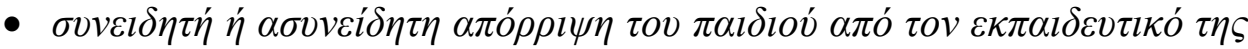

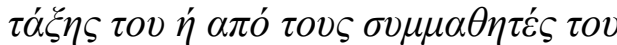

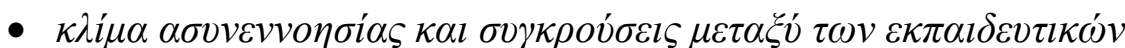




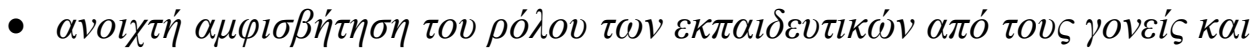

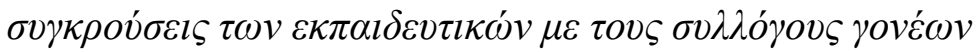

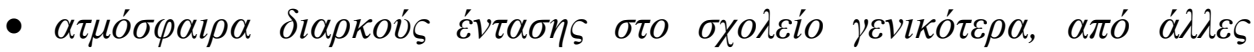

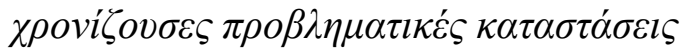

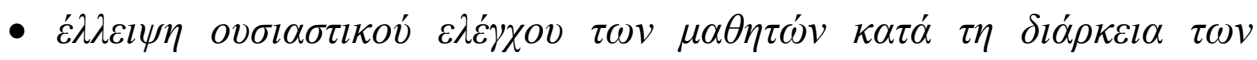
$\delta \imath \alpha \lambda \varepsilon \imath \mu \mu \alpha ́ \tau \omega v$

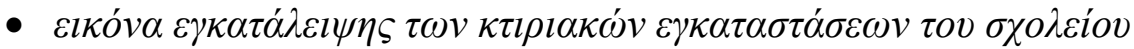

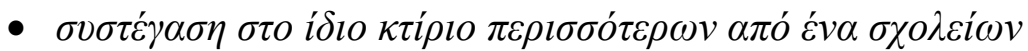

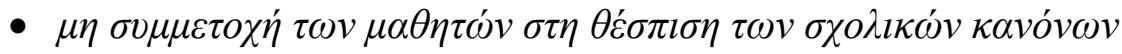

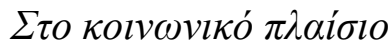

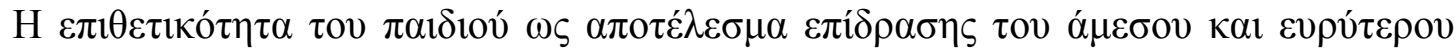

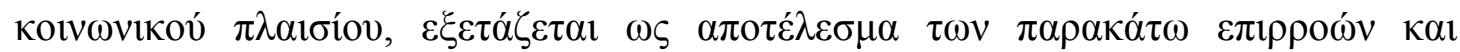
$\varepsilon \pi 1 \delta \rho \alpha ́ \sigma \varepsilon \omega v:$

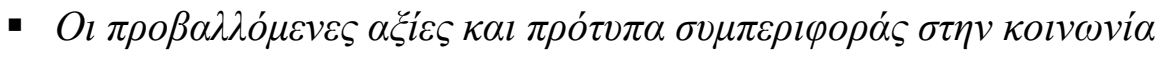

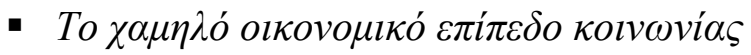

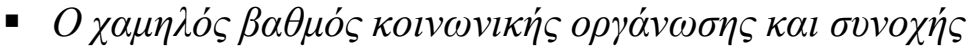

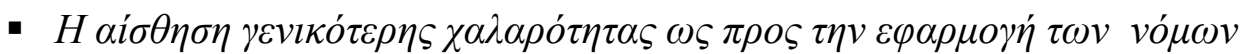

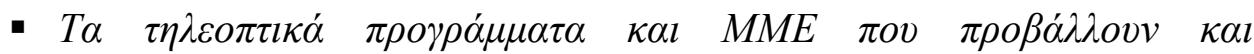
$\alpha v \alpha \pi \alpha \rho \dot{\gamma} \gamma o v v \sigma \kappa \eta v \varepsilon ́ \varsigma \beta i ́ \alpha \varsigma$

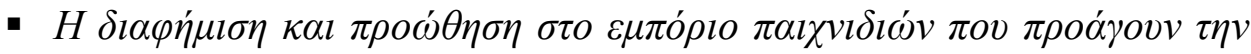
$\varepsilon \pi \imath \theta \varepsilon \tau \iota \kappa o ́ \tau \eta \tau \alpha$

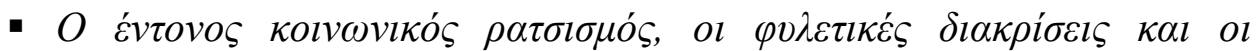

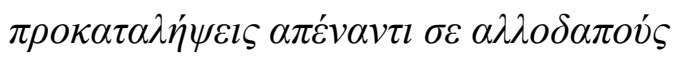




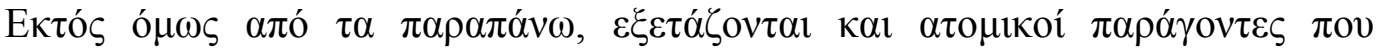

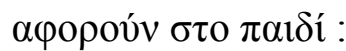

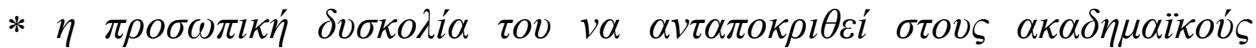
$\sigma \tau o ́ \chi o v \varsigma \tau o v ~ \sigma \chi o \lambda \varepsilon i ́ o v$

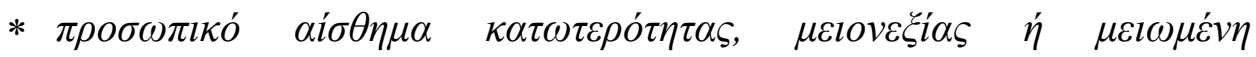

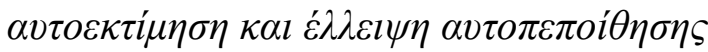

* $\sigma v v \alpha l \sigma \theta \dot{\eta} \mu \alpha \tau \alpha \delta i \omega \gamma \mu o v$, $\tau \alpha \pi \varepsilon i ́ v \omega \sigma \eta \varsigma \dot{\eta} \gamma \varepsilon \lambda o l o \pi o i ́ \eta \sigma \eta \varsigma$

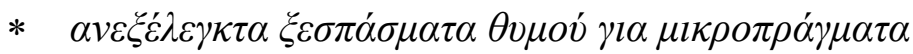

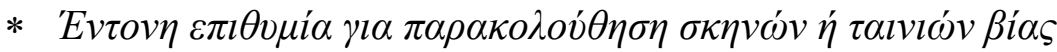

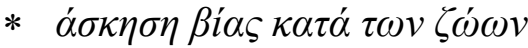

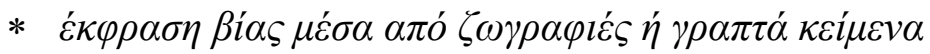

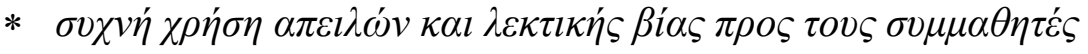

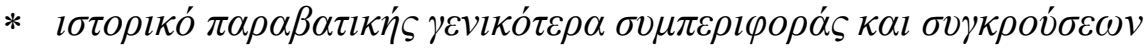

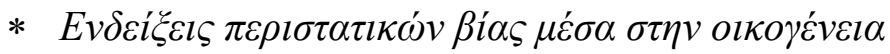

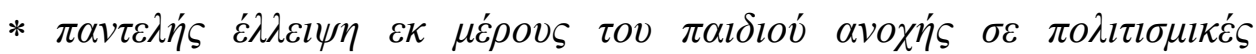
$\delta \imath \alpha \varphi \circ \rho \varepsilon^{\prime} \varsigma$

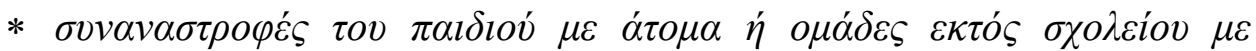

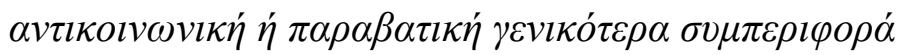

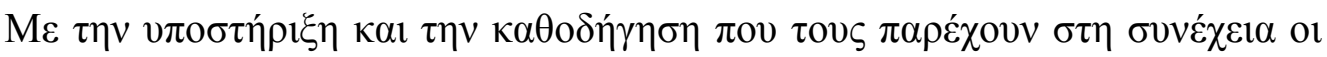

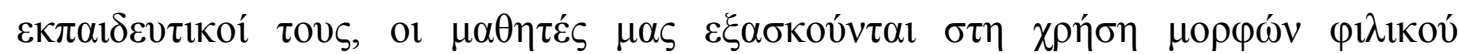

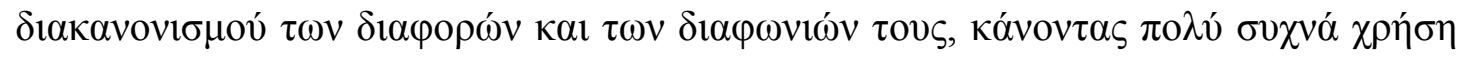

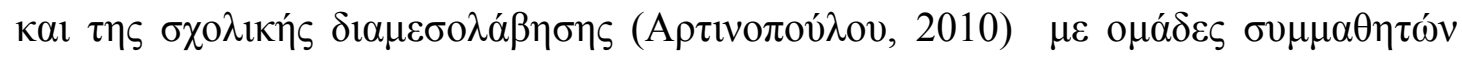

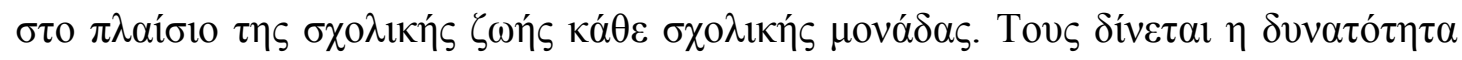

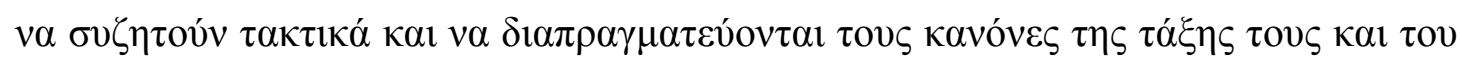




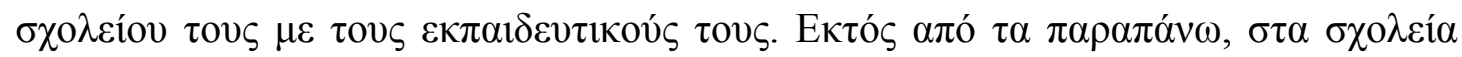

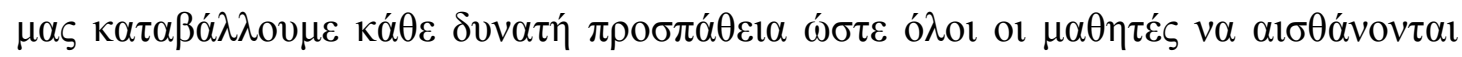

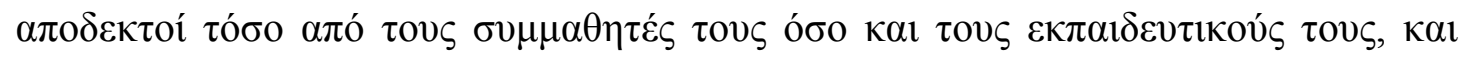

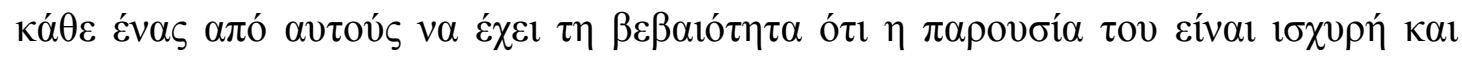

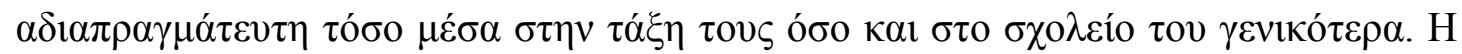

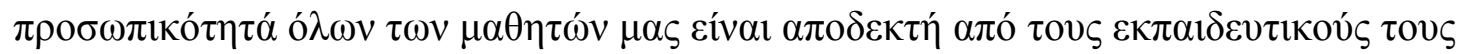

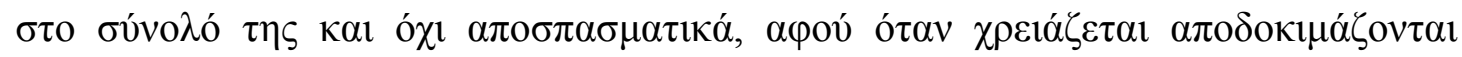

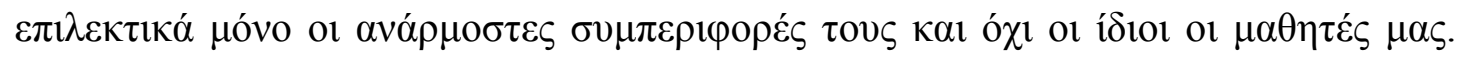

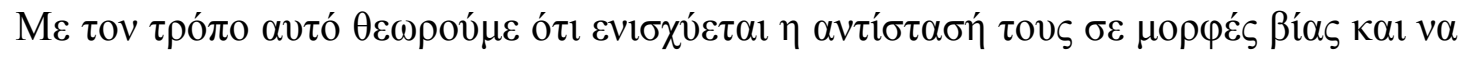

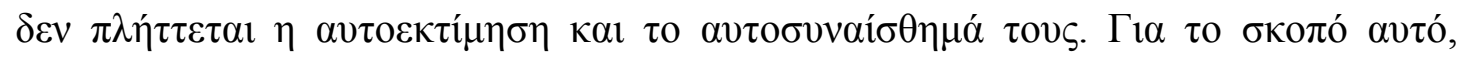

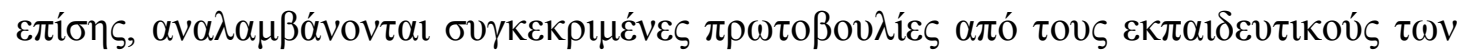

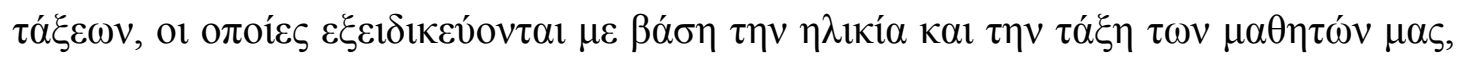

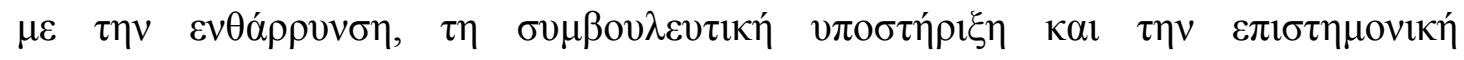

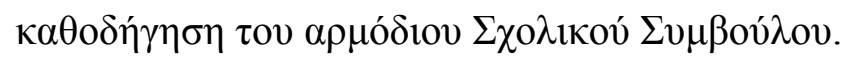

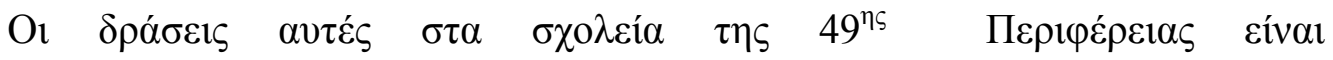

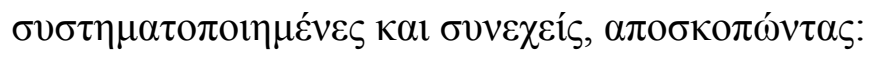

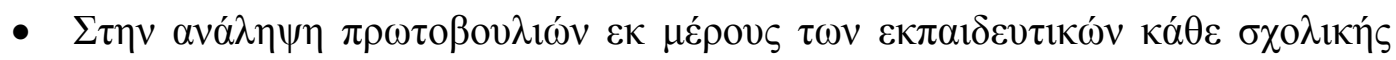

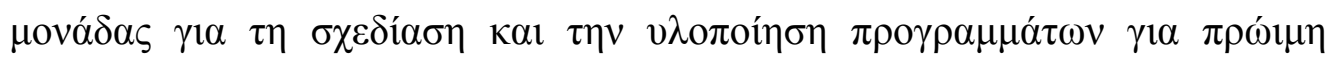

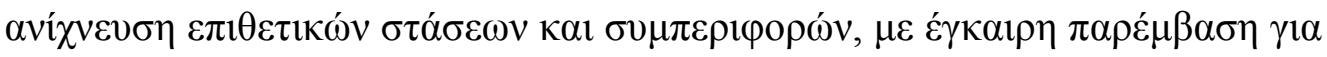

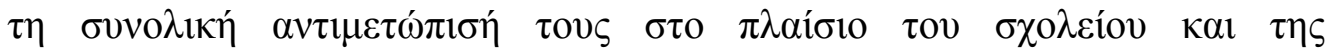

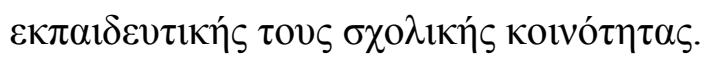

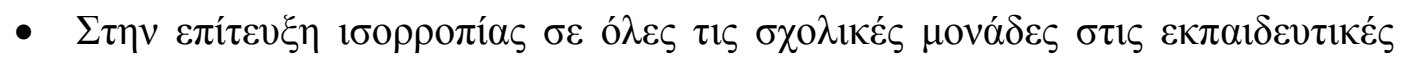

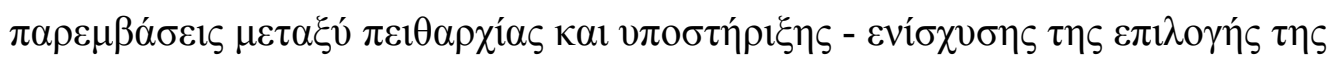
$\kappa \alpha \tau \alpha ́ \lambda \lambda \eta \lambda \eta \varsigma \sigma v \mu \pi \varepsilon \rho 1 \varphi о \rho \alpha ́ \varsigma$. 


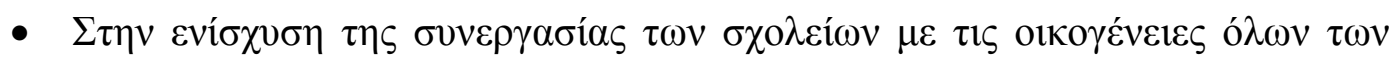

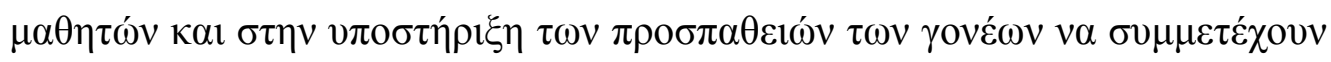

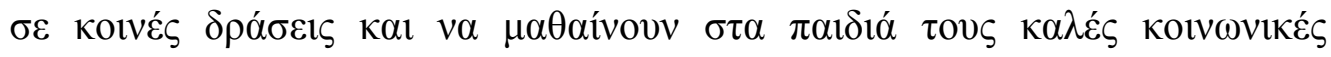
$\delta \varepsilon \xi$ เó $\eta \tau \varepsilon \zeta$.

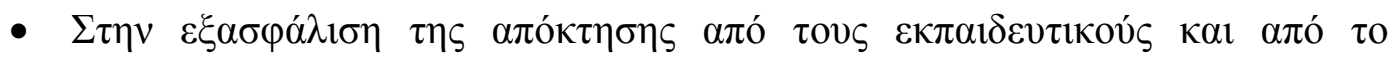

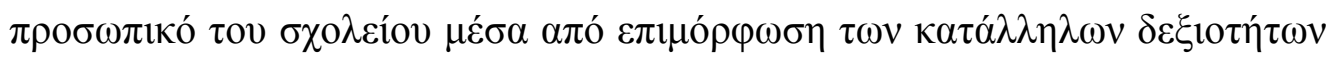

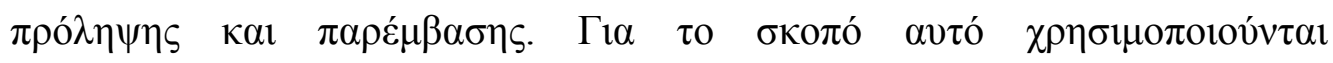

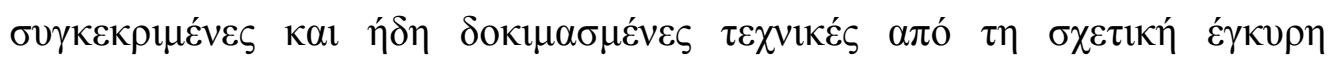

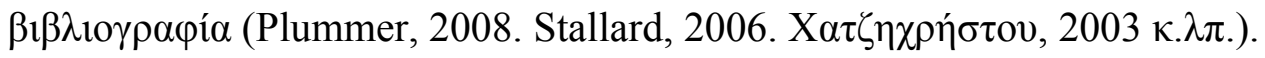

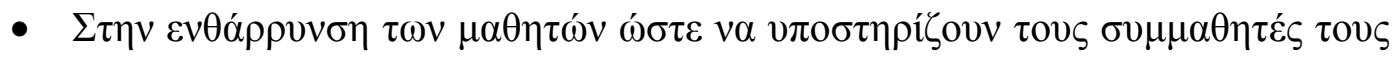

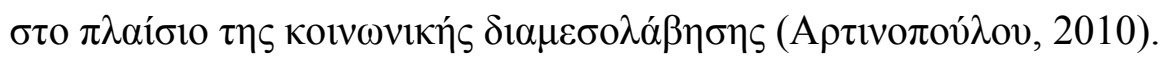

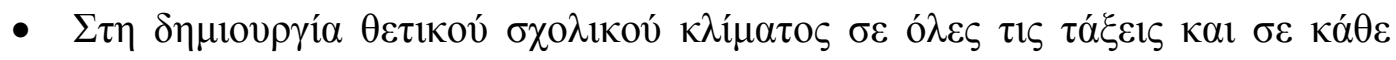

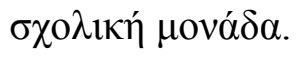

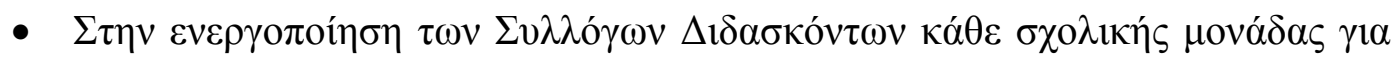

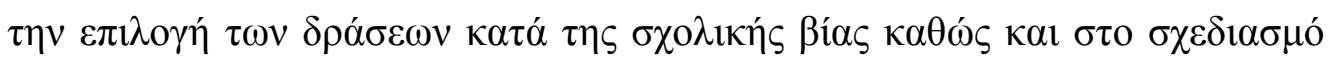

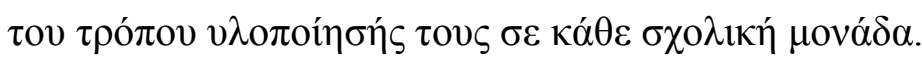

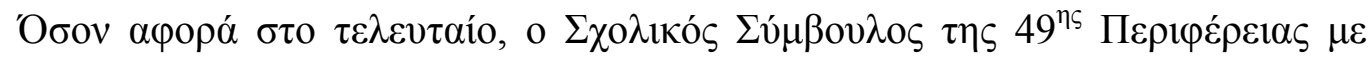

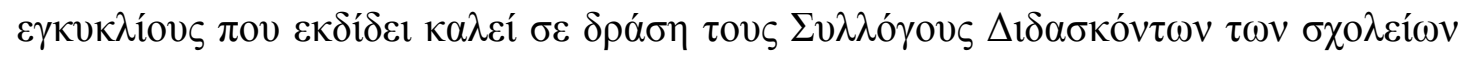

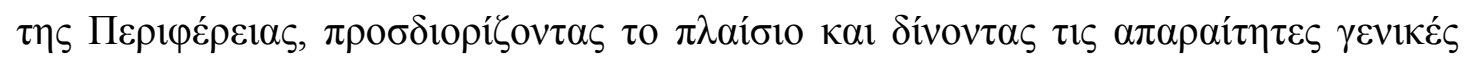

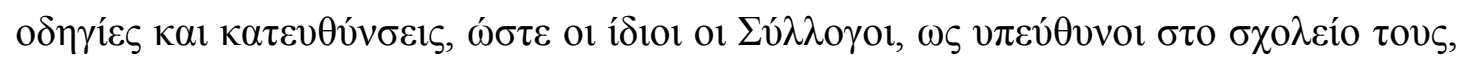

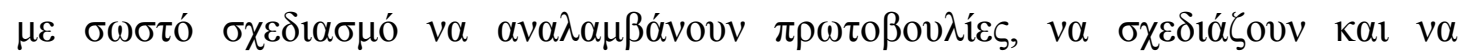

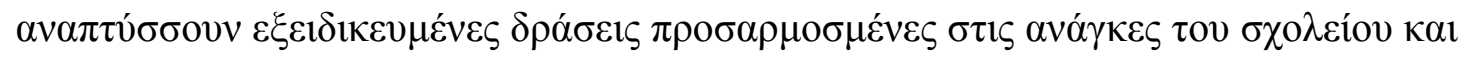

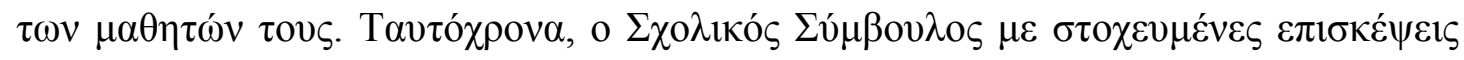

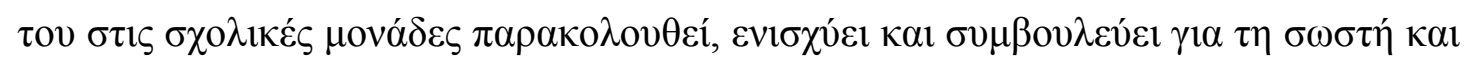




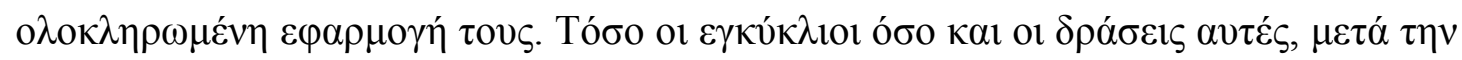

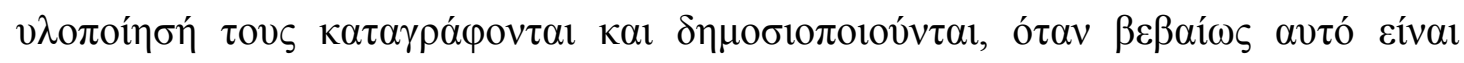

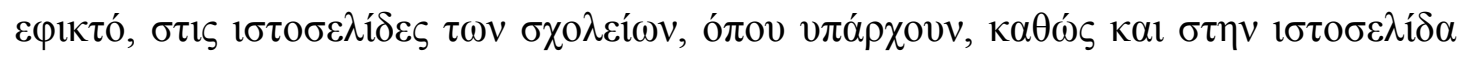

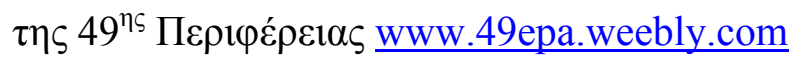

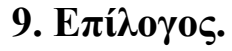

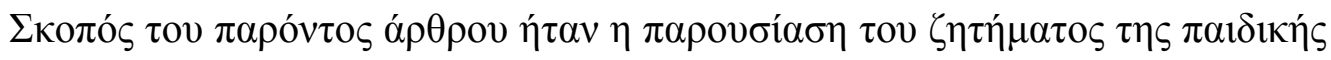

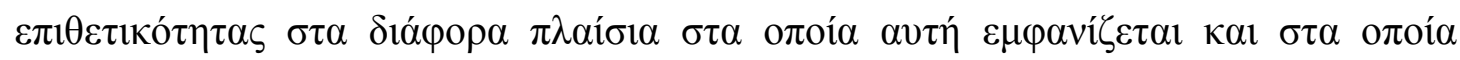

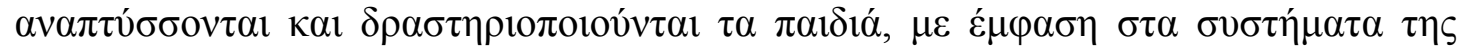

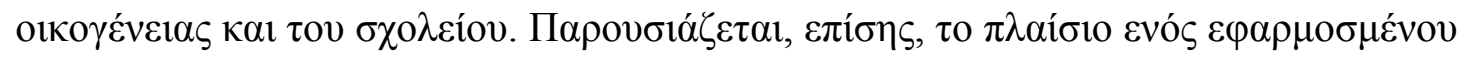

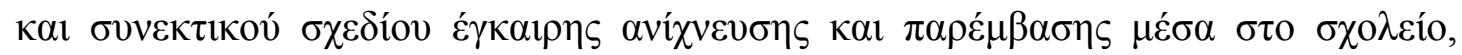

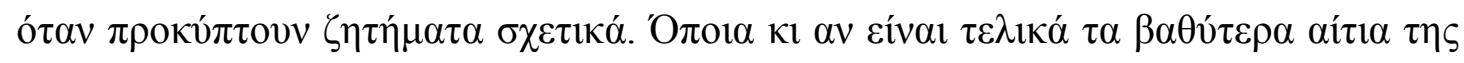

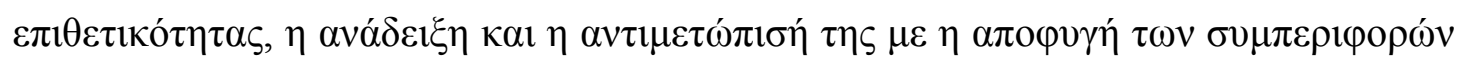

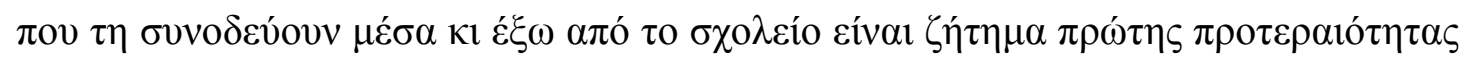

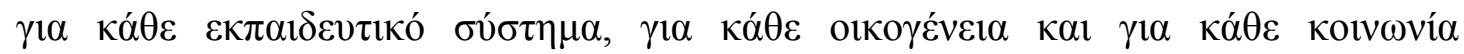

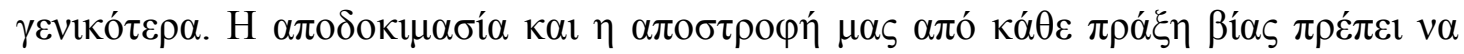

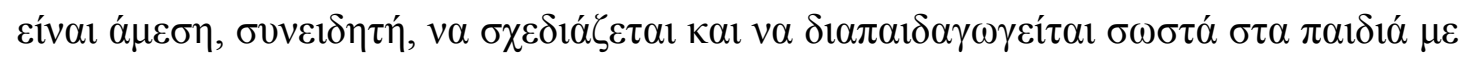

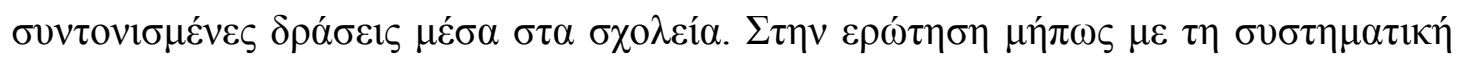

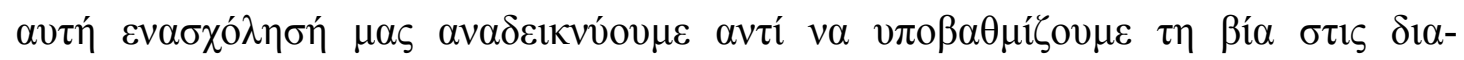

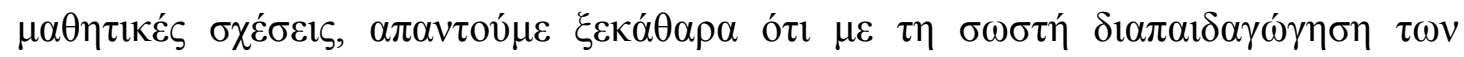

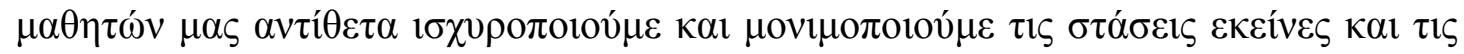

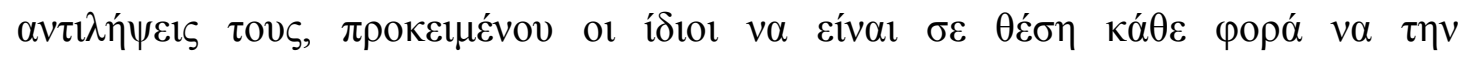

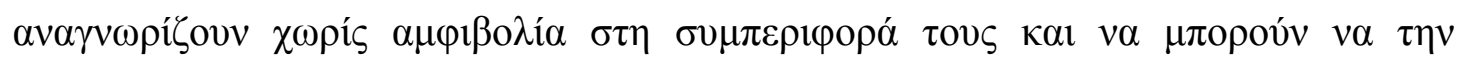

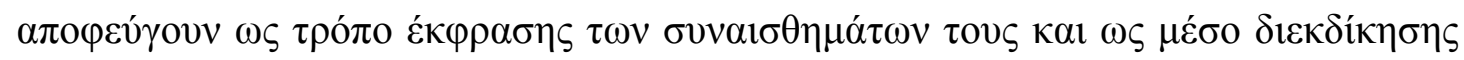




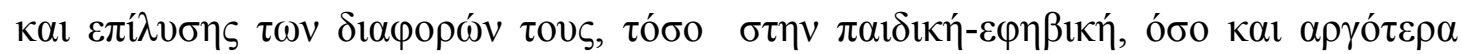

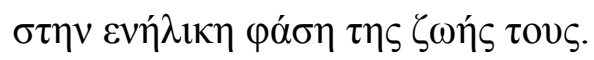




\section{ВIBАIОГРАФІА}

Ainsworth, M.D.S. (1982). Attachment: Retrospect and prospect. Im C.M. Parkes \& J. Stevenson-Hnde (Eds.), The place of attachment in human behavior: New York: Basic Books.

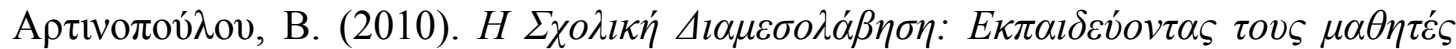

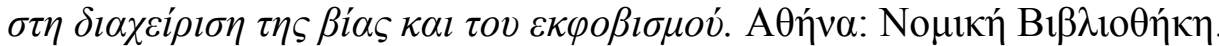

Bowlby,J. (1969). Attachment and loss: Vol.1. Attachment. N.Y.: Basic Books.

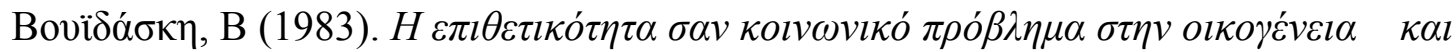

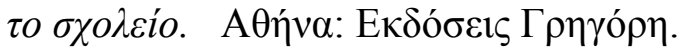

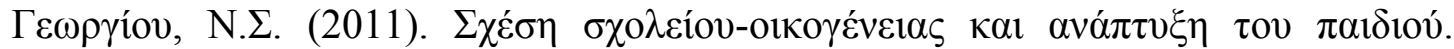
A $\theta \eta ́ v \alpha: \Delta \mathrm{i} \alpha ́ \delta \rho \sigma \eta$.

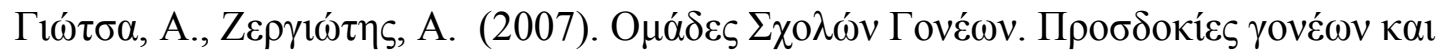

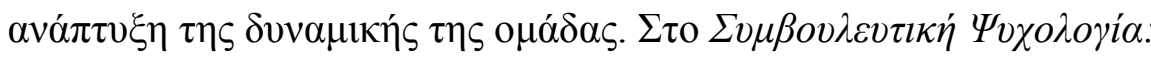

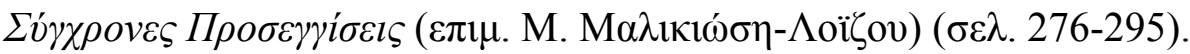

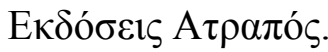

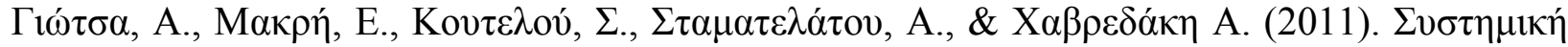

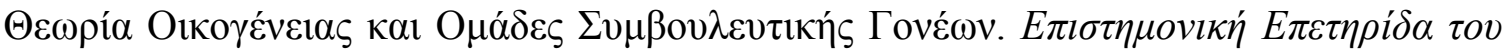

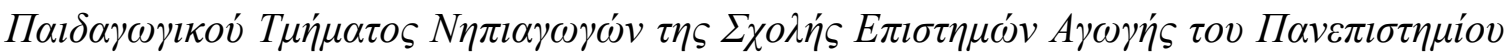
I $\omega \alpha v v i ́ v \omega v, 4^{o \varsigma} \tau o ́ \mu o \varsigma, \sigma \varepsilon \lambda .4-24$.

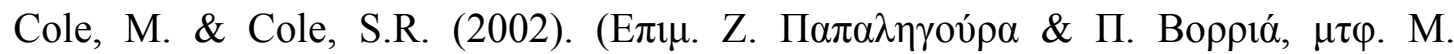
$\Sigma o ́ \lambda \mu \alpha v) . H \alpha v \alpha ́ \pi \tau v \xi \xi \tau \omega v \pi \alpha l \delta l \omega ́ v .(\tau \circ \mu .1,2)$ A $\theta \eta ́ v \alpha: \Delta \alpha \rho \delta \alpha v o ́ \varsigma$.

Cooley, C.H. (1902). Human nature and the social order. N.Y. : Scribner's.

Crick, N.R \& Grotpeter, J.K. (1996). Relational aggression, gender and socialpsychological adjustment. Child Development, 67, p.933-1002. 
Egeland, B. R., Caslson, E. \& Sroufe, L.A. (1993. Resilience as progress. Special Issue: Milestones in the development of resilience. Development and Psychopathology, 5, p. 517-528.

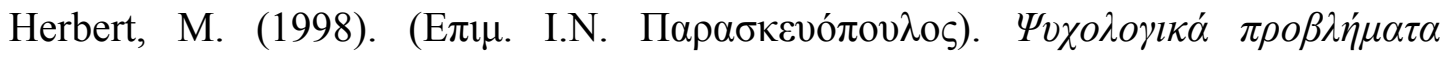

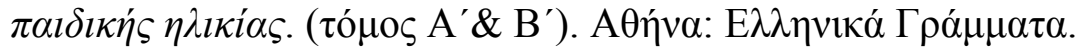

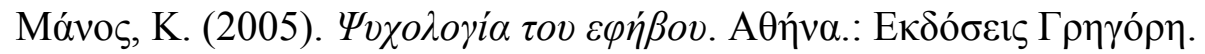

Mead, G.H. (1934). Mind, self and society. Chicago: University of Chicago Press.

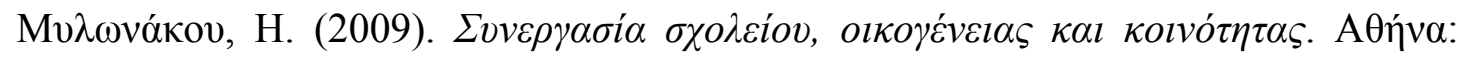

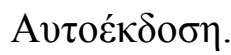

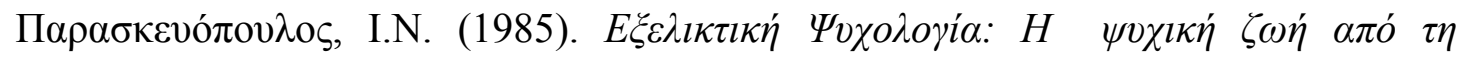

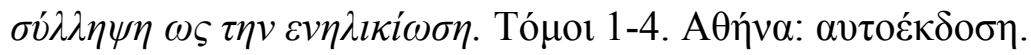

Perlman, M. \& Ross, H.S. (1997). The benefits of parent intervention in children's disputes: An examination of concurrent changes in children's fighting styles. Child Development, 68, p.600-700.

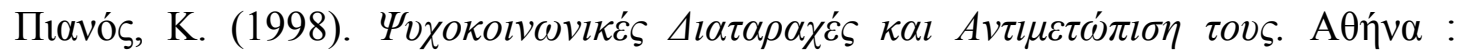

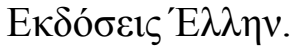

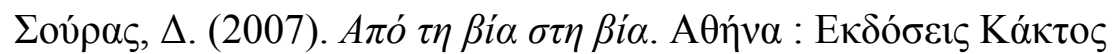

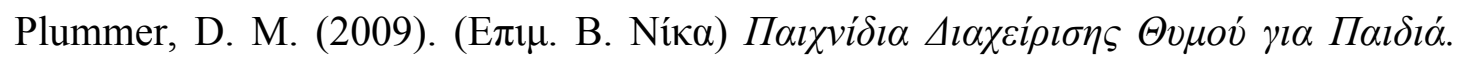

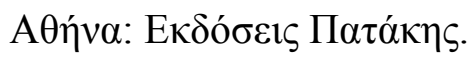

Rigby, K. (2010). Case Studies: Addressing Bulling in Queensland Schools. Developed for Queensland Government.

Rohner \& A. Khaleque (2008). Handbook for the Study of Parental Acceptance and Rejection (4 ${ }^{\text {th }}$ ed.) (pp. 43-106). Storrs, CT: Rohner Research Publications.

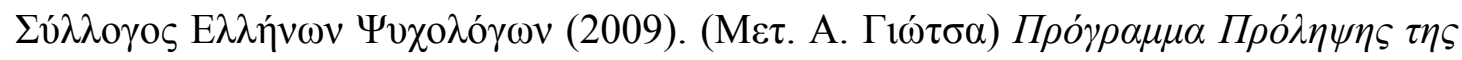

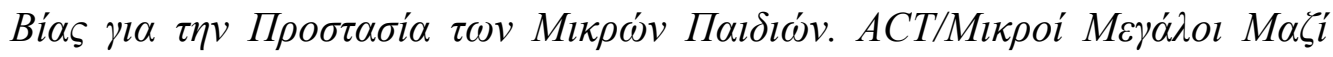




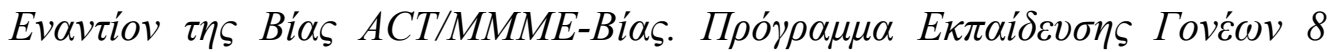

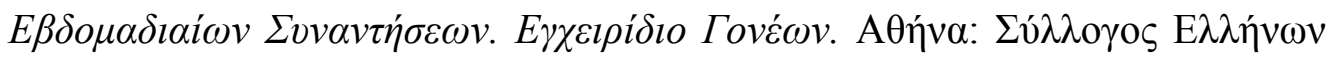

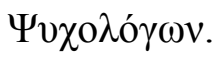

Silvern, S.B. \& Williamson, P.A. (1987). The effects of video game play on young children's aggression, fantasy, and prosocial behavior. Journal of Applied Developmental Psychology, Volume 8, Issue 4, October-December 1987, p. $453-462$.

Sroufe, L.A., Carlson E. \& Shulman, S. (1993). Individuals in relationships: Development from infancy through adolescence. In D.C. Funder, R.D. Parke, C. Tomilson-Keasey \& K. Widaman (Eds.) Studying life through time: Personality and development. Washington: A.P.A.

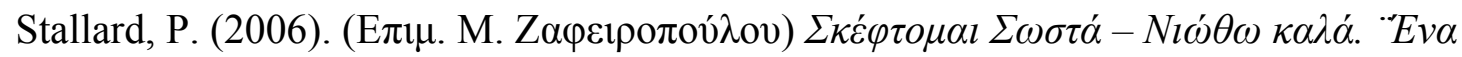

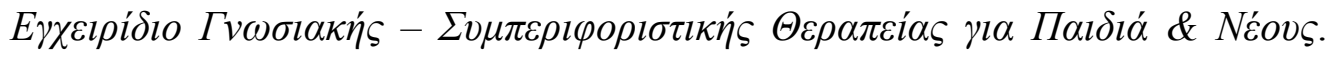

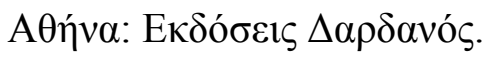

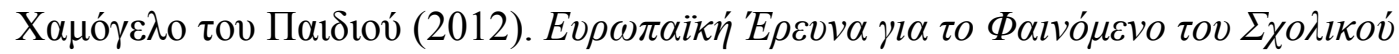

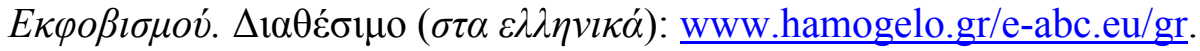

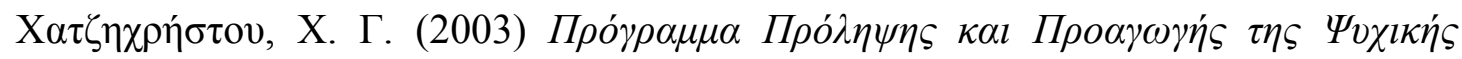

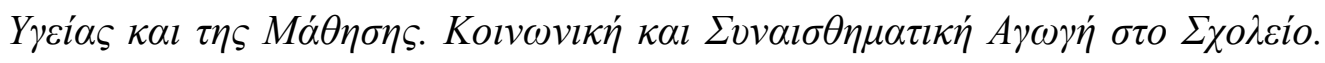

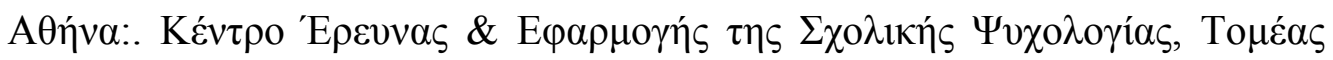

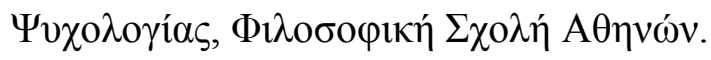

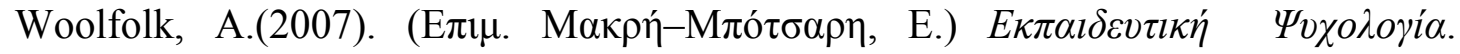

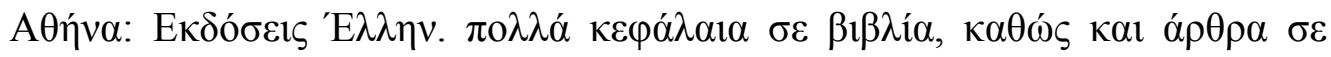

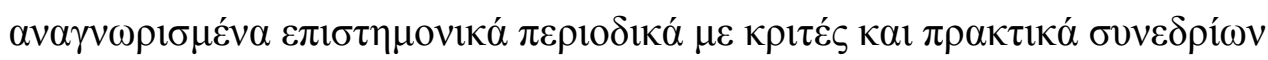

